Aus der Klinik für Unfallchirurgie, Orthopädie und Plastische Chirurgie

(Prof. Dr. med. W. Lehmann)

der Medizinischen Fakultät der Universität Göttingen

\title{
Einfluss der Ganzkörpervibration in Kombination mit Östrogen und Raloxifen auf die Skelettmuskulatur der ovarektomierten Ratte
}

\author{
INAUGURAL - DISSERTATION \\ zur Erlangung des Doktorgrades \\ der Medizinischen Fakultät der \\ Georg-August-Universität zu Göttingen
}

vorgelegt von

Sabine Schiefer

aus

Magdeburg

Göttingen 2017 
Dekan:

Prof. Dr. rer. nat. H. K. Kroemer

Referent:

Prof. Dr. Stephan Sehmisch

Ko-Referent:

Prof. Dr. Wolfgang Wuttke

Drittreferent/in:

Datum der mündlichen Prüfung: 25.04.2018 
Hiermit erkläre ich, die Dissertation mit dem Titel „Der Einfluss der Ganzkörpervibration in Kombination mit Östrogen und Raloxifen auf die Skelettmuskulatur der ovarektomierten Ratte“ eigenständig angefertigt und keine anderen als die von mir angegebenen Quellen und Hilfsmittel verwendet zu haben.

Göttingen, den 24.10.2017 


\section{Inhaltsverzeichnis}

1 Einleitung

1.1 Einführung und Zielsetzung 1

1.2 Sarkopenie 3

1.2.1 Definition 3

1.2.2 Prävalenz 3

1.2.3 Klassifikation 4

1.2.4 Ursachen 4

1.2.5 Diagnostik 5

1.2.6 Therapie / Prävention 6

$\begin{array}{lll}1.3 & \text { Osteoporose } & 7\end{array}$

1.3.1 Definition/Prävalenz $\quad 7$

1.3.2 Klassifikation/Einteilung 8

1.3.3 Ursachen/Risikofaktoren 8

1.3.4 Diagnostik 9

1.3.5 Therapie 9

$\begin{array}{ll}\text { 1.3.6 Prävention } & 10\end{array}$

1.4 Das muskuloskelettale System und dessen Interaktionen 10

1.4.1 Der Skelettmuskel 10

1.4.2 Die Muskelkontraktion 11

$\begin{array}{lll}1.4 .3 & \text { Muskelfasertypen } & 12\end{array}$

1.4.4 Der Knochen und seine Umbauprozesse 13

1.4.5 Knochenzellen 14

1.4.6 Die Mechanostat-Theorie 14

1.4.7 Knochen-Muskel-Interaktion 15

$\begin{array}{lll}1.5 & \text { Therapie } & 16\end{array}$

1.5.1 Medikamentöse Therapie 16

1.5.1.1 Östrogen 16

1.5.1.2 Raloxifen $\quad 20$

1.5.2 Vibrationstherapie 21 
2 Material und Methoden

2.1 Tierexperiment 24

2.1.1 Versuchstiere und ihre Haltung 24

2.1.2 Versuchsablauf 25

2.1.3 Ovarektomie 25

2.1.4 Osteosynthese 26

2.1.5 Therapien 26

2.1.5.1 Medikamente 26

2.1.5.2 Vibrationstherapie 27

2.1.6 Farbstoff-Applikation 27

2.1.7 Probenentnahme 28

2.2 Histologische Aufarbeitung 28

2.2.1 Mikrotom 28

2.2.2 Färbung der Schnitte 28

2.2.2.1 Amylase-PAS-Färbung 29

2.2.2.2 ATPase-/Diaphorase-Färbung 30

2.2.3 Eindeckung 31

2.3 Datenerhebung 31

2.3.1 Datenerhebung der Amylase-PAS-Färbung 32

2.3.2 Datenerhebung der ATPase-/Diaphorase-Färbung 33

2.4 Auswertung 35

3 Ergebnisse 36

3.1 Allgemein 36

3.1.1 Gewichtsverlauf 36

$\begin{array}{lll}3.1 .2 & \text { Futteraufnahme } & 37\end{array}$

3.1.3 Muskelgewichte 38

3.1.3.1 Muskelgewicht, M. soleus 38

3.1.3.2 Muskelgewicht/Tiergewicht, M. soleus $\quad 39$

3.1.3.3 Muskelgewicht, M. gastrocnemius 40

3.1.3.4 Muskelgewicht/Tiergewicht, M. gastrocnemius 41

3.1.4 Serum-Kreatininkinase 42 
3.2 Amylase-PAS-Färbung 42

3.2.1 M. soleus 43

3.2.2 M. longissimus 44

3.2.3 M. gastrocnemius 45

3.3 ATPase-/Diaphorase-Färbung 46

$\begin{array}{lll}3.3 .1 & \text { M. soleus } & 47\end{array}$

3.3.1.1 Durchmesser 47

3.3.1.2 Durchmesser/Gewicht 48

3.3.1.3 Fläche 49

3.3.1.4 Fläche/Gewicht $\quad 50$

3.3.2 M. longissimus 51

3.3.2.1 Durchmesser 51

3.3.2.2 Durchmesser/Gewicht 52

3.3.2.3 Fläche 53

3.3.2.4 Fläche/Gewicht 54

3.3.3 M. gastrocnemius $\quad 55$

3.3.3.1 Durchmesser 55

3.3.3.2 Durchmesser/Gewicht 56

3.3.3.3 Fläche 58

3.3.3.4 Fläche/Gewicht $\quad 59$

4 Diskussion $\quad \mathbf{6 0}$

$\begin{array}{lll}\text { 4.1 Die Ratte als Tiermodell } & 60\end{array}$

4.2 Tiergewicht, Futteraufnahme, Muskelgewicht, Serumkreatininkinase 61

4.3 Muskelgewichte 62

4.4 Amylase-PAS-Färbung 64

4.5 ATPase/Diaphorase-Färbung 65

4.6 Schlussfolgerungen für den klinischen Alltag 69

$\begin{array}{lll}4.7 & \text { Fazit } & 72\end{array}$

5 Zusammenfassung $\quad 73$

6 Anhang 76

$\begin{array}{lll}6.1 & \text { Abbildungsverzeichnis } & 76\end{array}$

$\begin{array}{lll}6.2 & \text { Tabellenverzeichnis } & 78\end{array}$

$\begin{array}{lll}6.3 & \text { Verwendete Chemikalien } & 79\end{array}$

6.4. Herstellung der Phosphatpuffer-Lösung und Glycinstammlösung 80 
Inhaltsverzeichnis

$\begin{array}{lll}6.5 & \text { Ergebnistabellen } & 81\end{array}$

6.5.1 Ergebnisse der Kreatininkinase 81

6.5.2 Ergebnisse der Muskelgewichte 81

6.5.3 Ergebnisse der Muskelgewichte im Verhältnis zum Tiergewicht 82

6.5.3 Ergebnisse der Kapillarfärbung 82

6.5.4 Ergebnisse der ATPase-/Diaphorase-Färbung 83

7 Literaturverzeichnis $\quad 86$ 


\section{Abkürzungsverzeichnis}

Abb. Abbildung

ADP Adenosindiphosphat

ATP Adenosintriphosphat

Aqua dest. Aqua destilata

AZ Aktenzeichen

BMD Bone Mineral Density

COPD Chronic Obstructive Pulmonary Disease

DVO Dachverbands Osteologie e.V.

DXA Dual-energy X-ray Absorptiometry

E Östrogen

E1 Estron

E2 Estradiol

ER Östrogenrezeptor

EWGSOP European Working Group on Sarcopenia in Older People

FG Fast Glycolytic

FOG Fast Oxidative Glycolytic

FRAX Fracture Risk Assessment Tool

$\mathrm{GH} \quad$ Growth Hormone

HRT Hormonersatztherapie

IGF Insulin-like Growth Factor

IE Internationale Einheiten

IL Interleukin

ISI International Sarcopenia Initiative

KG Körpergewicht

M. Musculus

mRNA Messenger Ribonucleic Acid

$\mathrm{NaCl} \quad$ Natrium-Chlorid

$\mathrm{NIH} \quad$ National Institutes of Health

P Phosphat

RLF Raloxifen

s.c. subcutan

SERM Selective Estrogen Receptor Modulators

SO Slow Oxidative 
SPPB Short Physical Performance Battery

Tab. Tabelle

TNF- $\alpha \quad$ Tumornekrosefaktor- $\alpha$

WBV Whole Body Vibration

WHI Women's Health Initiative

WHO World Health Organization

Z.n. Zustand nach

$\mu$ Strain MikroStrain 


\section{EINLEITUNG}

\subsection{Einführung und Zielsetzung}

„Das Alter ist eine unheilbare Krankheit.“

Lucius Annaeus Seneca (römischer Philosoph - ca. 1 - 65 n.Chr.)

Die Änderung der Altersstruktur stellt unsere Gesellschaft vor immer neue Herausforderungen. Das niedrige Geburtenniveau und die steigende Lebenserwartung in den letzten Jahrzehnten verursachten eine Verschiebung der Alterspyramide. Die durchschnittliche Lebenserwartung von ca. 83 Jahren bei Frauen und 78 Jahren bei Männern im Jahre 2013 wird nach Prognosen des Statistischen Bundesamtes auf 88 Jahre für Frauen und 84 Jahre für Männer im Jahr 2050 ansteigen (Statistisches Bundesamt 2006). Somit treten Erkrankungen des höheren Alters wie Herz-Kreislauferkrankungen, Neoplasien, Demenzen und auch Erkrankungen des Muskel-Skelett-Systems immer mehr in den Fokus unseres Gesundheitssystems.

Im Jahr 2008 wurden in Deutschland ca. 254 Milliarden Euro für die Behandlung von Krankheiten ausgegeben, 48,4\% der Kosten entfallen dabei auf Patienten, die älter als 65 Jahre sind (Statistisches Bundesamt 2006).

Während bei Männern im Krankenhaus vor allem Erkrankungen des HerzKreislauf-Systems, wie Herzinsuffizienz und Angina Pectoris, diagnostiziert werden, stehen bei Frauen vor allem die Herzinsuffizienz und Frakturen des Femurs im Vordergrund (Gesundheit und Krankheit im Alter 2009).

Untersuchungen haben gezeigt, dass Frakturen des Femurs und der Hüfte neben Wirbelkörper-Frakturen zu den häufigsten osteoporotisch bedingten Frakturen gehören. In Deutschland traten Im Jahre 2010 ca. 725.000 Frakturen aufgrund von Knochenbrüchigkeit auf. Im Jahr 2025 ist mit einem Anstieg um 28 \% zu rechnen (Svedbom 2013).

Derzeit ist davon auszugehen, dass 6,3 Millionen Menschen in Deutschland und 200 Millionen Menschen weltweit an einer Osteoporose erkrankt sind (Hadji et al. 2013, Lin und Lane 2004). Auch das Risiko, an einer Sarkopenie zu erkranken, steigt im Alter an. Hier spielen die Abnahme der Muskelmasse und 
die Abnahme der Muskelkraft bzw. die Abnahme der Muskelmasse und eine verminderte Leistungsfähigkeit eine wichtige Rolle bei der Diagnosestellung.

Mit der Sarkopenie und der Osteoporose wird häufig auch der Begriff des Frailty-Syndroms in Verbindung gebracht, welches jedoch nicht eindeutig definiert ist. Man versteht darunter einen klinisch erkennbaren Zustand älterer Menschen mit einem Anstieg der Verletzlichkeit, resultierend aus dem altersbedingten Verlust der körperlichen Reserven und Funktionen mehrerer Organsysteme (Chen et al. 2014). Somit können sowohl die Sarkopenie als auch die Osteoporose als Komponenten des Frailty-Syndroms gesehen werden. Mit einer Zunahme der Anzahl der Betroffenen ist weltweit aufgrund der steigenden Lebenserwartung in den nächsten Jahren zu rechnen.

Da im Gesundheitswesen derzeit der Fokus jedoch lediglich auf die Behandlung der Osteoporose gelegt wird, weil eine Frühdiagnose bisher noch nicht möglich ist und bei der Sarkopenie erst langsam die Bedeutung im Gesundheitswesen erkannt wird, ist es umso wichtiger, eine effektive und angesichts der steigenden Anzahl an Erkrankten auch eine Behandlung mit hohem Kosten-Nutzen-Anteil zu finden.

Die Interaktion zwischen Knochen und Muskeln war in den letzten Jahren vermehrt Gegenstand der Forschung. Die Effektivität der medikamentösen Therapien mit Östrogen und Raloxifen und von nicht-medikamentösen Therapien, wie der Vibrationstherapie, wurde bisher vielfach bei Osteoporose bewiesen (Agnusdei und lori 2000, Anderson et al. 2004, Jankovich 1972, Roussouw et al. 2002, Rubin et al. 2001, Xie et al. 2008). Ob und wie sich diese Medikamente auf eine Sarkopenie auswirken, wurde bisher jedoch noch nicht ausreichend untersucht. Unklar ist ebenfalls, ob eine Kombination der medikamentösen Therapie mit der nicht-medikamentösen Therapie einen gesteigerten Effekt bringen kann.

Ziel dieser Doktorarbeit ist es daher zu untersuchen, wie Östrogene, Raloxifen und die Ganzkörpervibration auf die Muskeln wirken und ob eine Kombination aus Vibrationstherapie + Östrogen und eine Vibrationstherapie + Raloxifen Vorteile gegenüber den Einzeltherapien bringen. 


\subsection{Sarkopenie}

Als in den 50er und 60er Jahren die Forschung begann, sich zunehmend mit der Thematik des alternden Menschen auseinanderzusetzen, untersuchte vor allem Nathan Shock, einer der Pioniere der Gerontologie, die physiologischen Alterungsprozesse am Herzen, in den Nieren, Lungen, Nerven und im Gehirn (Shock 1956, Cook 1989). Im Jahre 1988 kam auf einer Versammlung in Albuquerque, New Mexico, erstmals der Begriff der ,Sarkopenie' auf. Geprägt wurde dieser aus dem Griechischen stammende Begriff, bestehend aus sarx (= Fleisch) und penia (= Verlust) von Irvin Rosenberg. Er verstand darunter eine altersbedingte Abnahme der Muskelmasse (Rosenberg 2011). Diese Definition wurde später um die Begriffe: „Abnahme der Muskelkraft“ und „verminderte Leistungsfähigkeit" erweitert.

\subsubsection{Definition}

Die European Working Group on Sarcopenia in Older People (EWGSOP) erarbeitete im Jahre 2010 eine einheitliche Definition des Begriffes Sarkopenie in Europa. Demnach ist Sarkopenie ein Syndrom, das durch einen fortschreitenden und generalisierten Verlust der Skelettmuskelmasse und Kraft mit dem Risiko auf ungünstige Folgen, wie körperliche Unfähigkeit, schlechte Lebensqualität und Tod, charakterisiert ist (Cruz-Jentoft et al. 2010).

Aus der EWGSOP und der International Sarcopenia Working Group bildete sich 2012 die International Sarcopenia Initiative (ISI) und übernahm die vorab erarbeitete Definition.

\subsubsection{Prävalenz}

Durch die verschiedenen Definitionskriterien der Sarkopenie in der Vergangenheit gestaltet sich eine einheitliche Prävalenz-Angabe schwierig. Untersuchungen aus dem Jahre 2010 ergaben eine Prävalenz von 5-13 \% bei 60- bis 70-Jährigen und bei über 80-Jährigen sogar eine Prävalenz von 11-50 \% (von Haehling et al. 2010). Eine Analyse der Prävalenz durch eine Metaanalyse der EWGSOP ergab eine Prävalenz von 1-33 \% (Cruz-Jentoft et al. 2014). 


\subsubsection{Klassifikation}

Das Sarkopenie-Syndrom lässt sich nach den Kriterien der EWGSOP in drei Stadien einteilen. Bei der Prä-Sarkopenie ist lediglich die Muskelmasse vermindert. Zur Diagnose der Sarkopenie müssen entweder Muskelmasse und Muskelkraft oder Muskelmasse und Leistungsfähigkeit vermindert sein. Von einer schweren Sarkopenie spricht man, wenn sowohl Muskelmasse als auch Muskelkraft und die Leistungsfähigkeit vermindert sind (Cruz-Jentoft et al. 2010).

\subsubsection{Ursachen}

Die Ursachen für eine Sarkopenie können sehr vielfältig sein. Eine Übersicht über eine Auswahl möglicher Ursachen mit Beispielen zeigt Tabelle (Tab.) 1 (Cruz-Jentoft 2010, Kim und Choi 2013, Morley et al. 2014).

Tab. 1: Auswahl an Ursachen und Beispielen für Sarkopenie (modifiziert nach Cruz-Jentoft 2010, Kim und Choi 2013, Morley et al. 2014)

\begin{tabular}{|c|c|}
\hline Ursache & Beispiel \\
\hline Alterungsprozesse & $\begin{array}{l}\text { Reduzierte Proteinsynthese } \\
\text { Erhöhter Proteinabbau } \\
\text { Mitochondrien-Dysfunktion } \\
\text { Apoptose }\end{array}$ \\
\hline Nichtgebrauch & $\begin{array}{l}\text { Immobilität } \\
\text { Physikalische Inaktivität } \\
\text { Schwerelosigkeit }\end{array}$ \\
\hline Kachexie & $\begin{array}{l}\text { Mangelhafte Ernährung } \\
\text { Malabsorptionsstörungen }\end{array}$ \\
\hline Endokrin & $\begin{array}{l}\text { Anstieg der Kortikosteroide } \\
\text { Testosteronabfall } \\
\text { GH-Abfall } \\
\text { IGF-1-Abfall } \\
\text { Schilddrüsenerkrankungen } \\
\text { Insulinresistenz }\end{array}$ \\
\hline Neurodegenerative Erkrankung & Verlust von Motoneuronen \\
\hline Proinflammatorische Cytokine & IL1, IL 6, TNF- $\alpha$ \\
\hline Vaskulär & $\begin{array}{l}\text { Periphere Gefäßkrankheit } \\
\text { Verminderte Kapillarfunktion }\end{array}$ \\
\hline
\end{tabular}


Anhand der Ursachen lässt sich die Sarkopenie in 2 Formen einteilen (Cruz-Jentoft et al. 2010). Die primäre Form ist altersbedingt. Bei den sekundären Formen unterscheidet man: 1. eine Sarkopenie aufgrund von verminderter Aktivität, 2. eine Sarkopenie aufgrund von Erkrankungen (Organversagen, Entzündungen, Malignität, endokrinologische Erkrankungen) und 3. eine Sarkopenie aufgrund von Ernährung.

Der genaue Pathomechanismus für die Entstehung der Sarkopenie ist derzeit immer noch Gegenstand der Forschung. So gibt es z. B. Theorien, dass sich das Myosin während des Alterungsprozesses strukturell verändert. Bei einer in-vitro Untersuchung von Mäusen stellte S.V. Brooks die Hypothese auf, dass sich im Alter entweder die Anzahl an Querbrücken-Schlägen oder die Kraft, die bei einem einzelnen Querbrückenschlag entsteht, verringert (Brooks und Faulkner 1988). Lowe kam später ebenfalls zu dem Schluss, dass vor allem der Myosinkopf an diesem Alterungsprozess beteiligt ist (Lowe et al. 2001).

\subsubsection{Diagnostik}

Seit der Einigung auf eine einheitliche Definition gibt es 3 Parameter, die der Diagnosestellung dienen. Die Schwierigkeit in der täglichen Praxis liegt darin, eine geeignete Untersuchungsmethode für die einzelnen Parameter zu verwenden. Die EWGSOP schlägt folgende Untersuchungsmethoden für die einzelnen Parameter im klinischen Alltag vor:

\section{Muskelmasse}

Die Muskelmasse lässt sich gut durch die Dual-Röntgen-Absorptiometrie (DXA) ermitteln. Da die Geräte nicht transportierbar sind, ist im klinischen Alltag die Bioimpedance-Messung besser geeignet (Cruz-Jentoft et al. 2010). Hierbei wird mithilfe von Strom der Anteil verschiedener Körperbestandteile, wie beispielsweise der Muskeln, ermittelt.

\section{Muskelkraft}

Die Muskelkraft lässt sich gut durch die Bestimmung der Handgriff-Stärke mit einem Dynamometer ermitteln (Cruz-Jentoft et al. 2010). Studien haben gezeigt, dass die Handgriff-Stärke gute Korrelationswerte zur Muskelkraft an den unteren Extremitäten bietet (Lauretani et al. 2003). 
3. Leistungsfähigkeit/Mobilität

Zur Feststellung der Leistungsfähigkeit eignen sich verschiedene Methoden. So sind der "Timed Up and Go"-Test, die Messung der Ganggeschwindigkeit oder ein kurzer Belastungstest (z. B. SPPB-Test (Guralnik et al. 1994)) gute Möglichkeiten in der täglichen Anwendung.

Da bisher keine einheitlichen Grenzen zur Diagnosestellung festgelegt wurden, schlägt die EWGSOP ab 65 Jahren den in Abbildung (Abb.) 1 dargestellten Algorithmus vor.

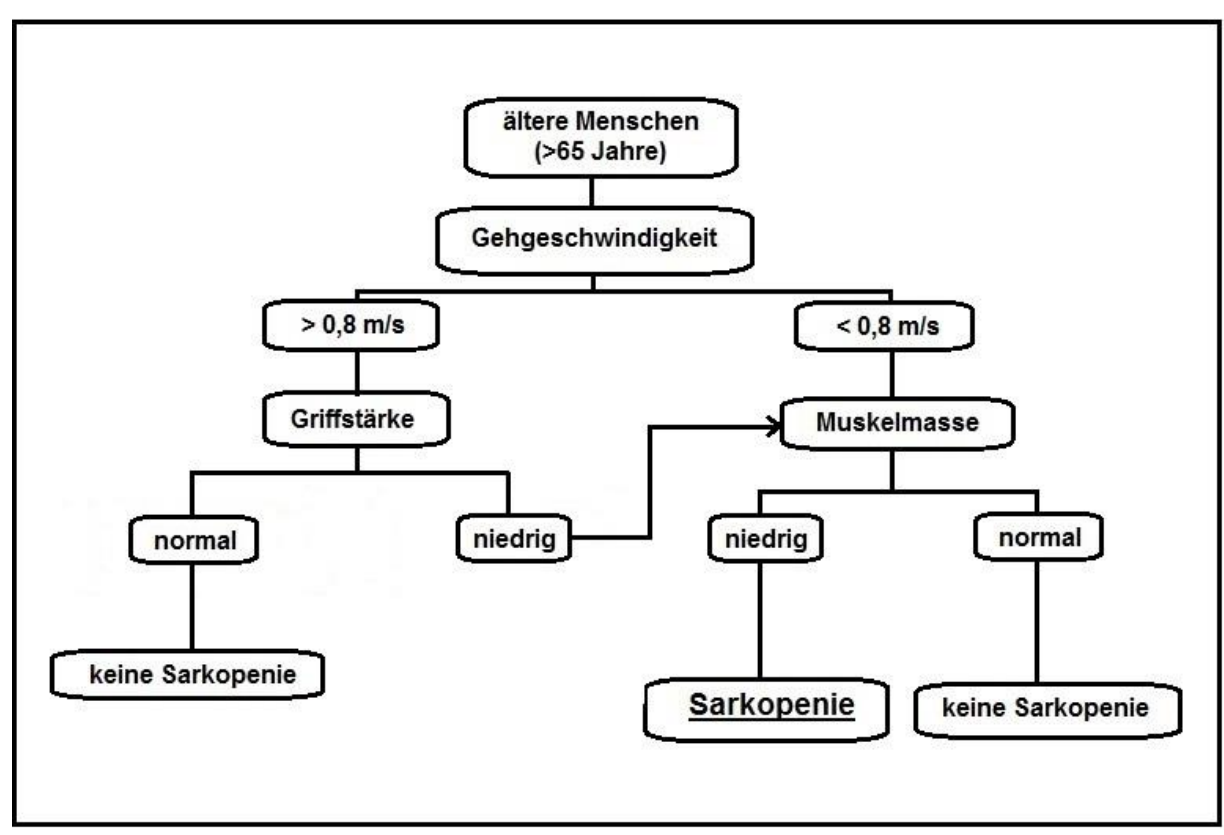

Abb. 1: Algorithmus zur Diagnosestellung der Sarkopenie

(modifiziert nach Cruz-Jentoft et al. 2010, Bahat et al. 2016)

\subsubsection{Therapie / Prävention}

Obwohl die Sarkopenie viele klinische Konsequenzen mit sich bringt, ist es bisher aufgrund einer uneinheitlichen Definition schwierig, Therapiemethoden miteinander zu vergleichen, um ein einheitliches Therapiekonzept zu entwickeln (Beaudart et al. 2014).

Muskeltraining, vor allem in Form von Kraftraining, ist eine effektive Präventionsmethode bei Sarkopenie (Rolland et al. 2011). Ein direkter Anstieg der Muskelmasse ist dabei nicht feststellbar, aber die Muskelstärke nimmt zu und die körperliche Leistung verbessert sich (Cruz-Jentoft et al. 2014). Durch das Muskeltraining werden entzündungshemmende und anti-oxidative Prozesse aktiviert, die den Proteinabbau vermindern und die Proteinsynthese fördern 
(Bowen et al. 2015). Körperliches Training auf einem Laufband konnte hingegen bei Ratten eine Zunahme der Muskelmasse nachweisen (Omi et al. 1994).

Weiterhin wird seitens der EWGSOP ein Screening mithilfe eines Algorithmus für ältere und immobilisierte Menschen empfohlen (siehe Kapitel 1.2.5, Abb. 1). Eine eindeutige Empfehlung für eine spezielle Ernährung existiert aufgrund unterschiedlicher Studienergebnisse derzeit nicht. Es wird jedoch angeregt, pro Tag mindestens $1,2 \mathrm{~g} / \mathrm{kg} \mathrm{KG}$ an Proteinen zu sich $\mathrm{zu}$ nehmen (Cruz-Jentoft et al. 2014).

\subsection{Osteoporose}

\subsubsection{Definition/Prävalenz}

2001 legten die National Institutes of Health (NIH) die Definition von Osteoporose folgendermaßen fest (Bartl 2011, NIH Consencus 2001):

„Die Osteoporose ist eine systemische Skeletterkrankung, die durch eine niedrige Knochenmasse und eine Verschlechterung der Mikroarchitektur des Knochengewebes charakterisiert ist, mit der Folge vermehrter Knochenbrüchigkeit"

Während des Lebens unterliegt der Knochen einem Remodeling-Prozess. Übersteigt die Funktion der knochenabbauenden Osteoklasten die Aktivität der knochenaufbauenden Osteoblasten, kommt es zu einem vermehrten Abbauprozess und einem Verlust an Knochensubstanz. Nachdem die Knochendichte ihr Maximum zwischen dem 25-30. Lebensjahr erreicht hat, baut sich der Knochen in den folgenden Jahren um etwa $1 \%$ jährlich ab (Schönau et al. 1996, Bainbridge et al. 2002). Der erhöhte Knochenverlust findet vor allem am Schenkelhals und der Lendenwirbelsäule statt und führt dort zu einem erhöhten Frakturrisiko (Bainbridge et al 2002). Frakturen führen nachweislich zu einer verminderten Lebensqualität (Cooper 1997) und einer erhöhten Mortalitätsrate (Rapp et al. 2010, Konnopka et al. 2009).

Nach den Ergebnissen der BEST-Studie aus dem Jahre 2013 sind in Deutschland 5,2 Millionen Frauen und 1,1 Millionen Männer an Osteoporose erkrankt. Die Prävalenz liegt bei Frauen bei $24 \%$ und bei $6 \%$ bei Männern (Hadji et al. 2013). Schätzungen zufolge leiden weltweit ca. 200 Millionen Menschen an einer Osteoporose (Lin und Lane 2004), Tendenz steigend. 


\subsubsection{Klassifikation/Einteilung}

Die Einteilung der Osteoporose kann nach verschiedenen Gesichtspunkten erfolgen. Eine mögliche Einteilung wird anhand der Ätiologie vorgenommen. Demnach unterscheidet man eine primäre und eine sekundäre Form: Als primäre oder idiopathische Osteoporose werden vor allem die postmenopausale und die senile Osteoporose bezeichnet. Sie umfasst in etwa $95 \%$ der Osteoporoseerkrankungen. Die Form der sekundären Osteoporose hingegen ist zumeist die Folge von endokrinologischen, hämatologischen oder onkologischen Erkrankungen, Medikamenteneinnahmen oder länger andauernder Immobilität (Bartl 2011, Ström et al. 2011).

Im klinischen Gebrauch findet vor allem die Einteilung der Weltgesundheitsorganisation (WHO) von 1994 (siehe Tabelle 2) Anwendung, dem sogenannten T-Score. Hierzu werden die Knochendichte der Wirbelsäule, der Hüfte oder des distalen Unterarms ermittelt und die Standardabweichung zum Referenzwert (Mittelwert von jungen Erwachsenen) errechnet (Bartl 2011).

Tab. 2: Einteilung nach WHO-Kriterien

\begin{tabular}{|l|l|l|}
\hline Einteilung & T-Score & Fraktur \\
\hline normale Knochen & $>-1$ & nein \\
\hline Osteopenie & $-2,5$ bis -1 & nein \\
\hline präklinische Osteoporose & $<-2,5$ & nein \\
\hline manifeste Osteoporose & $<-2,5$ & ja \\
\hline
\end{tabular}

\subsubsection{Ursachen/Risikofaktoren}

Die Risikofaktoren für eine Osteoporose sind sehr vielfältig. So können Untergewicht (Misra und Klibanski 2011), Nikotinkonsum (Yoon et al. 2012) und ein erhöhter Alkoholkonsum (Maurel et al. 2012) das Risiko für eine Osteoporose erhöhen. Nach vorherigen Frakturen ist das Risiko für eine Osteoporose ebenfalls erhöht (Ross et al. 1991, Cummings et al. 1995, Johnell et al. 2004). Auch die Einnahme von Medikamenten, wie Steroiden, Aromatasehemmern, Antiandrogenen, Antiepileptika, Sedativa, Opiaten, Neuroleptika, Antidepressiva und Glitazonen erhöhen das Risiko. Als größter Risikofaktor für Osteoporose ist jedoch weiterhin der Östrogenmangel 
anzusehen. So steigt das Risiko an einer Osteoporose zu erkranken nach der Menopause rapide an (Bartl 2001).

\subsubsection{Diagnostik}

Seitens des Dachverbands Osteologie e.V. (DVO) wird eine Basisdiagnostik empfohlen, wenn das Risiko innerhalb der nächsten 10 Jahre für eine radiographische Fraktur eines Wirbelkörpers oder einer proximalen Femurfraktur über $20 \%$ liegt (Leitlinie Osteoporose 2014).

Die Basisdiagnostik sollte dann aus einer Anamnese, einer klinischen Untersuchung, der Knochendichtemessung, gegebenenfalls einer Röntgenuntersuchung oder anderen bildgebenden Verfahren und einem Labor bestehen (Leitlinie Osteoporose 2014).

Aufgrund der Basisdiagnostik wird im Anschluss eine Risikobewertung, auch unter Berücksichtigung spezieller Risikofaktoren (siehe Kapitel 1.3.3), vorgenommen.

Eine Hilfestellung im klinischen Alltag bietet der Risikorechner FRAX (Fracture Risk Assessment Tool) der WHO, mit welchem man das individuelle Risikoprofil jedes Patienten ermitteln kann.

\subsubsection{Therapie}

Unterschieden werden eine Basistherapie und eine spezielle medikamentöse Therapie. Die Basistherapie besteht aus der Gabe von 1x täglich 1000 mg Calcium bei unzureichender Aufnahme durch Nahrungsmittel und der täglichen Gabe von 800 bis 1000 IE Vitamin D3. Eine spezielle medikamentöse Therapie ist indiziert, wenn das 10-Jahresrisiko für eine Fraktur um mehr als $30 \%$ erhöht ist. Zum Einsatz kommen vor allem Bisphosphonate (Alendronat, Ibandronat, Risedronat oder Zoledronat) sowie SERM (= selektive Rezeptor-Modulator, wie Raloxifen und Bazedoxifen), Östrogene, Parathyreoidhormone, Teriparatid, Strontiumranelat und Denosumab (Leitlinie Osteoporose 2014).

Auf Medikamente, die für diesen Versuch verwendet wurden, und die Ganzkörpervibration wird im weiteren Ablauf genauer eingegangen (siehe Kapitel 1.5). 


\subsubsection{Prävention}

Die DVO empfiehlt in ihren Leitlinien eine Osteoporose- und Frakturprophylaxe für Männer ab 60 Jahren und für Frauen ab der Menopause. Im Vordergrund stehen dabei die Vermeidung von Risikofaktoren (siehe Kapitel 1.3.3.), die Abwägung des Risiko-Nutzen-Verhältnisses von Medikamenten und die Prophylaxe von Sturzereignissen durch eine jährliche Sturzanamnese ab dem 70. Lebensjahr.

Aber auch die regelmäßige körperliche Aktivität wird empfohlen, um die Muskelkraft zu stärken und die Koordination zu fördern. Da in Studien keine Langzeitwirkungen nachgewiesen werden konnten, ist eine dauerhafte körperliche Betätigung erstrebenswert (Leitlinie Osteoporose 2014).

\subsection{Das muskuloskelettale System und dessen Interaktionen}

\subsubsection{Der Skelettmuskel}

Der menschliche Körper besitzt drei Arten von Muskelgeweben. Unterschieden werden die quergestreifte Herzmuskulatur, die glatte Muskulatur und die quergestreifte Skelettmuskulatur. Sie unterscheiden sich vor allem in ihrer Morphologie und ihrer Funktion. Alle Skelettmuskeln, mit Ausnahme der inneren Augenmuskulatur, entwickeln sich aus dem mittleren Keimblatt, dem Mesoderm.

Die Muskelfasern besitzen je nach Muskel einen Durchmesser von 20-80 $\mu \mathrm{m}$ und eine Länge von max. $10 \mathrm{~cm}$. Längere Muskeln sind aus mehreren hintereinander geschalteten Einzelfasern aufgebaut (Benninghoff und Drenckhahn 2008).

Die einzelnen Skelettmuskelfasern werden durch Bindegewebe zu Bündeln vereinigt und gehen schließlich in Sehnen über, die mit dem Skelett oder Weichteilen verbunden sind. Die Blutversorgung des Muskels erfolgt über Gefäße, die an mehreren Stellen in den Muskel eindringen und sich im Anschluss zu einem Kapillarnetz aufzweigen. Jede Muskelfaser wird somit über mehrere Kapillaren mit Blut versorgt (Welsch et al. 2014).

Betrachtet man die Muskelfasern im Längsschnitt, so ist die für die Skelettmuskulatur charakteristische Querstreifung erkennbar. Im Polarisationsmikroskop zeigen die einzelnen Muskelfasern dunkle (= anisotrope) A-Banden und helle (= isotrope) I-Banden. Innerhalb der A-Bande befindet sich die H-Bande (Henson-Bande). Zwischen den I-Banden liegt eine Z-Linie, die die I-Bande 
halbiert. An der Z-Linie setzen die Aktinfilamente an. Die A-Bande wird aus Myosinfilamenten gebildet, bestehend aus einem Schwanz, Hals und Kopf.

Der Bereich zwischen zwei Z-Linien wird als Sarkomer bezeichnet. Mehrere dieser Sarkomere bilden die Myofibrille. An ihren Enden sind die Myofibrillen mit dem Sarkolemm verbunden und können durch Kontraktion hervorgerufene Verkürzungen der Myofibrillen somit an das Sarkolemm und die daran ansetzenden Kollagenfibrillen der Sehnen weitergeben (Lüllman-Rauch 2009).

Die Muskelzelle ist von einer Plasmamembran umhüllt, aus der transversale Tubuli (T-Tubuli = T-System) ins Zytoplasma ragen. Auf beiden Seiten der T-Tubuli schließen sich terminale Zisternen des sarkoplasmatischen Retikulum an. Diese Triaden (ein T-Tubulus mit zwei Zisternen) sind über Triadenfüßchen verbunden. Die Abschnitte des sarkoplasmatischen Retikulums verlaufen nahezu in Längsrichtung zu den Myofibrillen (= longitudinale Tubuli = L-System) (Benninghoff und Drenckhahn 2008).

\subsubsection{Die Muskelkontraktion}

Entsteht an der postsynaptischen Membran der Muskelfaser ein Aktionspotential, wird es über das Sarkolemm entlang des T-Systems weitergeleitet und induziert die Öffnung spannungsabhängiger Kalzium-Kanäle (DihydropyridinRezeptoren). Über eine Konformationsänderung dieser Kanäle werden die Ryanodin-Rezeptoren in der Membran des sarkoplasmatischen Retikulums (L-System) aktiviert, und es entsteht ein Kalziumeinstrom entlang des elektrochemischen Gradienten aus dem sarkoplasmatischen Retikulum in das Sarkoplasma.

Das freiwerdende Kalzium setzt sich an das auf dem Aktinfilament sitzende Troponin. An der Myosin-Bindestelle, an der das Troponin und Tropomyosin sitzt, findet eine Konformationsänderung statt, sodass die Bindestelle für den Myosinkopf frei wird. Durch die ATP-Spaltung in ADP+P kann der Myosinkopf im 90-Grad-Winkel an das Aktinfilament binden. Das ADP+P löst sich vom Kopf und der Kopf-Hals-Übergang des Myosins knickt ab und gleitet am Aktinfilament entlang. Nach erneuter ATP-Bindung löst sich der Myosinkopf vom Aktinfilament. Dieser Vorgang des Querbrückenzyklus wird solange wiederholt, bis eine Kalzium-ATPase das Kalzium in das sarkoplasmatische Retikulum zurückpumpt und der Kalzium-Gradient im Sarkoplasma die Ausgangskonzentration erreicht. 
Durch die stattfindende Gleitbewegung wird das Sarkomer verkürzt und auf das Sarkolemm übertragen. Durch Kollagenfibrillen, die bis in die Basallamina ragen, wird die Kontraktionsbewegung auch über Sehnen an das Skelett übertragen (Behrends et al. 2012, Benninghoff und Drenckhahn 2008, Lüllman-Rauch 2009).

Stark geschädigte Muskelzellen, wie sie z. B. bei einem Kompartmentsyndrom entstehen, regenerieren schlecht und werden nach dem Absterben durch bindegewebiges Narbengewebe ersetzt. Bei guter Blut- und Nervenversorgung ist es jedoch bei leicht und mäßig geschädigtem Muskelgewebe möglich, den Muskel mithilfe von Satellitenzellen zu regenerieren.

Die in der Basallamina der Muskelzelle befindlichen Satellitenzellen sind teilungsfähig und können nach Aktivierung (z. B. nach Traumata) mit vorhandenen Muskelzellen fusionieren und neue Muskelfasern ausbilden (Welsch et al. 2014, Collins et al 2005). Die Anzahl an Satellitenzellen nehmen mit steigendem Alter in Ratten und Mäusen ab (Snow 1977, Gibson und Schultz 1983). Ein Vergleich der Anzahl der Satellitenzellen am älteren Mann mit und ohne Sarkopenie zeigte eine deutliche Abnahme bei den Männern mit nachgewiesener Sarkopenie (Patel et al. 2015).

\subsubsection{Muskelfasertypen}

Bei den Fasern der Skelettmuskulatur unterscheidet man zwischen Arbeitsmuskulatur (extrafusale Fasern) und Muskelspindeln (intrafusale Muskulatur). Die Muskelspindeln nehmen Spannungs- und Längenänderung des Muskels wahr und leiten die Impulse ans Rückenmark weiter. Die extrafusalen Fasern werden auch als Zuckungsfasern bezeichnet, da sie in Bruchteilen einer Sekunde kontrahieren und relaxieren können. In der Regel sind sie mit einer motorischen Nervenfaser verbunden. Diese Verbindung wird als motorische Endplatte bezeichnet. Längere Muskelfasern besitzen meist zwei oder mehr dieser motorischen Endplatten.

Es werden drei verschiedene Fasertypen der extrafusalen Muskulatur unterschieden. Sie kommen meist gemischt im Muskel vor. Zellen des Fasertyps I ermüden langsamer und dienen daher für langsame und länger dauernde Kontraktionen (= Typ S-Fasern; $\mathrm{s}=$ slow). Sie sind daher vermehrt in Muskeln vorhanden, die der Haltearbeit dienen (z. B. M. latissimus dorsi). Aufgrund ihres hohen Myoglobinanteils sind sie rot gefärbt. Sie enthalten viele 
Mitochondrien und gewinnen ihre Energie durch oxidative ATP-Synthese. Zellen des Fasertyps II sind schnell zuckend und ermüden schneller (= Typ F-Fasern; $f=f a s t)$. Sie sind besonders für schnelle und kurze kräftige Muskelkontraktionen geeignet (z. B. M. gastrocnemius). Ihre Energie gewinnen sie durch anaerobe Glykolyse. Sie besitzen daher mehr Glykogenspeicher. Aufgrund des geringen Myoglobingehaltes erscheinen sie heller als Typ I-Fasern.

Man kann Typ Ilb-Fasern, die erst bei starker Muskelaktivität aktiviert werden, von Typ Ila-Fasern unterscheiden, die (mit Typ I-Fasern zusammen) vor allem für die Dauerarbeit der Muskulatur benötigt werden (Benninghoff und Drenckhahn 2008, Welsch et al. 2014).

Die Umwandlung der Muskelfasern von einem Fasertyp in einen anderen ist möglich. Bei Immobilisation findet vor allem eine Umwandlung der Typ I-Fasern (Typ S) in Typ II-Fasern (Typ F) statt, wohingegen im Alter insbesondere eine Umwandlung von Typ II- in Typ I-Fasern (Typ F in Typ S) nachweisbar ist (Cho et al. 2016). Durch den Verlust und die Abnahme der Fasergröße der Typ II-Fasern schwindet vor allem die Muskelkraft. Im weiteren Verlauf des Alterungsprozesses nimmt schließlich die Anzahl an Typ I-Fasern ebenfalls ab (Lang et al. 2010).

\subsubsection{Der Knochen und seine Umbauprozesse}

Das menschliche Skelett besteht in der Regel aus 210 Knochen. Aufgrund ihrer verschiedenen Funktionen und der Topographie ist ihre Form sehr vielfältig.

Die Extremitäten bestehen zumeist aus einem langen, stabförmigen Knochen bestehend aus einer Diaphyse, Metaphyse und Epiphyse. Zwischen der Metaphyse und der Epiphyse befindet sich die Epiphysenfuge, die bis zum Zeitpunkt der Pubertät aus Knorpel besteht. An dieser Stelle findet das Längenwachstum statt. Die Epi- und Metaphyse bestehen aus Substantia spongiosa mit darin enthaltenem blutbildenden Knochenmark und sind von der Substantia corticalis umgeben. Die Diaphyse besteht aus Substantia compacta und ist außen von Periost umschlossen. Dieses besteht aus straffem Bindegewebe sowie osteogenen und chondrogenen Vorläuferzellen (Stratum osteogenicum). Die Kollagenfibrillen des Periosts reichen direkt bis zu den Kollagenfibrillen der Kortikalis und bilden eine feste Verbindung zwischen beiden Komponenten. 
Man unterscheidet zwei Arten von Knochengewebe: den Geflechtknochen und den Lamellenknochen. Der Geflechtknochen spielt nur während der Knochenentwicklung und bei der Knochenbruchheilung eine Rolle. Beim Erwachsenen besteht das Knochengewebe vorwiegend aus Lamellenknochen, bestehend aus kompakten Knochen (Substantia compacta und Substantia kortikalis) und spongiösem Knochen. Die Spongiosa bildet mit ihren Trabekeln ein gitterförmiges Gerüst in der Mitte des Knochens. Diese Trabekel sind zumeist entsprechend den im Knochen herrschenden Druck- und Zugspannungsverhältnissen ausgerichtet.

Die kleinste funktionelle Einheit der Kortikalis ist das Osteon: um einen zentralen Gefäß-Nervenkanal (Havers'scher Kanal) sind ca. 30 Lamellen angeordnet. Zwischen diesen Lamellen befinden sich Aussparungen in denen sich die Zellkörper der Osteozyten befinden (Osteozytenlakunen). Die Osteozytenfortsätze verlaufen in Canaliculi ossei, welche die Lakunen miteinander verbinden. Am Rand der Osteone befinden sich die Osteoblasten und Osteoklasten. Transversal sind die Havers'schen Kanäle über Volkmannsche Kanäle verbunden (Benninghoff und Drenckham 2008).

\subsubsection{Knochenzellen}

Bei den Knochenzellen werden die in Tab. 3 aufgeführten Zelltypen unterschieden.

Tab. 3: Knochenzelltypen (modifiziert nach Benninghoff und Drenckhahn 2008, Aust et al. 2014)

\begin{tabular}{|l|l|}
\hline Zelltyp & Funktion \\
\hline $\begin{array}{l}\text { Vorläufer-, Stamm-, } \\
\text { Progenitorzellen }\end{array}$ & mesenchymale Zellen \\
\hline Osteoblasten & bauen sich in die verkalkte Knochenmatrix ein \\
\hline Osteozyten & reife Knochenzellen \\
\hline Osteoklasten & bewirken Abbau der Knochenmatrix \\
\hline
\end{tabular}

\subsubsection{Die Mechanostat-Theorie}

Julius Wolff beschrieb 1892 erstmals die Zusammenhänge zwischen der Belastung des Knochens und des daraus resultierenden Knochenaufbaus. Sobald auf einen Knochen höhere Belastungen wirken, baut sich der Knochen auf, und seine Festigkeit nimmt zu. Ist die Belastung rückläufig, baut sich der 
Knochen wieder ab (Wolff 2010). Diese Erkenntnisse verwendete Harold Frost als Grundlage zur Erstellung des Mechanostat-Modells, welches die Aufbau-, Abbau- und Umbauprozesse des Knochens genauer beschreibt.

Sobald Kräfte (Schwerkraft und Muskelkraft) auf den Knochen wirken, findet eine elastische Verformung statt. Ab eine Längenänderung von 0,1\%, wirkt eine Kraft von $1000 \mu$ Strain auf den Knochen ein. Untersuchungen an der Tibia zeigten, dass man, je nach Stärke der einwirkenden Kraft, die vier in Tabelle 4 dargestellten Wirkungen unterscheiden kann (Frost 1987).

Tab. 4 Kraft und Auswirkung auf den Knochen (modifiziert nach Frost 1987)

\begin{tabular}{|l|l|}
\hline Kraft & Wirkung \\
\hline$<800 \mu$ Strain & Abbau der Knochenmasse und Knochenfestigkeit \\
\hline$>800$ und $<1500 \mu$ Strain & Knochenmasse und Knochenfestigkeit unverändert \\
\hline$>1500 \mu$ Strain & $\begin{array}{l}\text { Knochenaufbau (Knochenmasse und } \\
\text { Knochenfestigkeit nehmen } z u) ~\end{array}$ \\
\hline$>15.000 \mu$ Strain & Fraktur \\
\hline
\end{tabular}

Bei dem Mechanostat-Modell handelt es sich um ein dynamisches Modell. Sobald eine erhöhte Verformung auf den Knochen wirkt, ist ein Knochenabbau wieder rückläufig.

\subsubsection{Knochen-Muskel-Interaktion}

Die elastische Verformung des Knochens durch Muskelkontraktion bewirkt eine Verschiebung der intrakanalikulären Flüssigkeit (Weinbaum et al. 1994, Duncan und Turner 1995). Die dadurch entstehenden Druckwellen, Scherkräfte, Änderung des elektrischen Feldes und Formveränderungen werden durch Mechanosensoren an den Osteozyten registriert (Turner und Pavalko 1998). Dies hat eine Ausschüttung von Mediatoren, wie beispielsweise Prostaglandin und Stickstoffmonoxid zur Folge (Klein-Nulend et al. 1995, Burger und Klein-Nulend 1999). Diese wiederum wirken auf den Knochenstoffwechsel (Kerschan-Schindl 2012). Stickstoffmonoxid fördert die Osteoblastenaktivität und inhibiert die Osteoklastenaktivität (Otsuka et al. 1998, van't Hof und Ralston 1997). Prostaglandine stimulieren die Produktion von IGF in Osteoblasten (Raisz et al. 1993) und stimulieren somit die Osteoblastendifferenzierung (Xi et al. 2016). Gleichzeitig inhibiert Prostaglandin aber auch die Osteoklastenaktivität und verringert somit die Knochenresorption 
(Fuller und Chambers 1989). Da die verschiedenen physikalischen Signale zu ähnlichen zellulären Antworten führen, ist zu vermuten, dass sie letztendlich zu einem gemeinsamen Signaltransduktionsweg führen (Rubin et al. 2006).

Auch die direkte Ausschüttung von Botenstoffen (Myokinen) vom Muskel bei Beanspruchung haben autokrine, parakrine und endokrine Wirkungen auf verschiedene Organe, wie Knochen, Fettgewebe, Leber, Pankreas und Gehirn (Pedersen 2013). So werden u. a. durch Muskelkontraktion große Mengen von IL-6 ins Blutplasma abgegeben (Steensberg et al. 2000). Die Sekretion von IL-15 bewirkt beispielsweise eine Erhöhung des Mineralgehaltes im Knochen (Quinn et al. 2009).

\subsection{Therapie}

Auf die generellen Osteoporose-Therapieempfehlungen der DVO wurde bereits in Kapitel 1.3.6 eingegangen. Da die medikamentöse Therapie heutzutage einen sehr hohen Stellenwert einnimmt, liegt hierauf ein großer Fokus der Forschung. Die Einnahme von Medikamenten kann generell zu Neben- und zu Wechselwirkungen führen. Das Risiko für Wechselwirkungen steigt vor allem bei der Einnahme von vielen Medikamenten. Da die Multimorbidität im Alter zur Folge hat, dass vielfach Medikamente eingenommen werden müssen und die Indikationen im klinischen Alltag zumeist sehr breit gestellt werden, sollten bei der Behandlung der Osteoporose auch nicht-medikamentöse Therapien, wie z. B. die Ganzkörpervibration, als mögliche Optionen wahrgenommen und geprüft werden.

\subsubsection{Medikamentöse Therapie}

Im Folgenden wird nur auf die für diesen Versuch genutzten Medikamente der Osteoporose-Therapie genauer eingegangen.

\subsubsection{1 Östrogen}

Östrogene sind Sexualhormone aus der Klasse der Steroidhormone. Derzeit sind drei Östrogene bekannt: Östron (E1), Östradiol (E2) und Östriol (E3).

Dem Amerikaner Edward Doisy und dem deutschen Biochemiker Adolf Butenandt gelangen 1929 unabhängig voneinander die Isolation von Estron aus dem Urin von Schwangeren (Simoni et al. 2002, Shampo et al. 2012). 1931 isolierte Butenandt ebenfalls das männliche Sexualhormon Androsteron 
und 1933 das Hormon Progesteron. Für seine Forschungen erhielt er und Leopold Ruzicka 1939 den Nobelpreis für Chemie (Shampo et al. 2012).

Im Verlauf erforschte man die Biosynthese dieser Hormone (siehe Abb. 2) und entdeckte das Enzym Aromatase als Umwandlungsenzym von Testosteron zu Östradiol und von Androstendion zu Östron (Santen et al. 2009) und die Wirkungen von Östrogenen am Östrogenrezeptor (ER).

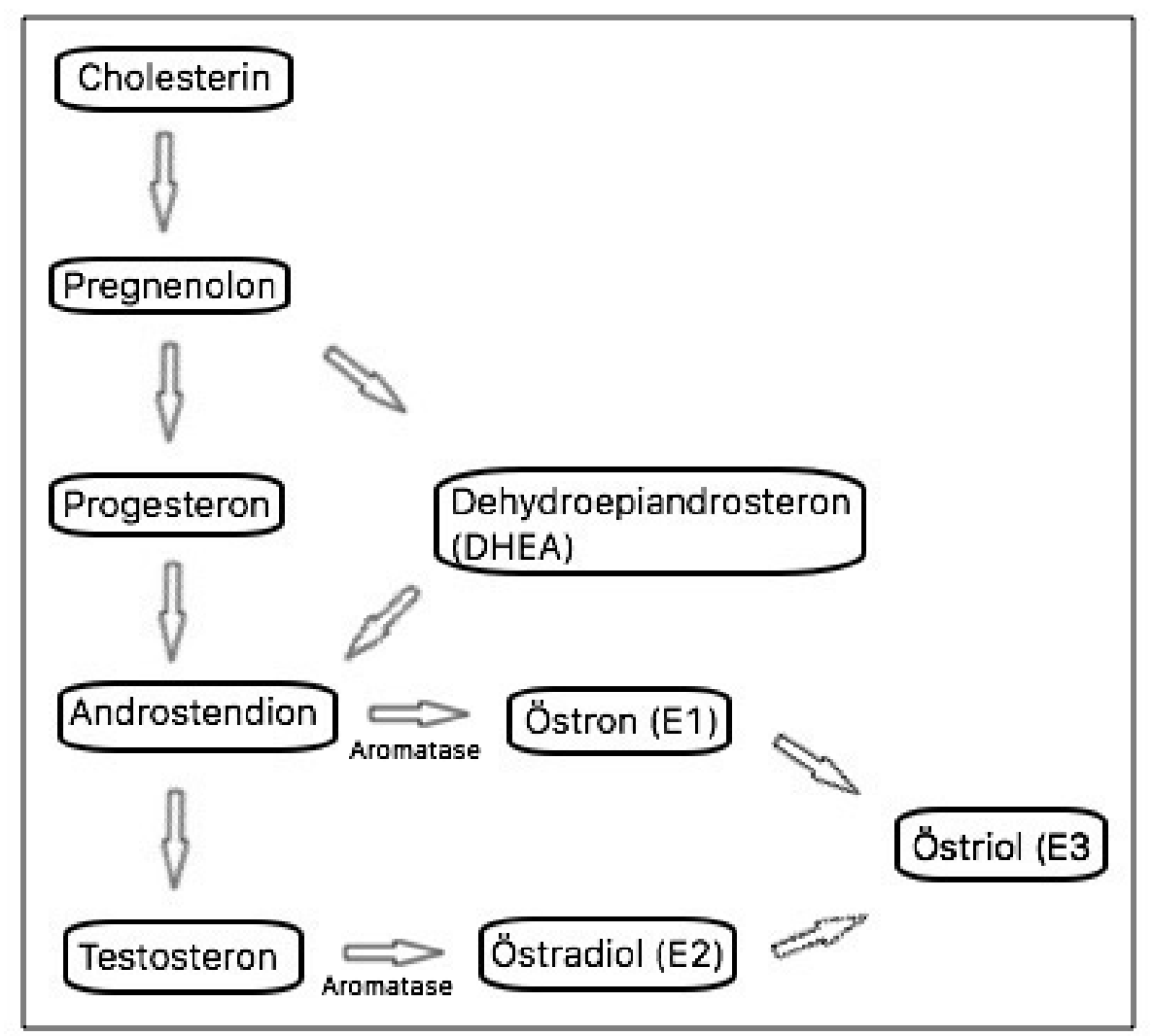

Abb. 2: Östrogen-Synthese aus Cholesterin (modifiziert nach Cui et al. 20013, Hojo et al. 2011)

Beim Östrogenrezeptor unterscheidet man hauptsächlich zwei Subtypen: Östrogenrezeptor $\alpha(E R \alpha)$ und Östrogenrezeptor ß (ER ß). Tabelle 5 zeigt die verschiedenen Gewebe, in denen sie exprimiert werden (Cui et al. 2013, Dahlmann-Wright et al. 2006, Lemoine et al. 2003, Wiik et al. 2003, Wiik et al. 2009). 
Tab. 5: Rezeptorvorkommen im Gewebe (modifiziert nach Cui et al. 2013, Dahlmann-Wright et al. 2006, Lemoine et al. 2003, Wiik et al. 2003, Wiik et al. 2009)

\begin{tabular}{|l|l|}
\hline Rezeptor & Vorkommen im Gewebe \\
\hline ER $\alpha$ & $\begin{array}{l}\text { Uterus, Nebenhoden, Knochen, Muskel, Leber, Niere, Fettgewebe, } \\
\text { Prostata, Ovar, Leydig-Zellen, Endometrium, Brust, ZNS, PNS, } \\
\text { Gehirn, kardiovaskuläres System, Hoden }\end{array}$ \\
\hline ER B & $\begin{array}{l}\text { Darm, Hoden, Knochenmark, Endothel, Lunge, Blase, Prostata, } \\
\text { Ovar, Knochen, Muskel, Uterus, Brustdrüse, Nebenhoden, Niere, } \\
\text { ZNS, PNS }\end{array}$ \\
\hline
\end{tabular}

Seit dem Zeitpunkt der Entdeckung der Hormone behandelte man Östrogenmangel und postmenopausal auftretende klimakterische Beschwerden großzügig mit der Hormonersatztherapie (HRT), bei der entweder Östrogen als Monotherapie oder in Kombination mit Gestagen eingesetzt wurden.

Im Jahre 2002 wurde erstmals in einer Studie der Women's Health Initiative (WHI) vor den möglichen negativen Folgen dieser Hormontherapie gewarnt. Die erste Studie, die aufgrund eines negativen Risiko-Nutzen-Verhältnisses vorzeitig abgebrochen wurde, ergab bei der Kombinationstherapie, bestehend aus Östrogen und Gestagen, vor allem ein erhöhtes Risiko für Brustkrebs und kardiovaskuläre Komplikationen, wie Thrombose und Schlaganfälle (Roussouw et al. 2002). Auch die zweite Studie, bei der hysterektomierte Frauen eine Monotherapie mit Östrogen gegenüber Placebo erhielten, zeigte ein erhöhtes Risiko für Thrombosen und Schlaganfälle und wurde ebenfalls vorzeitig beendet (Anderson et al. 2004). Beide Studien ergaben bei Medikamenteneinnahme gegenüber der Placebo-Gruppe aber auch eine Abnahme der Wahrscheinlichkeit für Oberschenkelhalsbrüche (Roussouw et al. 2002, Anderson et al. 2004).

Das Bekanntwerden der Studie führte in den USA zu einem Rückgang der Verschreibungen von Januar bis Juni 2003 im Vergleich zum Vorjahr von $66 \%$ für die Kombinationstherapie und einen Rückgang von 33 \% für die Monotherapie (Hersh et al. 2004). Gleichzeitig zeigte sich ein Rückgang der Inzidenz für Brustkrebs um 6,7 \% von 2002 zu 2003 (Ravdin et al. 2007). Die Ergebnisse der WHI-Studie wurden u. a. auch in der Million Woman-Studie bestätigt (Million Women Study Collaborators 2003). 
Der Dachverband Osteologie e.V. empfiehlt daher den Einsatz von Östrogenen zur Osteoporoseprävention bei postmenopausalen Frauen nur, wenn ein erhöhtes Frakturrisiko besteht und eine Unverträglichkeit oder Kontraindikation gegenüber den primär empfohlenen Medikamenten besteht. Beim Einsatz hat eine sorgfältige Nutzen-Risiko-Abschätzung zu erfolgen. Bei nichthysterektomierten Frauen ist außerdem eine Kombinationstherapie mit einem Gestagen durchzuführen, um das erhöhte Risiko für Endometriumkarzinome unter Monotherapie zu senken (Beral et al. 2005).

Der genaue Einfluss von Östrogen auf Muskelzellen ist bis heute nicht endgültig geklärt. Im Muskel beim Menschen wurden beide Formen des Östrogenrezeptors (ER a und ER B) nachgewiesen (Lemoine et al. 2003, Wiik et al. 2003, Wiik et al. 2009), wobei der ERa um ein vielfaches häufiger exprimiert wird (Wiik et al. 2003). Bei Mäusen war lediglich der Nachweis vom ER a möglich (Couse et al. 1997).

In einer Studie wurde nachgewiesen, dass nach einem Zeitraum von 24 Stunden nach der Verabreichung von $10 \mathrm{~nm}$ Östradiol auf menschliche Muskelzellen die mRNA-Expression vom ER $\alpha$ anstieg, bei der mRNAExpression vom ER B zeigte sich allerdings keine signifikante Veränderung (Dieli-Conwright et al. 2009). Eine andere Studie ergab hingegen, dass nach dem Entzug von Östrogen durch eine Ovarektomie die Anzahl an ER a und ER $B$ sank und nach Applikation von Östrogen die Anzahl beider Rezeptoren wieder anstieg (Bunratsami et al. 2015).

Nachdem beobachtet worden war, dass bei Frauen ab der Menopause die Muskelstärke abnimmt und sich dieser Effekt durch den Einsatz der Hormontherapie verhindern lässt (Phillips et al. 1993), wurden verschiedene Hypothesen aufgestellt, wie sich die Gabe von Östrogen auf die Muskelzellen auswirken könnte.

In Mäusen wurde ebenfalls eine schwächere Beinmuskulatur bei ovarektomierten Tieren gegenüber nicht ovarektomierten Tieren und Tieren mit 17ß-ÖstradiolTherapie nachgewiesen (Moran et al. 2006). Später untersuchte Moran die Anzahl an starkbindendem Myosin in weiblichen Mäusen und fand heraus, dass die Anzahl bei ovarektomierten Ratten signifikant erniedrigt ist im Vergleich zu Ratten, die eine Therapie mit 17ß-Östradiol erhielten (Moran et al. 2007). 
Aber auch die Produktion anti-oxidantieller Proteine, die nach Östrogengabe entstehen und zu einem Erhalt der stabilen Myosinstruktur führen, könnten positiv auf den Muskel wirken (Baltgalvis et al. 2010).

Schiessl und Kollegen erstellten eine These, wie Östrogene einen positiven Effekt beim Knochenaufbau hervorrufen. Sie erkannten, dass in der Pubertät Mädchen gegenüber Jungen eine erhöhte Knochenmasse bei gleicher Muskelstärke aufwiesen. Ihre Überlegungen besagen, dass Östrogene die Remodeling-Grenze des Knochens herabsetzen und durch den Zug der Muskeln am Knochen bei Mädchen bei einem höheren Östrogenspiegel auch eine höhere Knochenmasse nachweisbar ist (Schiessl et al. 1998).

\subsubsection{Raloxifen}

Raloxifen (RLF) ist ein Medikament aus der Klasse der SERMs. SERMs sind Selective Estrogen Receptor Modulators und weisen Östrogen-agonistische und Östrogen-antagonistische Wirkungen auf. Raloxifen ist ein Medikament der 2. Generation und besitzt eine Östrogen-agonistische Wirkung am Knochen und auf den Lipidstoffwechsel sowie eine antagonistische Wirkung an der Brust und dem Uterus (Bartl 2010). Es ist davon auszugehen, dass Raloxifen denselben Effekt wie Östrogen auf Osteoklasten und Osteoblasten besitzt.

Unter Raloxifen-Gabe wurde ebenfalls eine vermehrte mRNA-Expression des $E R \alpha$ in menschlichen Muskelzellen nachgewiesen, die Veränderung des ER $B$ war jedoch nicht signifikant (Dieli-Conwright et al. 2009).

In der MORE-Studie im Jahr 1994 wurde die Wirksamkeit von Raloxifen gegenüber Placebo zur Osteoporose-Prävention an postmenopausalen Frauen untersucht. Bei einer täglichen Dosis von 60 mg Raloxifen (in Kombination mit 500 mg Calcium und 400 IE Vitamin D) zeigte sich ein signifikanter Rückgang an Wirbelkörperfrakturen von 55 \% bei Frauen ohne vorherige Fraktur und von $31 \%$ bei Frauen, die vorher bereits eine Fraktur erlitten hatten. Ein vermindertes Risiko für andere Frakturen war nicht nachweisbar. Weiterhin zeigte sich in der Studie ein Anstieg der Knochendichte (BMD = bone mineral density) um 2,1\% am Schenkelhals und 2,6 \% an der Wirbelsäule. Auch das Risiko eines Mamma-Karzinoms sank um 65 \%. Das Risiko für tiefe Venenthrombosen und Lungenembolie war hingegen um das Dreifache erhöht gegenüber der Placebo-Gruppe (Agnusdei und lori 2000). 
Eine spätere Studie, die einen möglicherweise kardioprotektiven Effekt von Raloxifen untersuchen sollte, fand ein erhöhtes Risiko für Schlaganfälle. Ein kardioprotektiver Effekt konnte hingegen nicht nachgewiesen werden (Barrett-Connor et al. 2006). Nur wenn bereits vorher ein erhöhtes Risiko für kardiovaskuläre Erkrankungen vorliegt, kann Raloxifen das Risiko für weitere Ereignisse verringern (Barrett-Connor et al. 2002).

Die Wirkung von Raloxifen auf Muskelzellen ist bisher weitestgehend unerforscht. Lediglich eine über zwölf Monate durchgeführte Studie konnte zeigen, dass die tägliche Einnahme von $60 \mathrm{mg}$ Raloxifen bei postmenopausalen Frauen keine signifikanten Unterschiede in der Muskelstärke und Muskelkraft gegenüber der Placebo-Kontrollgruppe ergab (Jacobson et al. 2010).

Da Raloxifen einen hohen First-Pass-Effekt besitzt, wenn es oral in Tablettenform eingenommen wird, werden derzeit Untersuchungen durchgeführt, ob auch eine andere Applikationsart z. B. transdermal in Form von Pflastern möglich ist (Mahmood et al. 2014). Eventuell könnte somit eine andere Applikationsart positive Wirkungen am Muskel bei postmenopausalen Frauen hervorrufen und zu einer erhöhten Muskelstärke und Muskelkraft führt.

\subsubsection{Vibrationstherapie}

Derzeit gibt die DVO in ihrer Leitlinie von 2014 keine Therapieempfehlung für eine Vibrationstherapie. Bei der Ganzkörpervibrationstherapie (WBV) werden die Probanden auf eine vibrierende Plattform gestellt. Durch die Vibrationen im ganzen Körper werden die Muskeln durch Aktivierung der Dehnreflexe zur Kontraktion gebracht (Rauch 2009, Rittweger 2010).

Die Auswirkungen der Ganzkörpervibration auf den Muskel im Tiermodell ist wenig untersucht und die Ergebnisse sind nicht einheitlich. Eine Untersuchung an Mäusen zeigte, dass durch die Ganzkörpervibration bei $45 \mathrm{~Hz}$ für 15 Minuten täglich über sechs Wochen die Querschnittsfläche des untersuchten M. soleus und auch die Fläche der Muskelfasern (Typ I und II) signifikant erhöht gegenüber der gleichaltrigen Kontrollgruppe waren (Xie et al. 2008). Im Vergleich von zuvor ovarektomierten Ratten, die mit 17, 30 oder $45 \mathrm{~Hz}$ für 30 Minuten pro Tag über 90 Tage vibriert wurden, konnte keine Zunahme der Muskelmasse (M. soleus, M. gastrocnemius, M. tibialis anterior, 
M. extensor digitorum longus) gegenüber den nicht vibrierten Tieren nachgewiesen werden (Oxlund et al. 2003).

Auch am Menschen ist ein positiver Effekt der Vibrationstherapie nachgewiesen. Bei postmenopausalen Frauen, die dreimal für zwei Minuten, also sechs Minuten insgesamt, zweimal wöchentlich über sechs Monate mit $28 \mathrm{~Hz}$ einer Ganzkörpervibration behandelt wurden, zeigte sich ein Anstieg der Muskelstärke um $5 \%$ (Russo et al. 2003).

Die Ganzkörpervibration hat gezeigt, dass sie in etwa dieselben Wirkungen auf Muskelkräfte im Knie hat, wie ein Standard-Fitnessprogramm bestehend aus Herz-Kreislauftraining und Krafttraining (Roelants et al. 2004). Allerdings ist bei der Ganzkörpervibration mit einer erhöhten Compliance der Teilnehmer zu rechnen, da der Zeitaufwand hier im Gegensatz zum normalen Fitnesstraining niedriger ist und in kürzerer Zeit ein höherer Nutzen erzielt werden kann. Durch das Vibrationstraining kann die Balance und die Mobilität bei alten Menschen gesteigert werden (Bautmanns et al. 2005), somit ist von einer generellen Förderung der Aktivität im Alter auszugehen.

Da sich alle Studien hinsichtlich Frequenz, Amplitude und Bewegung der Vibrationsplatte (vertikal, horizontal, seitenalternierend) teilweise sogar sehr wesentlich unterscheiden (Rauch 2009), ist es schwierig, die Studien miteinander zu vergleichen und eine einheitliche Therapieempfehlung zu entwickeln.

Alle Untersuchungen sind bisher auch nur über einen begrenzten Zeitraum erfolgt. Langfristige Studien, ob die Ganzkörpervibration eventuell sogar schädliche Wirkungen hervorrufen kann, fehlen derzeit.

Es ist jedoch bekannt, dass die langjährige Einwirkung von GanzkörperSchwingungen im Sitzen durch vor allem vertikal wirkende Frequenzen von 3-5 Hz zu einer Stoffwechselstörung der Bandscheiben mit degenerativen Veränderung führen können und bandscheibenbedingte Erkrankungen, wie lokale Lumbalsyndrome, lumbale Wurzelreizungen und das Kaudasyndrom hervorrufen. Diese Erkrankungen können bei oben beschriebener Belastung als Berufskrankheit Nr. 2110 anerkannt werden (Bundesministerium für Arbeit und Soziales 2005). Diese Wirkungen sind bisher nur bei einer langjährigen Aussetzung gegenüber der Schwingungen beschrieben. Ganzkörpervibrationen über Zeiträume von über einem Jahr und über mehrere Stunden und daraus 
eventuell resultierende negative Auswirkungen sollten daher in Zukunft ebenfalls Gegenstand der Forschung sein.

Der Einsatz der Ganzkörpervibration in Kombination mit der Östrogen- bzw. Raloxifen-Therapie ist bisher nicht Gegenstand von Untersuchungen gewesen. 


\section{Material Und Methoden}

\section{$2.1 \quad$ Tierexperiment}

Der gesamte Versuch wurde entsprechend der Genehmigung der Bezirksregierung Oldenburg (AZ 33.9-42502-04-11/0389) und den Richtlinien des deutschen Tierschutzgesetzes durchgeführt

\subsubsection{Versuchstiere und ihre Haltung}

Für den Versuch wurden 84 weibliche Sprague-Dawley-Ratten (Harlan Winkelmann, Borchen) verwendet. Das Durchschnittsgewicht der Tiere betrug zu Beginn des Versuchs 236,3 g. Tabelle 6 zeigt die Gruppeneinteilung der Versuchstiere auf. Die Ratten wurden in sieben Gruppen zu jeweils 12 Tieren unterteilt und in 21 Käfigen der Firma Ehret (Typ Makrolon®IV) untergebracht. Zu Beginn des Experiments wurde jede Ratte mit einem Transponder (UNO, 6900 AA Zevenaar, Niederlande) ausgestattet, um später eine bessere Identifizierung der einzelnen Tiere zu ermöglichen.

Tab. 6: Gruppeneinteilung mit Eingriff und Therapie

\begin{tabular}{|l|l|l|l|l|l|}
\hline Gruppe & Tiere & Ovarektomie & Osteotomie & Vibration & Medikament \\
\hline 1 (non-OVX) & 12 & Nein & Ja & Nein & -- \\
\hline 2 (OVX) & 12 & $\mathrm{Ja}$ & $\mathrm{Ja}$ & Nein & -- \\
\hline $3(\mathrm{WBV})$ & 12 & $\mathrm{Ja}$ & $\mathrm{Ja}$ & $\mathrm{Ja}$ & -- \\
\hline $4(\mathrm{E})$ & 12 & $\mathrm{Ja}$ & $\mathrm{Ja}$ & Nein & Östradiol \\
\hline $5(\mathrm{E}+\mathrm{WBV})$ & 12 & $\mathrm{Ja}$ & $\mathrm{Ja}$ & $\mathrm{Ja}$ & Östradiol \\
\hline $6(\mathrm{RLF})$ & 12 & $\mathrm{Ja}$ & $\mathrm{Ja}$ & Nein & Raloxifen \\
\hline $7(\mathrm{RLF}+\mathrm{WBV})$ & 12 & $\mathrm{Ja}$ & $\mathrm{Ja}$ & $\mathrm{Ja}$ & Raloxifen \\
\hline
\end{tabular}

Der Versuchsablauf fand während des gesamten Zeitraums innerhalb der Räumlichkeiten der Zentralen tierexperimentellen Einrichtung der Universitätsmedizin Göttingen statt.

Dort wurden die Tiere bei einer Temperatur von $22+/-1{ }^{\circ} \mathrm{C}$ und einer relativen Luftfeuchtigkeit von $55 \%$ gehalten. Durch eine Zeitschaltuhr war ein Tages-/Nachtrhythmus von jeweils 12 Stunden gewährleistet.

Während des Versuches konnten sich die Tiere innerhalb des Käfigs frei bewegen und hatten jederzeit freien Zugang zu Nahrung und Wasser. 
Die Basisnahrung, bestehend aus phytoöstrogenfreien Pellets (Ssniff SM R/M, $10 \mathrm{~mm}$ Pellets, Ssniff Spezialdiäten $\mathrm{GmbH}$, Soest), wurde in ausreichender Menge zur Verfügung gestellt und wöchentlich aufgefüllt. Das Wasser wurde täglich erneuert. Das Gewicht der Tiere und der Futterverbrauch wurden wöchentlich ermittelt.

\subsubsection{Versuchsablauf}

Zur besseren Übersicht stellt Abbildung 3 den Verlauf des Versuches dar. Die einzeln durchgeführten Maßnahmen werden im weiteren Verlauf genauer erläutert.

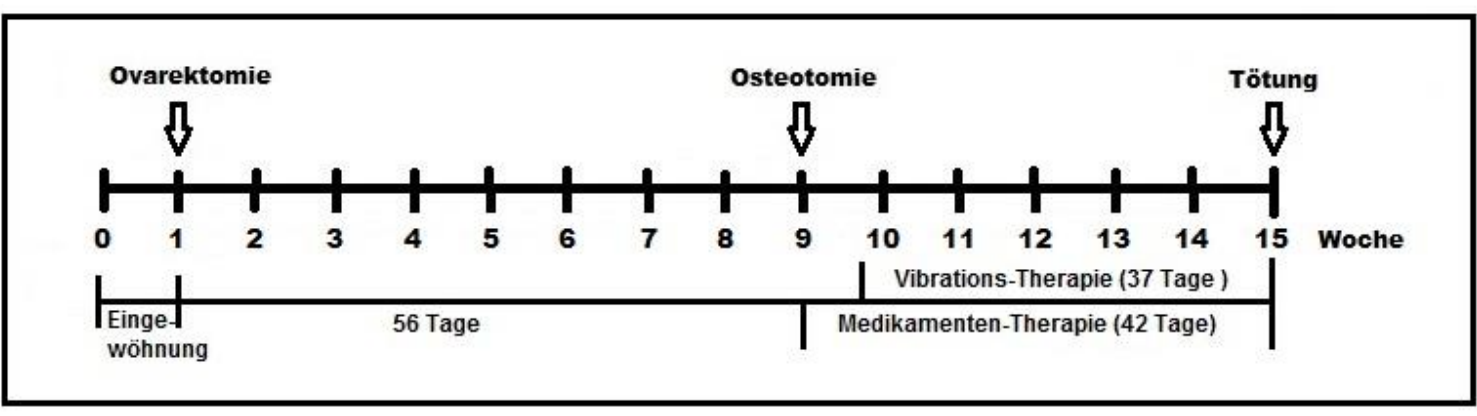

Abb. 3: Versuchsablauf

\subsubsection{Ovarektomie}

Zum Zeitpunkt der Ovarektomie waren die Tiere drei Monate alt. 72 der 84 Ratten wurden dieser Operation unterzogen. Da alle Tiere während dieses Eingriffs den oben bereits erwähnten Transponder appliziert bekamen, wurden die Kontrolltiere (non-OVX) ebenfalls in Narkose versetzt.

Die Anästhesie erfolgte durch eine intraperitoneale Applikation von $115 \mathrm{mg} / \mathrm{kg} \mathrm{KG} \mathrm{Ketamin} \mathrm{(Medistar,} \mathrm{Holzwickede)} \mathrm{und} \mathrm{8mg/kg} \mathrm{KG} \mathrm{Xylazine}$ (Riemser, Greifswald-Insel Riems). Nach Überprüfung einer vollständigen Narkotisierung wurde allen Tieren zuerst der Transponder eingesetzt.

Bei den zu ovarektomierenden Tieren wurde die Haut zwischen dem hinteren Bein und dem Rippenbogen rasiert und anschließend desinfiziert. Die Haut wurde mittels Skalpell inzidiert und das Peritoneum stumpf freipräpariert. Im Anschluss erfolgte die Eröffnung der Bauchhöhle sowie die Darstellung beider Adnexen. Nachdem die Tuba uterina aufgesucht und legiert wurde, wurden die Ovarien mittels Skalpell abgesetzt. Auf der Gegenseite wurde in gleicher Weise verfahren. 
Nach der Blutstillung erfolgte der Wundverschluss des Peritoneums und des Abdomens durch eine resorbierbare Vicryl-Naht (Ethicon, Johnson \& Johnson Medical $\mathrm{GmbH}$, Norderstedt). Abschließend wurde die Hautinzision durch eine Klammernaht (Michel wound brackets 7,5 x 1,75 mm, Gebrüder Martin GmbH \& Co. KG, Tuttlingen) wieder verschlossen.

Um einen Flüssigkeitsverlust zu verhindern, wurde jedem Tier ein Depot mit $3 \mathrm{ml}$ $0,9 \% \mathrm{NaCl}$-Lösung s.c. verabreicht. Außerdem erfolgte die einmalige Gabe von 5 mg/kg KG Rimadyl (Pfizer, Berlin) zur Schmerztherapie.

Der hier beschriebene Operationsablauf wurde bereits früher erfolgreich in anderen Studien der Arbeitsgruppe (Sehmisch et al. 2009, Stuermer et al. 2010) durchgeführt.

\subsubsection{Osteosynthese}

Um die Knochenheilung und -stabilität in weiteren Untersuchungen außerhalb dieser Dissertation zu untersuchen, wurden alle Tiere am 56 Tage nach der Ovarektomie einer beidseitigen metaphysären Osteotomie der Tibia unterzogen und mit einer 5-Loch-Mini-Platte aus Titan (Stryker Trauma, Selzach, Switzerland) versorgt.

\subsubsection{Therapien}

\subsubsection{Medikamente}

Direkt nach der oben beschriebenen Osteosynthese wurde die Nahrung der Tiere in den Medikamenten-Gruppen ausgetauscht. Für den Versuch wurde die in Tabelle 7 aufgeführte Nahrung mit den erwähnten Futterzusätzen verwendet.

Tab. 7: Nahrungszusätze der Medikamenten-Gruppen

\begin{tabular}{|l|l|l|l|}
\hline Gruppen & Futter & Futterzusatz & Dosierung \\
\hline $\begin{array}{l}\text { E und } \\
\text { E+WBV }\end{array}$ & $\begin{array}{l}\text { phytoöstrogenfreie } \\
\text { Pellets }\end{array}$ & $\begin{array}{l}\text { 17ß-Östradiolbenzoate } \\
\text { (Sigma Aldrich, Seelze) }\end{array}$ & $10 \mathrm{mg} / \mathrm{kg}$ Futter \\
\hline $\begin{array}{l}\text { RLX und } \\
\text { RLX+WBV }\end{array}$ & phytoöstrogenfreie & $\begin{array}{l}\text { Raloxifen } \\
\text { Pellets }\end{array}$ & $167 \mathrm{mg} / \mathrm{kg}$ Futter \\
\hline
\end{tabular}




\subsubsection{Vibrationstherapie}

Fünf Tage nach der Osteotomie begann die Vibrationstherapie. Sie erfolgte zwei Mal täglich für jeweils 15 Minuten an insgesamt 37 Tagen (siehe Tabelle 6, Seite 24).

Hierzu wurden jeweils acht bis zehn Tiere in einen speziellen Käfig (siehe Abb. 4) gesetzt. Dieser Käfig wurde vorab seitlich gepolstert, um eine Verletzung der Tiere während der Vibration auszuschließen. Der Käfig wurde auf einem Vibrationstisch (Vibriertisch VTG, Drehstrom- Vibrationsmotor Typ HVL/HVE, Vibra Maschinenfabrik Schultheis GmbH \& Co, Offenbach) befestigt und im Anschluss bei einer Frequenz von $70 \mathrm{~Hz}$ und einer Amplitude von 0,4 mm vertikal zum Vibrieren gebracht.

Während der Vibration wurde darauf geachtet, dass die Tiere die gesamte Zeit Bodenkontakt haben, um eine gleichbleibende Vibration zu gewährleisten. Die Tiere der Kontrollgruppe wurden ebenfalls in den Raum mit dem Vibrationstisch gebracht und dort der Geräuschkulisse während der Vibration ausgesetzt.

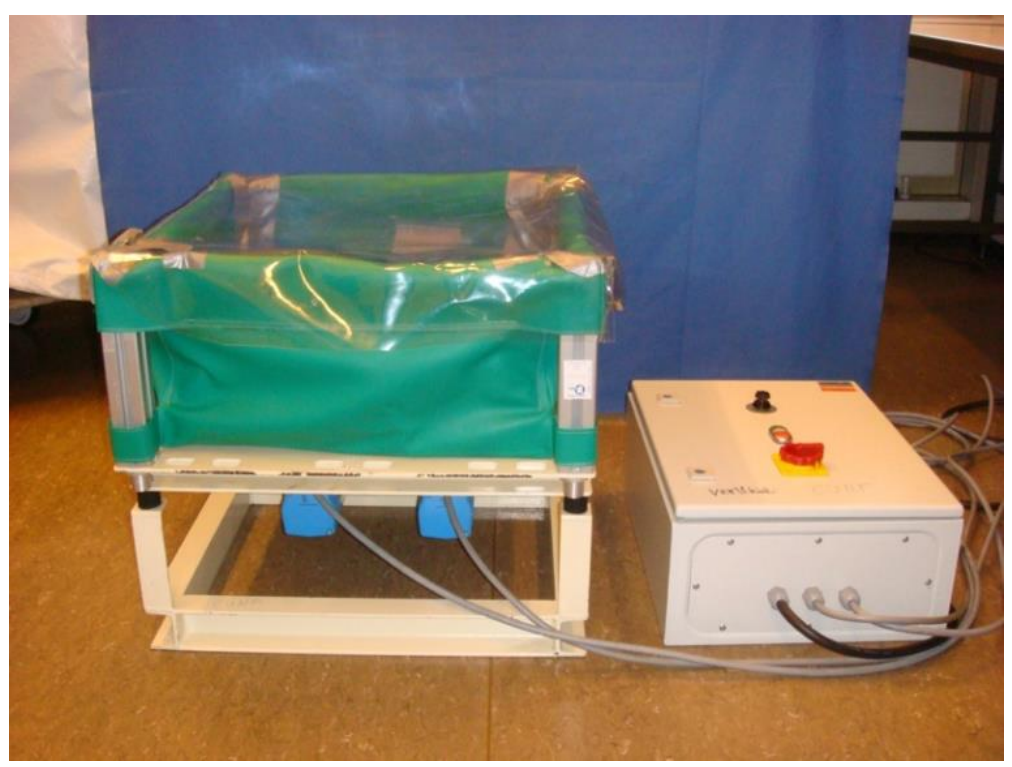

Abb. 4: Vibrationseinheit bestehend aus Käfig (links) und Motor (rechts), mit freundlicher Genehmigung des Labors der Abteilung Unfallchirurgie, Orthopädie und Plastische Chirurgie,, Universitätsmedizin Göttingen

\subsubsection{Farbstoff-Applikation}

Zur Überprüfung der Knochenneubildung in anderen Versuchen der Arbeitsgruppe wurde den Tieren jeweils eine Farbmarkierung s.c. gespritzt. Dies erfolgte nach dem in Tabelle 8 auf Seite 28 aufgeführten Schema. 
Tab. 8: Spritzplan der Farbmarkierungen (Merck, Darmstadt)

\begin{tabular}{|l|l|l|}
\hline Tag nach Osteotomie & Farbmarkierung & Dosierung \\
\hline 12 & Xylenol-Orange & $90 \mathrm{mg} / \mathrm{kg} \mathrm{KG}$ \\
\hline 22 & Calcein & $10 \mathrm{mg} / \mathrm{kg} \mathrm{KG}$ \\
\hline 32 & Alizarinkomplexon & $30 \mathrm{mg} / \mathrm{kg} \mathrm{KG}$ \\
\hline $42=1 \mathrm{~h}$ vor Tötung & Tetracyclin & $25 \mathrm{mg} / \mathrm{kg} \mathrm{KG}$ \\
\hline
\end{tabular}

\subsubsection{Probenentnahme}

Am 42. Tag nach der Osteotomie ( $=15$. Versuchswoche) wurden die Ratten unter tiefer $\mathrm{CO}_{2}$-Narkose dekapitiert. Das Blutserum wurde zur Bestimmung der Kreatinkinase aufbewahrt und später aufbereitet und ausgewertet.

Für den weiteren Versuch wurden nach Hautschnitt und Präparation der M. soleus und der M. gastrocnemius aus dem Hinterbein sowie ein Teil des M. longissimus aus dem Rücken gewonnen. Die Entnahme erfolgte randomisiert jeweils von der rechten bzw. linken Seite. Vom M. soleus und des M. gastrocnemius wurde das Gewicht ermittelt. Alle drei Muskeln wurden sofort nach Entnahme in Flüssigstickstoff schockgefroren und für die weitere Verwendung bei $-72{ }^{\circ} \mathrm{C}$ gelagert.

Für weitere Untersuchungen innerhalb der Arbeitsgruppe wurden den Tieren ebenfalls die Tibia, das Femur und Wirbelkörper entnommen.

\subsection{Histologische Aufarbeitung}

\subsubsection{Mikrotom}

Zur Weiterverarbeitung wurden die Muskelpräparate von $-72{ }^{\circ} \mathrm{C}$ auf $-22{ }^{\circ} \mathrm{C}$ im Mikrotom (Leica CM1900, Wetzlar) erwärmt, auf eine Dicke von $12 \mu \mathrm{m}$ geschnitten und auf Objektträger (SuperFrost Ultra plus®, Menzel-Gläser, Braunschweig) aufgebracht. Diese wurden im Anschluss bei Raumtemperatur mindestens für eine Stunde getrocknet und anschließend wieder bei $-72{ }^{\circ} \mathrm{C}$ eingefroren.

\subsubsection{Färbung der Schnitte}

Die Färbung der Schnitte erfolgte nach den im Folgenden dargestellten Protokollen. Die Hersteller der einzelnen Chemikalien sind zusammenfassend in Tabelle 13 (siehe Seite 79) im Anhang aufgeführt. 


\subsubsection{Amylase-PAS-Färbung}

Die Amylase-PAS-Färbung erfolgte nach dem in Tabelle 9 aufgeführten Färbeprotokoll. Die Herstellung der einzelnen Chemikalien erfolgte nach dem in Tabelle 10 aufgeführten Schema (nach Andersen 1975).

Tab. 9: Färbeprotokoll für Amylase-PAS-Färbung (nach Andersen 1975)

\begin{tabular}{|l|l|l|}
\hline & Chemikalien & Dauer \\
\hline 1. & Fixierlösung & $1 \mathrm{~h}, 4^{\circ} \mathrm{C}$, dann $10 \mathrm{~min} \mathrm{RT}$ \\
\hline 2. & Aqua dest. & $10 \times$ spülen \\
\hline 3. & Amylase & $25 \mathrm{~min}, 37^{\circ} \mathrm{C}$ \\
\hline 4. & Aqua dest. & $10 \times$ spülen \\
\hline 5. & Perjodsäure & 30 min \\
\hline 6. & Aqua dest. & $10 \times$ spülen \\
\hline 7. & Schiffs Reagenz & $1-25$ min, je nach Färbegrad \\
\hline 8. & Schwefeldioxid-Wasser & 30 min \\
\hline 9. & Leitungswasser & 10 min, fließend \\
\hline 10. & Aqua dest. & 3 min \\
\hline
\end{tabular}

Tab. 10: Chemikalien-Herstellung für Amylase-PAS-Färbung (nach Andersen 1975)

\begin{tabular}{|lll|}
\hline 1. & Fixierungslösung (frisch hergestellt) & \\
& Ethanol & $43 \mathrm{ml}$ \\
& Chloroform & $8 \mathrm{ml}$ \\
& Essigsäure & $2,7 \mathrm{ml}$ \\
\hline 2. & Amylaselösung (frisch hergestellt) & $185 \mathrm{mg}$ \\
& Amylase & $60 \mathrm{ml}$ \\
& Aqua dest. & \\
\hline 3. & Perjodsäurelösung (frisch hergestellt) & $600 \mathrm{mg}$ \\
& Perjodsäure & $60 \mathrm{ml}$ \\
& Aqua dest. & \\
\hline 4. & Schiffs Reagenz (fertig gemischt) & $600 \mathrm{ml}$ \\
\hline 5. & Schwefeldioxid-Wasser & $30 \mathrm{ml}$ \\
& Aqua dest. & $30 \mathrm{ml}$ \\
\hline & Kaliumdisulfid-Lösung & Salzsäure
\end{tabular}




\subsubsection{ATPase-/Diaphorase-Färbung}

Die Muskelfasern wurden mithilfe der ATPase-/Diaphorase-Färbung nach den in Tabelle 11 aufgeführten Schritten gefärbt (Anlehnung an die Horak-Methode (Horak 1983)):

Tab. 11: Färbeprotokoll für ATPase-/Diaphorase-Färbung (nach Horak 1983)

\begin{tabular}{|c|c|c|c|}
\hline & Chemikalien & Dauer & pH-Wert \\
\hline 1. & Fixierung nach Meier & $1 \mathrm{~min}$ & $6,3-6,6$ \\
\hline 2. & Aqua dest. & $2 \times 5$ min spülen & \\
\hline 3. & Diaphoraseinkubation (500 $\mu$ l/Deckglas) & $60 \min , 37^{\circ} \mathrm{C}$ & \\
\hline 4. & Aqua dest. & $15 \min$ & \\
\hline 5. & $\begin{array}{l}\text { Säurevorinkubation } \\
\text { (pH-Wert der Tris- und ATPase-Lösung einstellen) }\end{array}$ & $15 \min$ & 4,2 \\
\hline 6. & Tris-CaCl ${ }_{2}-\mathrm{Lsg}$ & $2 \min$ & 7,8 \\
\hline 7. & ATPase-Inkubationslösung & $30 \min , 37^{\circ} \mathrm{C}$ & 9,4 \\
\hline 8. & $\mathrm{CaCl}_{2}-$ Waschlösung & $3 \times 30 \mathrm{~s}$ & \\
\hline 9. & Kobaltchloridlösung & $2 \min$ & \\
\hline 10. & Aqua dest. & $3 \times 45$ s spülen & \\
\hline 11. & Ammoniumsulfidlösung (Abzug!) & $2 \min$ & \\
\hline 12. & Leitungswasser (fließend) & $10 \mathrm{~min}$ & \\
\hline 13. & Aqua dest. & $5 \mathrm{~min}$ & \\
\hline
\end{tabular}

Die Herstellung der einzelnen Chemikalien erfolgte nach dem in Tabelle 12 aufgeführten Schema.

Tab. 12: Chemikalien-Herstellung für ATPase-/Diaphorase-Färbung (nach Horak 1983)

\begin{tabular}{|c|c|c|}
\hline 1. & Fixierungslösung (nach Meier) & \\
\hline & Paraformaldehyd & $600 \mathrm{mg}$ \\
\hline & $\mathrm{CaCl}_{2}$-2-hydrat & $588 \mathrm{mg}$ \\
\hline & Saccharose & $3600 \mathrm{mg}$ \\
\hline & Aqua dest. & $60 \mathrm{ml}$ \\
\hline 2. & Diaphorase-Inkubationslösung & \\
\hline & $\mathrm{NADH}$-Dinatriumsalz & $13 \mathrm{mg}$ \\
\hline & Phosphatpuffer $(0,1 \mathrm{M}, \mathrm{pH} 7,4)$ (Herstellung siehe Tabelle 14 im Anhang S. 80) & $2,08 \mathrm{ml}$ \\
\hline & Nitro-BT (40 mg Nitro-Blaues Tetrazoliumchlorid + 40 ml Aqua dest.) & $2,6 \mathrm{ml}$ \\
\hline & Aqua dest. & $3,12 \mathrm{ml}$ \\
\hline
\end{tabular}




\begin{tabular}{|c|c|c|}
\hline \multirow[t]{4}{*}{3.} & \multicolumn{2}{|l|}{ Säure Vorinkubation } \\
\hline & $\mathrm{CaCl}_{2}$-Stammlösung (6,62 g CaCl2-dihydrat (M $\left.147.02 \mathrm{~g} / \mathrm{mol}\right)+250 \mathrm{ml}$ Aqua dest.) & $6,67 \mathrm{ml}$ \\
\hline & Eisessig & $0,27 \mathrm{ml}$ \\
\hline & Aqua dest. & $60 \mathrm{ml}$ \\
\hline \multirow[t]{4}{*}{4.} & Tris-CaCl2-Lösung & \\
\hline & Tris & $740 \mathrm{mg}$ \\
\hline & $\mathrm{CaCl}_{2}$-Stammlösung (6,62 g CaCl 2 -dihydrat (M $\left.147.02 \mathrm{~g} / \mathrm{mol}\right)+250 \mathrm{ml}$ Aqua dest. $)$ & $6,1 \mathrm{ml}$ \\
\hline & Aqua dest. & $55 \mathrm{ml}$ \\
\hline \multirow[t]{6}{*}{5.} & ATPase Inkubationslösung & \\
\hline & Kaliumchlorid & $226 \mathrm{mg}$ \\
\hline & ATP $(\mathrm{M}=551,2 \mathrm{~g} / \mathrm{mol})$ & $93 \mathrm{mg}$ \\
\hline & Glycinpuffer (125 ml Glycinstammlösung (Herstellung: Tabelle 15 im Anhang, S. 80) & $55 \mathrm{ml}$ \\
\hline & + $42 \mathrm{ml} \mathrm{NaOH}(0.4 \mathrm{M})+333 \mathrm{ml}$ Aqua dest. $)$ & \\
\hline & $\mathrm{CaCl}_{2}$-Stammlösung (6,62 $\mathrm{g} \mathrm{CaCl}_{2}$-dihydrat (M $\left.147.02 \mathrm{~g} / \mathrm{mol}\right)+250 \mathrm{ml}$ Aqua dest.) & $6,1 \mathrm{ml}$ \\
\hline \multirow[t]{3}{*}{6.} & Kobaltchlorid-Lösung & \\
\hline & Kobaltchlorid & $1200 \mathrm{mg}$ \\
\hline & Aqua dest. & $60 \mathrm{ml}$ \\
\hline \multirow[t]{3}{*}{7.} & Ammoniumsulfid-Lösung & \\
\hline & Ammoniumsulfid & $0,08 \mathrm{ml}$ \\
\hline & Aqua dest. & $60 \mathrm{ml}$ \\
\hline
\end{tabular}

\subsubsection{Eindeckung}

Nach dem Färben wurden die Präparate eingedeckt und vor der Datenerhebung für 48 h bei Zimmertemperatur getrocknet.

\subsection{Datenerhebung}

Zur Datenerhebung wurden zuerst die Muskelpräparate im Blindversuch unter dem Mikroskop (Eclipse E 6000, Nikon AG, Zürich (Schweiz)) bei 10-facher Vergrößerung betrachtet. Im Anschluss wurden bei der Amylase-PAS-Färbung jeweils zwei Bereiche und bei der ATPase-/Diaphorase-Färbung jeweils drei Bereiche herausgesucht und mittels Digitalkamera (DVC 1301, DVC Company (Woburn, MA, USA)) fotografiert. 


\subsubsection{Datenerhebung der Amylase-PAS-Färbung}

Unter Zuhilfenahme der Amylase-Färbung konnte das Verhältnis der Kapillaren zu den Muskelzellen ermittelt werden. Mit der Bildanalyse-Software NIS-Elements AR (Version 4.00.08, Nikon) wurde zunächst pro Aufnahme ein Abschnitt mit der Kantenlänge von $500 \mu \mathrm{m} \times 500 \mu \mathrm{m}$ festgelegt und anschließend ausgezählt. Da diese Auszählung an zwei Aufnahmen erfolgte, ergibt sich die Auszählung für einen Bereich von $0,5 \mathrm{~mm}^{2}$.

Abbildung 5 zeigt an einem Beispiel die Auszählung der Zellen (A) und der mit Pfeilen markierten Kapillaren.

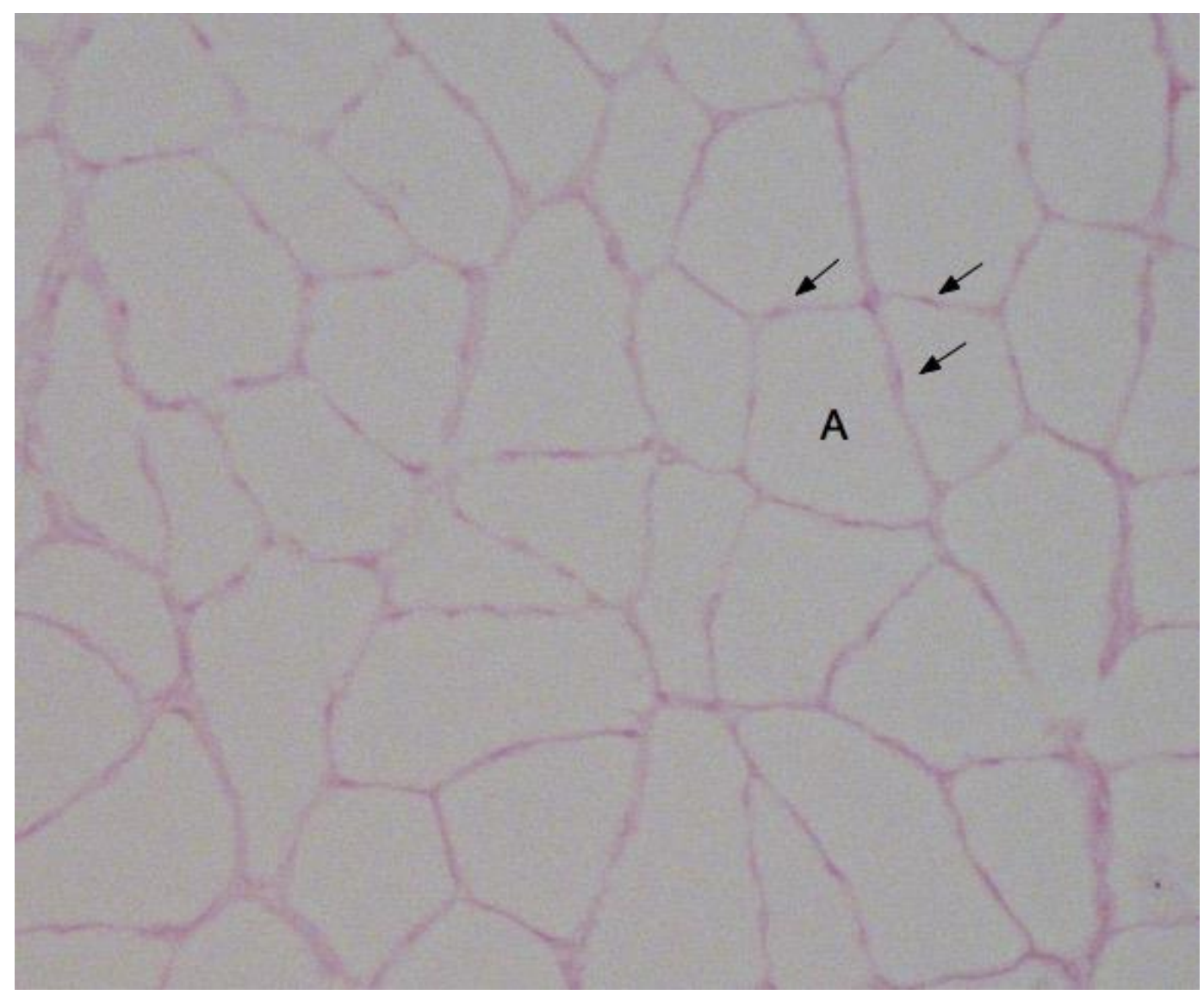

Abb. 5: Auszählung der Zellen und Kapillaren in der Amylase-PAS-Färbung (Pfeile = Kapillaren, $A=$ Muskelzelle)

Die somit ermittelte Anzahl an Zellen und Kapillaren wurde nun ins Verhältnis gesetzt:

$$
\text { Kapillaren pro Zelle }=\frac{\text { Anzahl der Kapillaren }}{\text { Anzahl der Zellen }}
$$

Im Anschluss wurden die Tiere der einzelnen Versuchsgruppen miteinander verglichen. 


\subsubsection{Datenerhebung der ATPase-/Diaphorase-Färbung}

Die Flächenermittlung der Zellen in der ATPase-/Diaphorase-Färbung erfolgte ebenfalls mithilfe der Bildanalyse-Software NIS-Elements AR (Version 4.00.08, Nikon).

Beim M. longissimus sowie beim M. gastrocnemius waren jeweils drei verschiedene Zelltypen zu finden, die als Beispiel auf Abbildung 6 markiert sind. Bei beiden Muskeln wurde pro Aufnahme der Durchmesser und die Querschnittsfläche von 30 glykolytischen Zellen (FG-Faserzellen) sowie von 30 intermediären (FOG-Faserzellen) + oxidativen Zellen (SO-Faserzellen) ermittelt. Bei drei Aufnahmen ergibt sich somit eine Auszählung von 180 Zellen pro Tier.

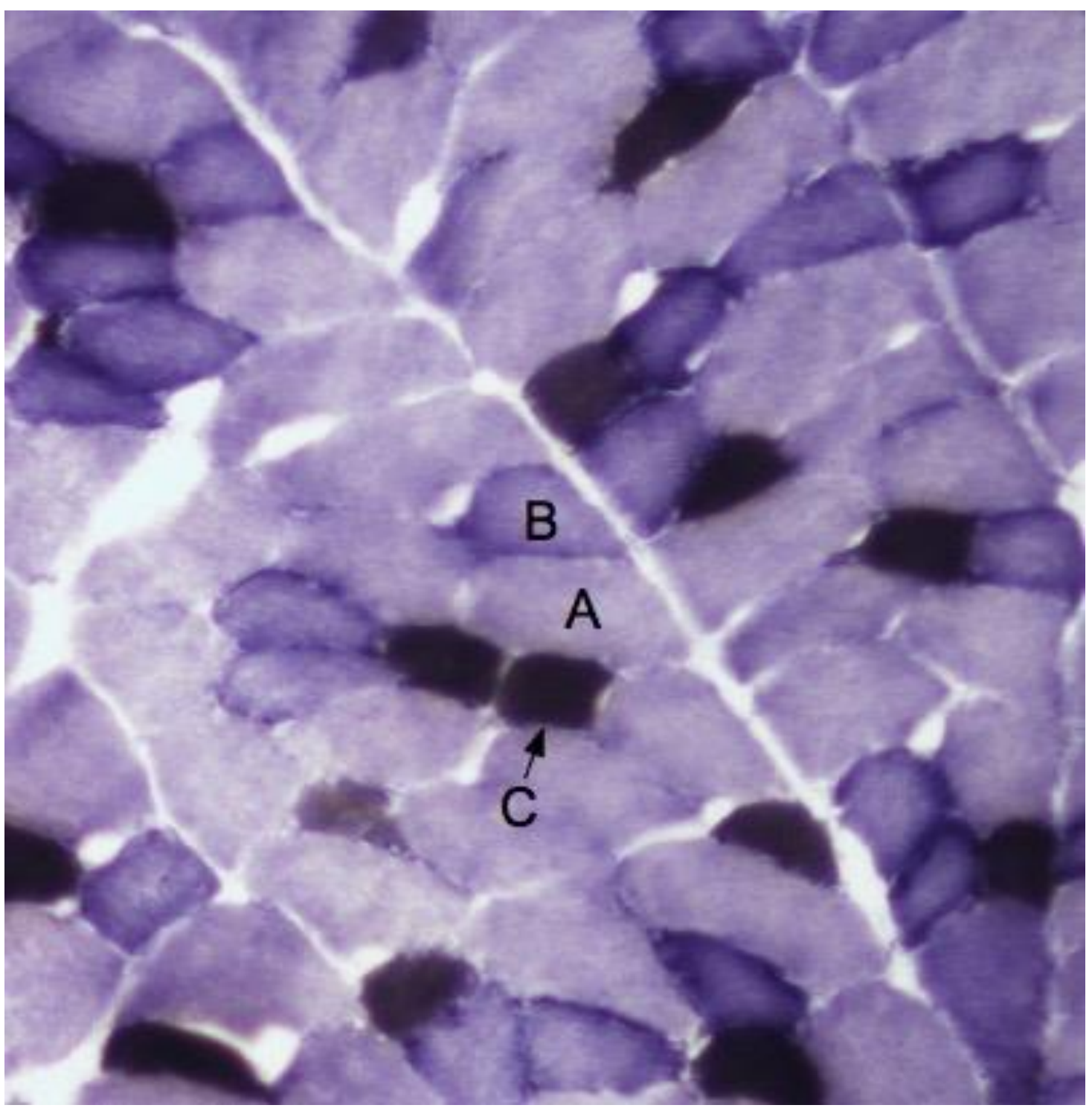

Abb. 6: ATPase-/Diaphorase-Färbung, M. longissimus mit drei Zelltypen ( $A=$ FG-Faserzelle, $B=$ FOG-Faserzelle, $C=$ SO-Faserzelle) 
Da beim M. soleus nur oxidative Zellen (SO-Fasertyp) vorhanden sind, wie man in Abbildung 7 erkennen kann, wurden hier pro Aufnahme 30 Zellen ausgewertet. Es ergibt sich somit eine Anzahl von 90 Zellen pro Tier.

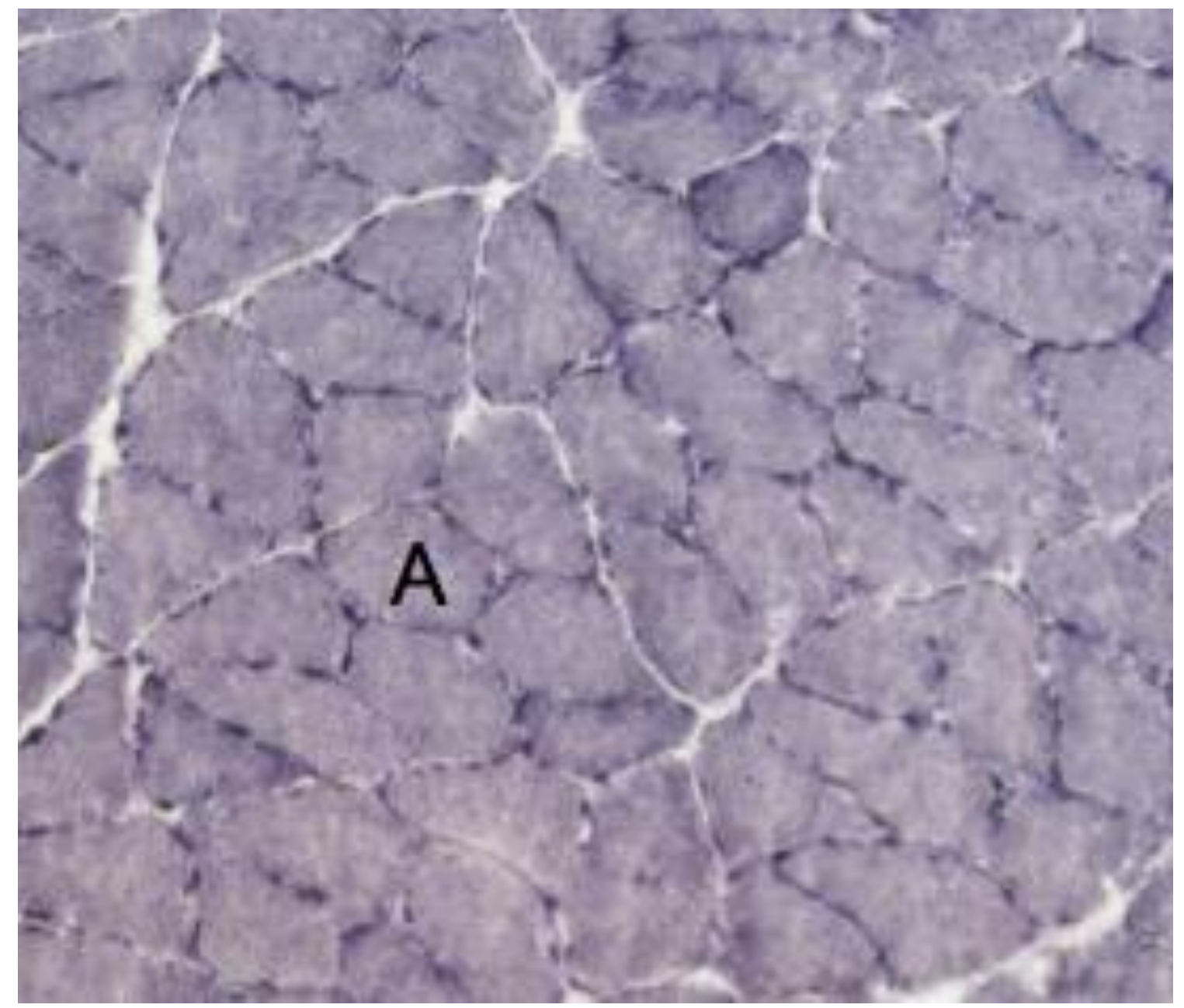

Abb. 7: ATPase-/Diaphorase-Färbung, M. soleus mit einem Zelltyp ( $A=$ SO-Fasertyp)

Zur Ermittlung des Durchmessers und der Querschnittsfläche wurden jeweils die Umrisse der jeweiligen Zelle umfahren. Das Ergebnis wurde durch die Software automatisch errechnet.

Zur weiteren Auswertung wurde der Mittelwert der Zellen ermittelt, sprich beim M. soleus der Mittelwert der oxidativen Zellen und beim M. gastrocnemius und M. longissimus einmal der Mittelwert der glykolytischen Zellen und einmal der Mittelwert der oxidativen + intermediären Zellen. 


\subsection{Auswertung}

Nach erfolgter Datenerhebung wurden die ermittelten Werte mit dem StatistikProgramm GraphPad PRISM (Version 5.0a, Dezember 2007, GraphPad Software Inc.) ausgewertet.

Zuerst wurde für jede Versuchsgruppe der Mittelwert sowie die Standardabweichung errechnet. Im Anschluss wurde im one-way-ANOVA-Test analysiert, ob es signifikante Unterschiede in den Gruppen gab.

Um weitere Signifikanzen zu differenzieren, wurde der Tukey-Kramer-post-hocTest durchgeführt. Als Signifikanzniveau wurde ein $p-W e r t$ mit $p<0,05$ festgelegt. 


\section{ERgebNISSE}

Die durchschnittlichen Tiergewichte und Futteraufnahmen in den Versuchsgruppen aus der Arbeitsgruppe wurden bereits publiziert (Stuermer et al. 2014).

\subsection{Allgemein}

\subsubsection{Gewichtsverlauf}

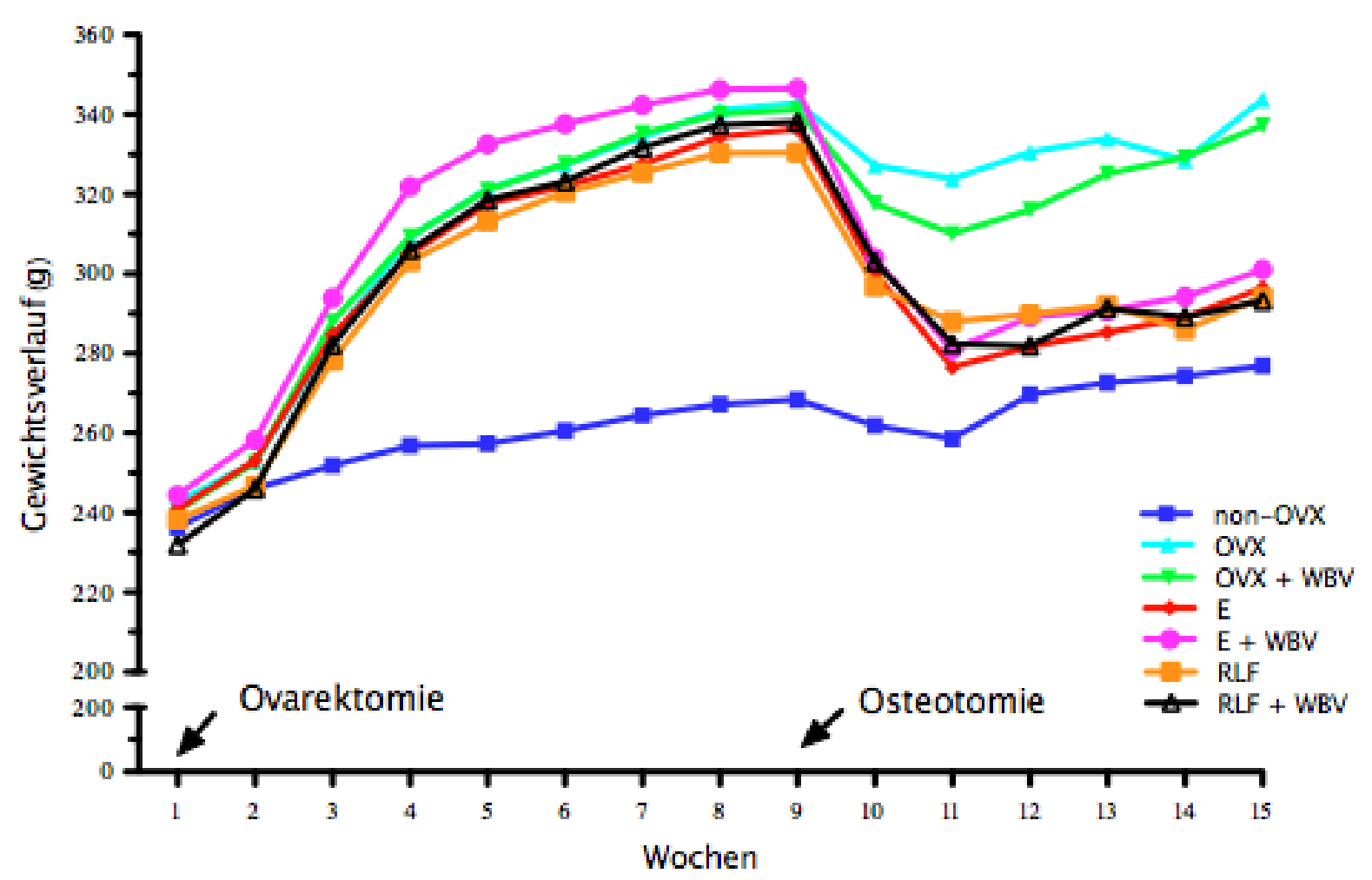

Abb. 8: Gewichtsverlauf während des Versuchsablauf

Abbildung 8 stellt den Gewichtsverlauf dar. Ab Woche 2 zeigen alle ovarektomierten Tiere (OVX, OVX+WBV, E, E+WBV, RLF, RLF+WBV) einen signifikanten Anstieg beim Körpergewicht gegenüber den non-OVX-Tieren. Nach der Osteotomie in Woche 9 kommt es bei allen Tieren zu einem Abfall des Gewichtes, wobei dieser am stärksten bei den Medikamenten-Therapiegruppen (E, E+WBV, RLF, RLF+WBV) ausfällt. Ab Woche 11 nehmen alle Tiere wieder an Gewicht zu. Allerdings erreichen die Medikamenten-Therapiegruppen im Gegensatz zur non-OVX, OVX und OVX+WBV-Gruppe das Ausgangsgewicht zum Zeitpunkt der Osteotomie nicht mehr. Weiterhin wird deutlich, dass die non-OVX-Gruppe auf ihrem niedrigen Gewichts-Niveau verbleibt und die OVX und OVX+WBV-Gruppe mit ihrem Gewicht weit oberhalb der Medikamententherapie-Gruppe liegt. 


\subsubsection{Futteraufnahme}

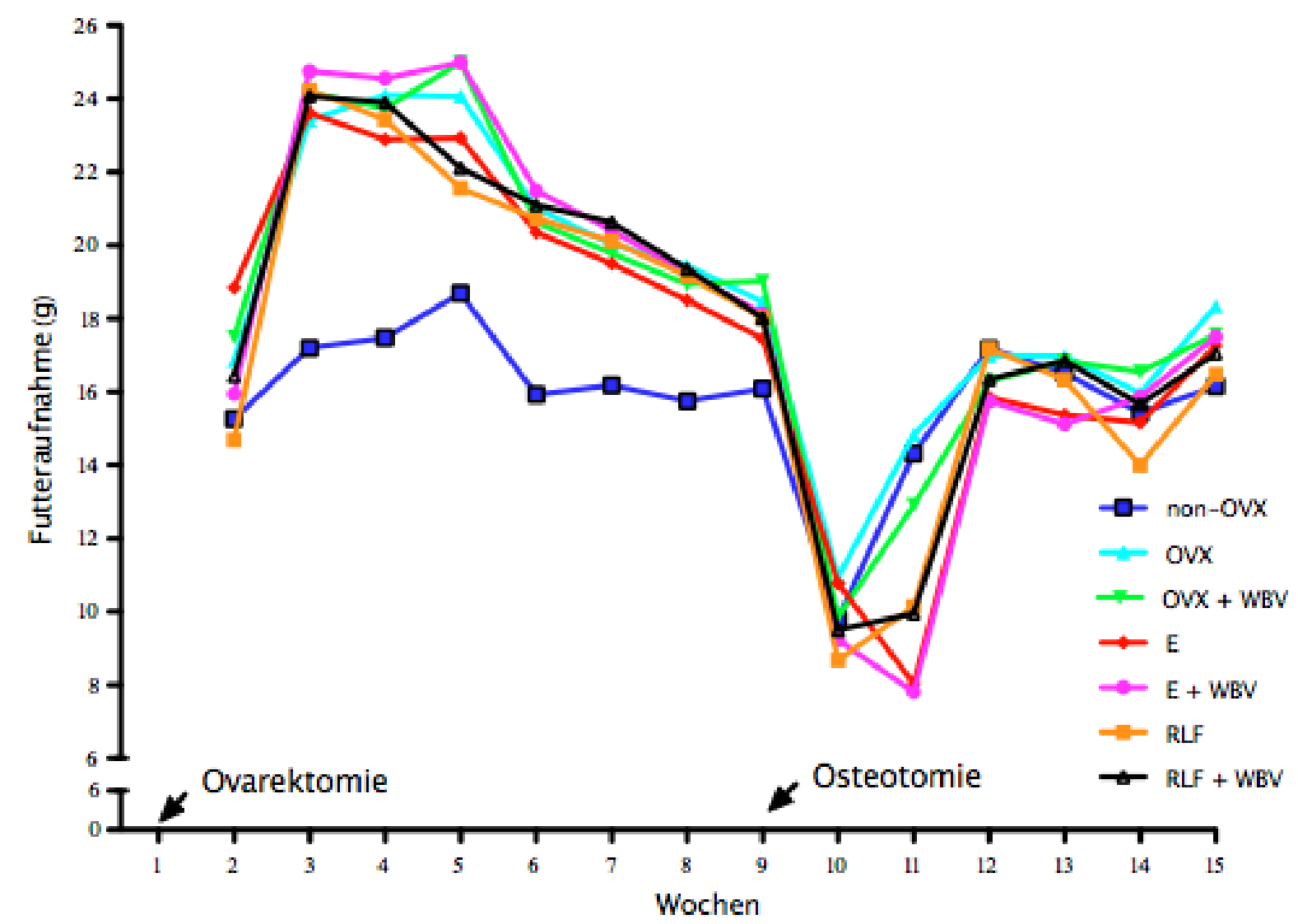

Abb. 9: Verlauf der Futteraufnahme während des Versuchsablauf

Abbildung 9 stellt den Verlauf der Futteraufnahme der Versuchstiere dar. Beim Vergleich der täglichen Futteraufnahme liegen die Werte der non-OVX-Gruppe im Vergleich zu den ovarektomierten Tieren signifikant erniedrigt. In der Woche nach der Osteotomie sinkt die Futteraufnahme bei allen Versuchsgruppen rapide ab. Eine Woche später nimmt sie zu und erreicht drei Wochen nach Osteotomie wieder das Ausgangsniveau vor der Osteotomie (Woche 9). In der Woche 11 sind die Gruppen non-OVX, OVX und OVX+WBV gegenüber den Medikamententherapiegruppen signifikant erhöht.

Die vorab gezeigte signifikante Verminderung in der non-OVX-Gruppe ist nach der Osteotomie gegenüber allen anderen Gruppen nicht mehr vorhanden. 


\subsubsection{Muskelgewichte}

Die einzelnen Muskelgewichte des $M$. soleus, M. gastrocnemius und M. longissimus werden zuerst als absolute Werte verglichen und im Anschluss nochmals im Verhältnis zum Tiergewicht. Dabei wird jeweils die non-OVX-Gruppe mit allen anderen Gruppen sowie die OVX-Gruppe mit allen Therapie-Gruppen (OVX+WBV, E, E+WBV, RLF, RLF+WBV) verglichen. Ebenso werden die Vibrationstherapiegruppen (OVX-WBV- mit der E+WBV- und der RLF+WBV-Gruppe) sowie die E- mit der E+WBV-Gruppe, die RLF- mit der RLF+WBV-Gruppe und die E- mit der RLF-Gruppe verglichen.

\subsubsection{Muskelgewicht, M. soleus}

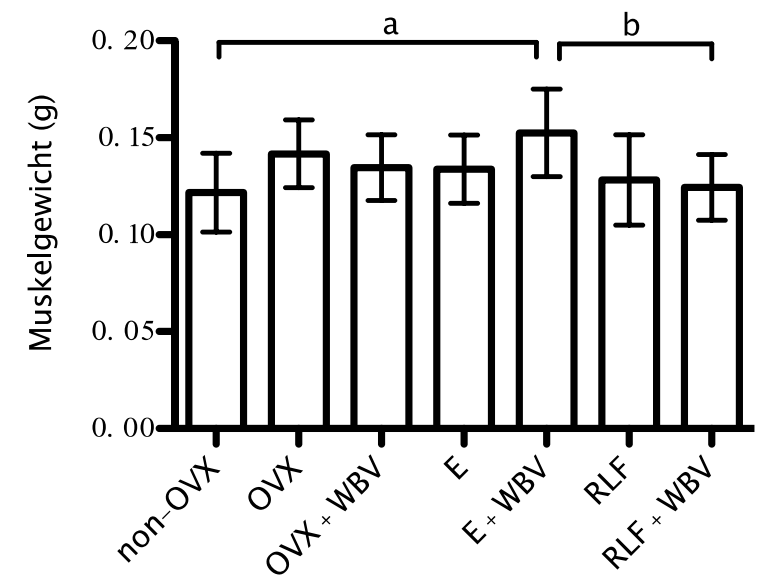

Abb. 10: Muskelgewicht, M. soleus

a: non-OVX signifikant gegenüber $E+W B V$

b: $E+W B V$ signifikant gegenüber $R L F+W B V$

Abbildung 10 zeigt das Muskelgewicht des M. soleus auf. Das Gewicht des Muskels in der E+WBV-Gruppe ist signifikant erhöht im Vergleich zur non-OVX Gruppe sowie im Vergleich zur RLF+WBV-Gruppe.

Die non-OVX-Gruppe weist im Vergleich zu allen anderen Gruppen das geringste Muskelgewicht auf. Mit Ausnahme der E+WBV-Gruppe liegen alle Gewichte unterhalb der OVX-Gruppe.

Das Gewicht aus der E+WBV-Gruppe ist höher als das der OVX+WBV-Gruppe und auch höher als das der RLF+WBV-Gruppe. Das Gewicht des Muskels in der E-Gruppe ist niedriger als in der E+WBV-Gruppe. Die Gewichte innerhalb der RLF- und RLF+WBV-Gruppe sind annähernd gleich. Die E-Gruppe ist leicht erhöht im Vergleich zur RLF-Gruppe. 


\subsubsection{Muskelgewicht/Tiergewicht, M. soleus}

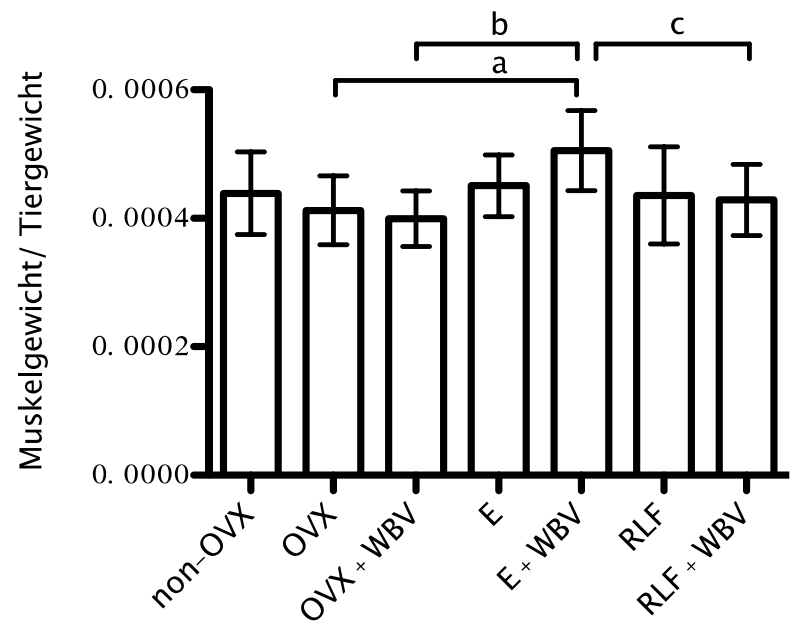

Abb. 11: Muskelgewicht im Verhältnis zum Tiergewicht, M. soleus

a: OVX signifikant gegenüber $E+W B V$

b: $O V X+W B V$ signifikant gegenüber $E+W B V$

c: $E+W B V$ signifikant gegenüber $R L F+W B V$

Setzt man das Muskelgewicht ins Verhältnis zum Tiergewicht, ergeben sich die in Abbildung 11 dargestellten Werte. Die OVX-Gruppe ist signifikant erniedrigt gegenüber der E+WBV-Gruppe. Die E+WBV-Gruppe ist ebenfalls signifikant erhöht im Vergleich zur OVX+WBV-Gruppe sowie zur RLF+WBV-Gruppe.

Die E+WBV-Gruppe hat innerhalb des Vergleichs den höchsten Wert. Vergleicht man die non-OVX-Gruppe mit den anderen Gruppen, so sind die E- und E+WBV-Gruppe erhöht, die OVX-, OVX+WBV-, RLF- und RLF+WBV sind erniedrigt.

Im Vergleich der OVX-Gruppe mit den Therapie-Gruppen weisen die OVX+WBV-Gruppe erniedrigte, die RLF- und RLF+WBV-Gruppe annähernd gleiche Werte und die E- und E+WBV-Gruppe erhöhte Werte auf.

Die E-Gruppe ist erniedrigt im Vergleich zur E+WBV-Gruppe. Die RLF-Gruppe ist nur minimal erhöht im Vergleich zur RLF+WBV-Gruppe. Die E-Gruppe ist erhöht im Vergleich zur RLF-Gruppe. 


\subsubsection{Muskelgewicht, M. gastrocnemius}

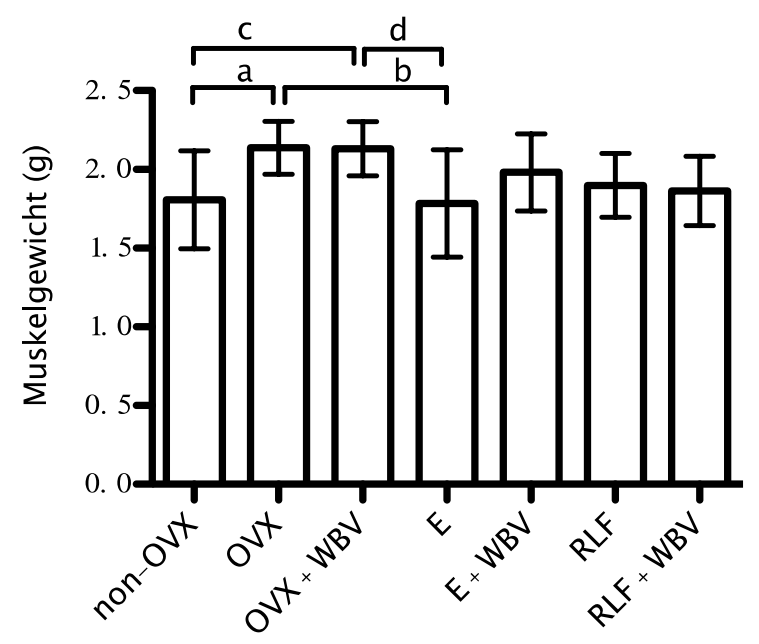

Abb. 12: Muskelgewicht, M. gastrocnemius

a: non-OVX signifikant gegenüber OVX

b: OVX- signifikant gegenüber $E$

c: non-OVX signifikant gegenüber OVX+WBV

$d: O V X+W B V$ signifikant gegenüber $E$

Der Vergleich der Muskelgewichte des M. gastrocnemius wird in Abbildung 12 dargestellt. Die non-OVX-Gruppe zeigt ein signifikant erniedrigtes Gewicht des Muskels im Vergleich zur OVX-Gruppe sowie zur OVX+WBV-Gruppe. Das Gewicht in der OVX-Gruppe ist signifikant erhöht im Vergleich zur E-Gruppe (und auch das Muskelgewicht der OVX+WBV-Gruppe ist signifikant erhöht im Vergleich zur E-Gruppe.).

Mit Ausnahme der E-Gruppe weisen alle anderen Gruppen ein höheres Gewicht im Vergleich zur non-OVX-Gruppe auf. Die OVX-Gruppe besitzt das höchste Gewicht, welches leicht über der OVX+WBV-Gruppe liegt. Das Gewicht der E-, E+WBV, RLF- und RLF+WBV-Gruppe liegen darunter.

Das Gewicht des M. gastrocnemius in der E-Gruppe ist erniedrigt im Vergleich zur E+WBV-Gruppe. Das Gewicht der RLF-Gruppe ist nur minimal erhöht im Vergleich zur RLF+WBV-Gruppe. Die Werte der E-Gruppe sind erniedrigt im Vergleich zur RLF-Gruppe. 


\subsubsection{Muskelgewicht/Tiergewicht, M. gastrocnemius}

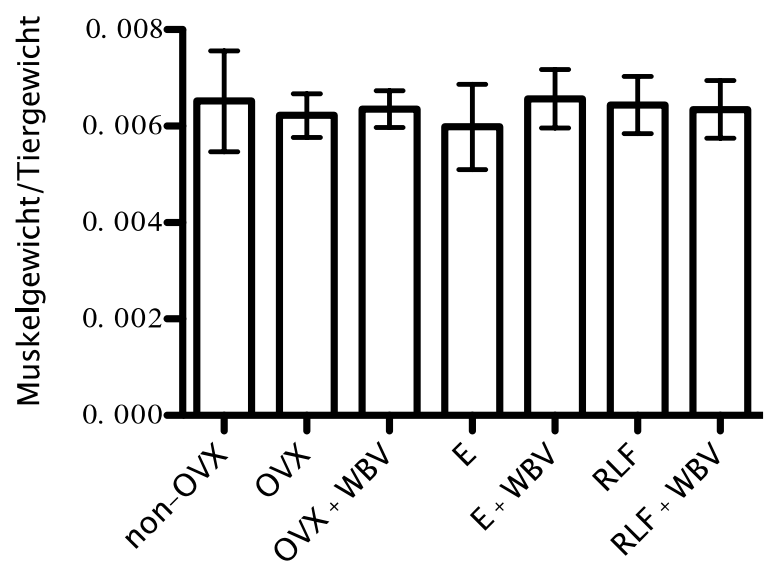

Abb. 13: Muskelgewicht im Verhältnis zum Tiergewicht, M. gastrocnemius

Setzt man das Muskelgewicht ins Verhältnis zum Tiergewicht, wie in Abbildung 13 dargestellt, lassen sich keine signifikanten Unterschiede nachweisen. Innerhalb der Gruppen finden sich nur minimale Unterschiede.

Die E+WBV-Gruppe besitzt dabei den höchsten Wert. Bis auf diese Gruppe und die RLF-Gruppe weisen alle anderen Gruppen niedrigere Werte als die non-OVX-Gruppe auf. Mit Ausnahme der E-Gruppe liegen alle GewichtsVerhältnisse in den Therapiegruppen (OVX+WBV, E+WBV, RLF, RLF+WBV) über dem Verhältnis der OVX-Gruppe.

Die Werte der E+WBV-Gruppe sind erhöht im Vergleich zur E-Gruppe. Die Werte der RLF-Gruppe sind nur minimal erhöht im Vergleich zur RLF+WBV-Gruppe. Die E-Gruppe weist niedrigere Werte im Vergleich zur RLF-Gruppe auf. 


\subsubsection{Serum-Kreatininkinase}

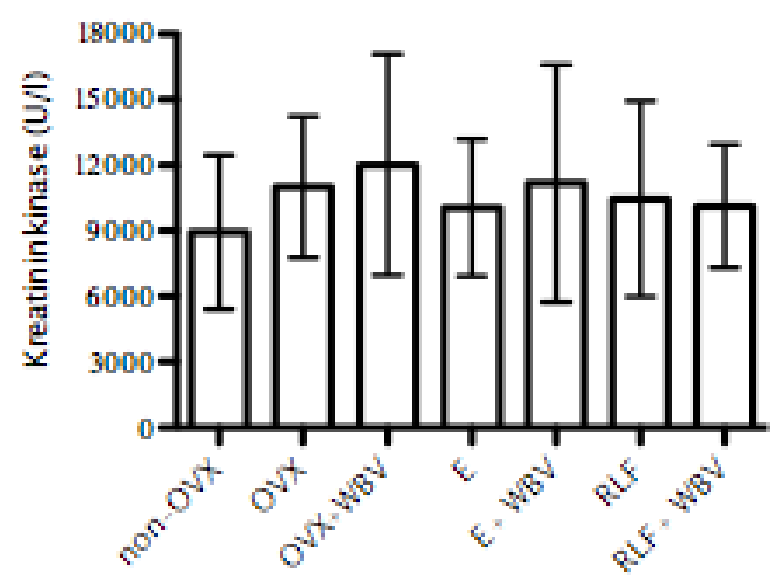

Abb. 14: Kreatininkinase im Serum

Beim Vergleich der Serum-Kreatininkinase (siehe Abb. 14) zeigen sich keine signifikanten Unterschiede. Die Blutwerte der non-OVX-Gruppe sind am geringsten. Die Werte der OVX-Gruppe sind höher als in der E-, RLF- und RLF+WBV-Gruppe und liegen niedriger als in der OVX+WBV- und E+WBVGruppe. Die E+WBV-Gruppe weist niedrigere Werte als die OXV+WBV-Gruppe und höhere Werte als die RLF+WBV-Gruppe auf.

Die E-Gruppe weist niedrigere Werte im Vergleich zur E+WBV-Gruppe auf. Die Werte der RLF-Gruppe sind leicht erhöht gegenüber der RLF+WBV-Gruppe. Die Kreatininkinase der E-Gruppe ist niedriger als in der RLF-Gruppe.

\subsection{Amylase-PAS-Färbung}

Die in der Amylase-PAS-Färbung ermittelten Verhältnisse zwischen der Anzahl der Kapillaren und der Anzahl der Muskelfasern werden innerhalb der einzelnen Muskelgruppen (M. soleus, M. longissimus und M gastrocnemius) verglichen. Dabei werden jeweils die non-OVX-Gruppe mit allen anderen Gruppen, die OVX-Gruppe mit allen Therapie-Gruppen (OVX+WBV, E, E+WBV, RLF, $R L F+W B V)$ verglichen. Außerdem werden die Vibrationstherapiegruppen (die OVX-WBV- mit der E+WBV- und der RLF+WBV-Gruppe) sowie die E- mit der E+WBV-Gruppe, die RLF- mit der RLF+WBV-Gruppe und die E- mit der RLF-Gruppe verglichen. 


\subsubsection{M. soleus}

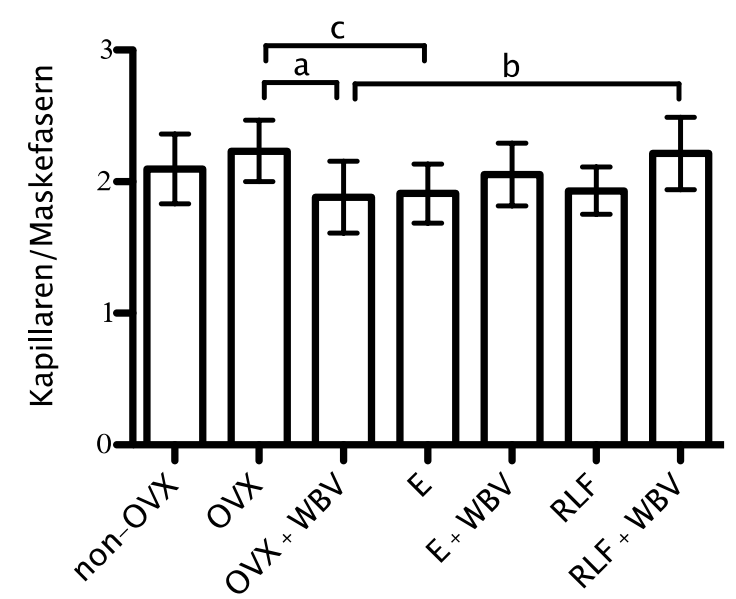

Abb. 15: Anzahl Kapillaren im Verhältnis zu Muskelfasern, M. soleus a: OVX signifikant gegenüber OVX+WBV

b: OVX+WBV signifikant gegenüber $R L F+W B V$

c: OVX signifikant gegenüber $E$

Beim Vergleich der Anzahl der Kapillaren im Verhältnis zur Anzahl der Muskelzellen des M. soleus (siehe Abb. 15) zeigt sich eine signifikante Erhöhung der OVX-Gruppe im Vergleich zur OVX+WBV-Gruppe sowie zur E-Gruppe. Ebenfalls lässt sich eine signifikante Erniedrigung der OVX+WBV-Gruppe gegenüber der RLF+WBV-Gruppe nachweisen.

Im Vergleich zur non-OVX-Gruppe weisen die OVX- und RLF+WBV-Gruppe erhöhte Werte auf, die anderen Gruppen (OVX+WBV, E, E+WBV und RLF) zeigen erniedrigte Werte. Die OVX-Gruppe weist den höchsten Wert im Vergleich zu allen Therapie-Gruppen (OVX+WBV, E, E+WBV, RLF und RLF+WBV) auf.

Die E+WBV-Gruppe weist ein höheres Verhältnis im Vergleich zur OVX+WBVund ein niedrigeres im Vergleich zur RLF+WBV-Gruppe auf. Das Verhältnis der E+WBV-Gruppe ist erhöht gegenüber der E-Gruppe. Die RLF+WBV-Gruppe weist höhere Werte im Vergleich zur RLF-Gruppe auf. Innerhalb der E-Gruppe sind die Verhältnisse leicht erniedrigt im Vergleich zur RLF-Gruppe. 


\subsubsection{M. longissimus}

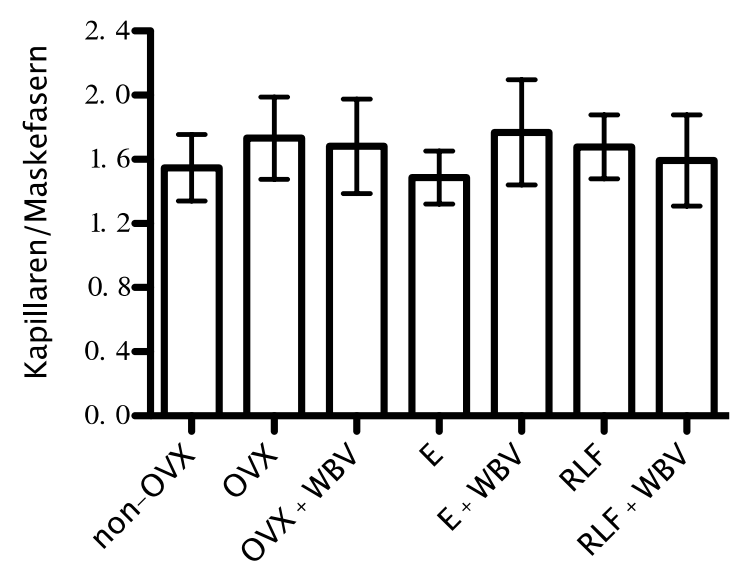

Abb. 16: Anzahl Kapillaren im Verhältnis zu Muskelfasern, M. longissimus

Beim Vergleich der Verhältnisse innerhalb des M. longissimus (siehe Abb. 16) zeigen sich in der non-OVX- und E-Gruppe die niedrigsten Werte sowie in der E+WBV-Gruppe der höchste Wert. Die Unterschiede sind nicht signifikant.

Mit Ausnahme der E-Gruppe weisen alle Gruppen höhere Werte im Vergleich zur non-OVX-Gruppe auf. Außer der E+WBV-Gruppe liegen alle Werte unterhalb der Werte in der OVX-Gruppe.

Die Werte der OVX+WBV-Gruppe sind erniedrigt im Vergleich zur E+WBV und erhöht im Vergleich zur RLF+WBV-Gruppe. Das Verhältnis der E-Gruppe ist erniedrigt im Vergleich zur E+WBV-Gruppe. Das Verhältnis der RLF-Gruppe ist erhöht im Vergleich zur RLF+WBV-Gruppe. Die E-Gruppe weist niedrigere Werte im Vergleich zur RLF-Gruppe auf. 


\subsubsection{M. gastrocnemius}

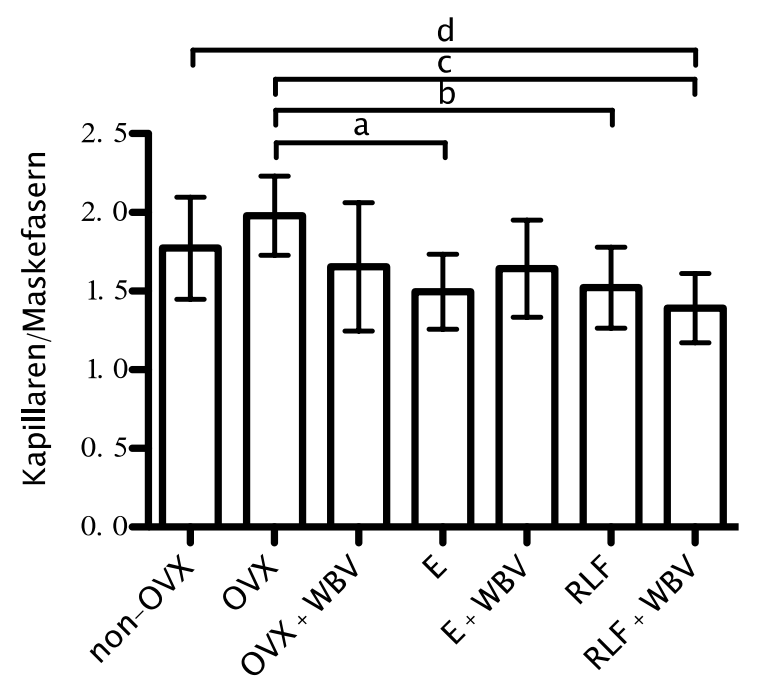

Abb. 17: Anzahl Kapillaren im Verhältnis zu Muskelfasern, M. gastrocnemius

a: OVX signifikant gegenüber $E$

b: OVX signifikant gegenüber $R L F$

c: OVX signifikant gegenüber $R L F+W B V$

d: non-OVX signifikant gegenüber $R L F+W B V$

In der Gruppe des M. gastrocnemius (siehe Abb. 17) zeigen sich die Werte der OVX-Gruppe beim Vergleich der Kapillaren im Verhältnis zu den Muskelfasern signifikant erhöht im Vergleich zur E-, RLF- und RLF+WBV-Gruppe. Ebenfalls sind die Werte der non-OVX-Gruppe signifikant erhöht gegenüber der RLF+WBV-Gruppe.

Mit Ausnahme der OVX-Gruppe sind die Verhältnisse aller Gruppen erniedrigt im Vergleich zur non-OVX-Gruppe. Die Werte der OVX-Gruppe sind im Vergleich zu allen anderen Gruppen erhöht.

Die E+WBV-Gruppe weist höhere Werte als die RLF+WBV-Gruppe auf und nur leicht erniedrigte Werte im Vergleich zur OVX+WBV-Gruppe. Die Werte der E+WBV-Gruppe sind gegenüber der E-Gruppe erhöht. In der RLF-Gruppe sind die Werte im Vergleich zur RLF+WBV-Gruppe erhöht. Die E-Gruppe weist leicht erniedrigte Werte im Vergleich zur RLF-Gruppe auf. 


\subsection{ATPase-/Diaphorase-Färbung}

Die Muskelfaserzellen der drei entnommenen Muskeln (M. soleus, M. longissimus, M. gastrocnemius) werden zuerst innerhalb der TherapieGruppen im Durchmesser und der Fläche in absoluten Werten verglichen sowie später ins Verhältnis zum Tiergewicht gesetzt und verglichen. Da die ATPase-/Diaphorase-Färbung beim $\mathrm{M}$. longissimus und $\mathrm{M}$. gastrocnemius eine Unterscheidung der Muskelzellen zulässt, werden die FG-Fasertypen und die FOG-+SO-Fasertypen separat dargestellt und verglichen. Beim M. soleus wird nur der eine vorhandene SO-Fasertyp ausgewertet.

Es werden jeweils die non-OVX-Gruppe mit allen anderen Gruppen, die OVX-Gruppe mit allen Therapie-Gruppen (OVX+WBV, E, E+WBV, RLF, $R L F+W B V)$, die Vibrationstherapiegruppen (OVX+WBV- gegen E+WBV- und RLF+WBV-Gruppe) sowie die E- gegen die E+WBV-Gruppe, die RLF-gegen die RLF+WBV-Gruppe und die E-gegen die RLF-Gruppe verglichen. 


\subsubsection{M. soleus}

\subsubsection{Durchmesser}

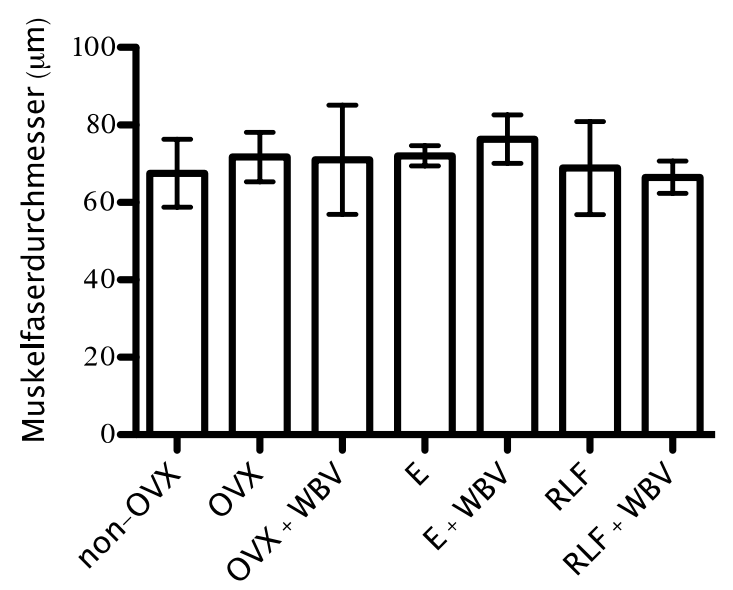

Abb. 18: Muskelfaserdurchmesser, M. soleus

Beim Vergleich des Faserdurchmessers des M. soleus (siehe Abb. 18) lassen sich keine signifikanten Unterschiede innerhalb der Gruppen nachweisen. Der höchste Durchmesser findet sich in der E+WBV-Gruppe, der niedrigste Durchmesser in der RLF+WBV-Gruppe.

Im Vergleich zur non-OVX-Gruppe weisen die RLF- und RLF+WBV-Gruppe höhere Durchmesser und die OVX-, OVX+WBV-, E- und E+WBV-Gruppe niedrigere Durchmesser auf. Mit Ausnahme der E+WBV und der E-Gruppe sind die Werte der anderen Gruppen (OVX+WBV, RLF und RLF+WBV) erniedrigt im Vergleich zur OVX-Gruppe.

Die Durchmesser der OVX+WBV-Gruppe sind erniedrigt im Vergleich zur E+WBV- und erhöht im Vergleich zur RLF+WBV-Gruppe. Der Faserdurchmesser der E+WBV-Gruppe ist erhöht gegenüber der E-Gruppe. Der Durchmesser der RLF-Gruppe ist leicht erhöht gegenüber der RLF+WBV-Gruppe. Die E-Gruppe weist erhöhte Werte im Vergleich zur RLF-Gruppe auf. 


\subsubsection{Durchmesser/Gewicht}

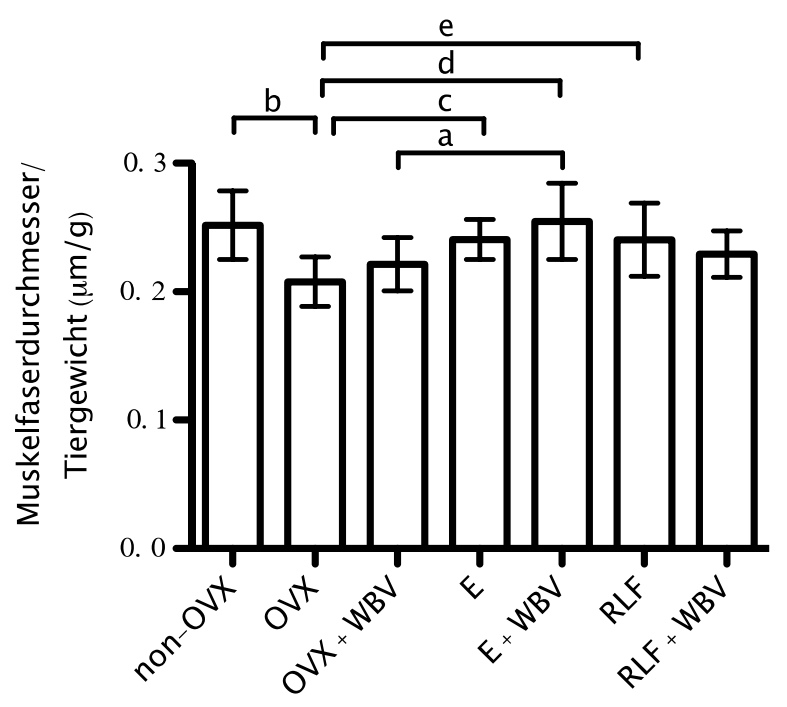

Abb. 19: Muskelfaserdurchmesser im Verhältnis zum Tiergewicht, M. soleus

a: OVX+WBV signifikant zu $E+W B V$

b: non-OVX signifikant zu OVX

c: OVX signifikant zu E

d: OVX signifikant zu $E+W B V$

e: OVX signifikant zu RLF

Setzt man den Durchmesser ins Verhältnis zum Tiergewicht (siehe Abb. 19), zeigen sich die Werte der OVX-Gruppe signifikant erniedrigt zur non-OVX-, E-, E+WBV- und RLF-Gruppe. Weiterhin ist die OVX+WBV-Gruppe signifikant erniedrigt gegenüber der E+WBV-Gruppe.

Mit Ausnahme der E+WBV-Gruppe sind die Verhältnisse aller anderen Gruppen (OVX, OVX+WBV, E, RLF, RLF+WBV) erniedrigt im Vergleich zur non-OVX-Gruppe. Die OVX-Gruppe weist die niedrigsten Werte im Vergleich zu den Therapie-Gruppen (OVX+WBV, E, E+WBV, RLF und RLF+WBV) auf.

Die Werte der RLF+WBV-Gruppe sind erniedrigt im Vergleich zur E+WBV-Gruppe und erhöht im Vergleich zur OVX+WBV-Gruppe. Die Werte der E+WBV-Gruppe sind erhöht im Vergleich zur E-Gruppe. Das Verhältnis der RLF-Gruppe ist erhöht im Vergleich zur RLF+WBV-Gruppe. Die RLF-Gruppe weist minimal erniedrigte Werte gegenüber der E-Gruppe auf. 


\subsubsection{Fläche}

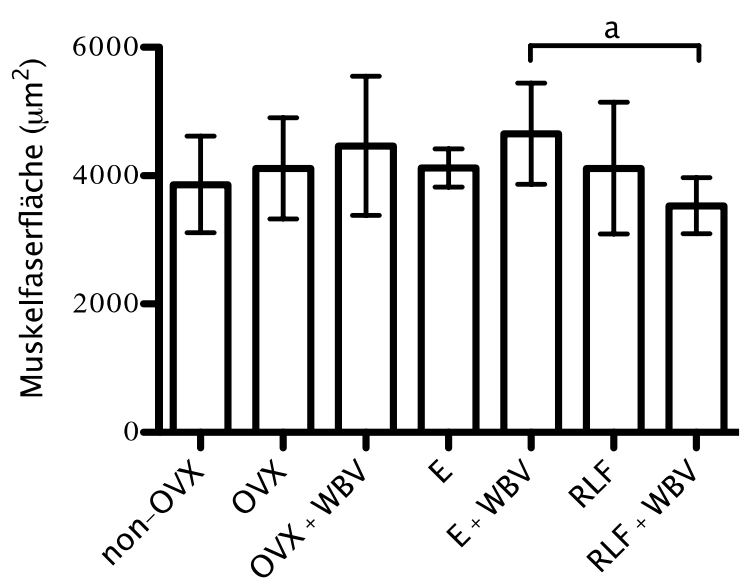

Abb. 20: Muskelfaserfläche, M. soleus

a: $E+W B V$ signifikant $z U R L F+W B V$

Beim Vergleich der Muskelfaserfläche im M. soleus (siehe Abb. 20) lässt sich ein signifikanter Unterschied der E+WBV-Gruppe gegenüber der RLF+WBV-Gruppe nachweisen.

Mit Ausnahme der RLF+WBV-Gruppe liegen alle Werte über denen der non-OVX-Gruppe und über denen der OVX-Gruppe.

Die Faserfläche der OVX+WBV-Gruppe weist höhere Werte gegenüber der RLF+WBV-Gruppe und niedrigere Werte gegenüber der E+WBV-Gruppe auf. Die Fläche der E+WBV-Gruppe ist größer als innerhalb der E-Gruppe. Die Werte der RLF+WBV-Gruppe liegen unterhalb denen der RLF-Gruppe. Beim Vergleich der Fläche der RLF-Gruppe ist diese leicht erniedrigt im Vergleich zur E-Gruppe. 


\subsubsection{Fläche/Gewicht}

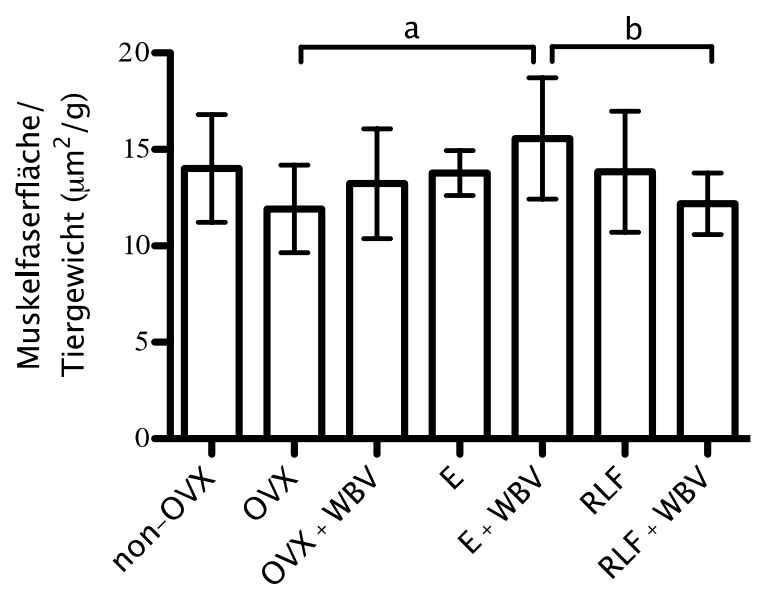

Abb. 21: Muskelfaserfläche im Verhältnis zum Tiergewicht, M. soleus

a: OVX signifikant zu $E+W B V$

b: $E+W B V$ signifikant $z U R L F+W B V$

Setzt man die Fläche ins Verhältnis zum Tiergewicht (siehe Abb. 21), so bleibt die Signifikanz innerhalb der E+WBV-Gruppe gegenüber der RLF+WBV-Gruppe weiterhin bestehen. Hinzu kommt eine signifikante Erhöhung im Vergleich der E+WBV-Gruppe mit der OVX-Gruppe.

Mit Ausnahme der E+WBV-Gruppe, die im Versuch den höchsten Wert zeigt, weisen alle anderen Gruppen (OVX, OVX+WBV, E, RLF, RLF+WBV) niedrigere Werte als die non-OVX-Gruppe und höhere als in der OVX-Gruppe auf.

Das Verhältnis innerhalb der OVX+WBV-Gruppe liegt unterhalb des Verhältnisses in der E+WBV-Gruppe aber über dem in der RLF+WBV-Gruppe. Die Werte der E+WBV-Gruppe sind größer als die der E-Gruppe. Der Vergleich des Verhältnisses der RLF- zur RLF+WBV-Gruppe zeigt höhere Werte. Die Werte der E-Gruppe sind nur minimal erniedrigt im Vergleich zur RLF-Gruppe. 


\subsubsection{M. longissimus}

\subsubsection{Durchmesser}

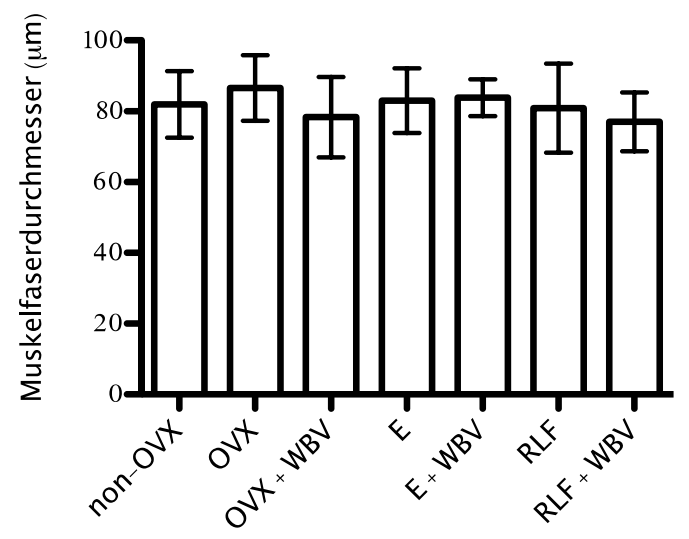

Abb. 22: Muskelfaserdurchmesser des FG-Fasertyps, M. longissimus

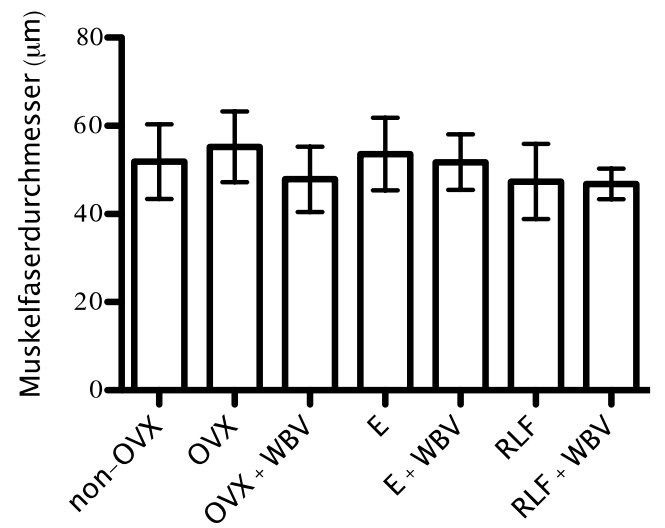

Abb. 23: Muskelfaserdurchmesser des FOG-+SO-Fasertyps, M. longissimus

Beim Vergleich der Muskelfaserdurchmesser des M. longissimus (siehe Abb. 22 und 23) zeigen sich in beiden Fasertyp-Gruppen keine signifikanten Unterschiede.

Der Durchmesser der OVX-Gruppe ist in beiden Gruppen am höchsten. Der Wert der RLF+WBV-Gruppe ist in beiden Gruppen am geringsten. In der Gruppe des FG-Fasertyps (siehe Abb. 22) liegt der Durchmesser der OVX+WBV-, RLF- und RLF+WBV-Gruppe unter der non-OVX-Gruppe, die Werte der OVX-E- und E+WBV-Gruppe liegen über denen der non-OVX-Gruppe. In der Gruppe des FOG-+SO-Fasertyps (siehe Abb. 23) weisen die OVX+WBV-, die E+WBV-, die RLF- und die RLF+WBV-Gruppe niedrigere Werte als die non-OVX-Gruppe auf. Die Werte der OVX- und E-Gruppe sind erhöht im Vergleich zur non-OVX-Gruppe. Bei beiden Fasertyp-Gruppen sind die Durchmesser der OVXGruppe am höchsten im Vergleich zu allen anderen Gruppen.

Bei beiden Fasertypen sind die Werte der OVX+WBV-Gruppe niedriger als die der RLF+WBV-Gruppe, aber höher als die der E+WBV-Gruppe. In der FG-Fasertyp-Gruppe ist die E-Gruppe leicht erhöht gegenüber der E+WBV-Gruppe. In der FOG-+SO-Fasertyp-Gruppe ist die E-Gruppe leicht erniedrigt im Vergleich zur E+WBV-Gruppe. Die RLF-Gruppe weist im Vergleich zur RLF+WBV-Gruppe bei beiden Fasertyp-Gruppen höhere Werte auf. Auch der Durchmesser innerhalb der E-Gruppe ist im Vergleich zur RLF-Gruppe bei beiden Fasertypen leicht erhöht. 


\subsubsection{Durchmesser/Gewicht}

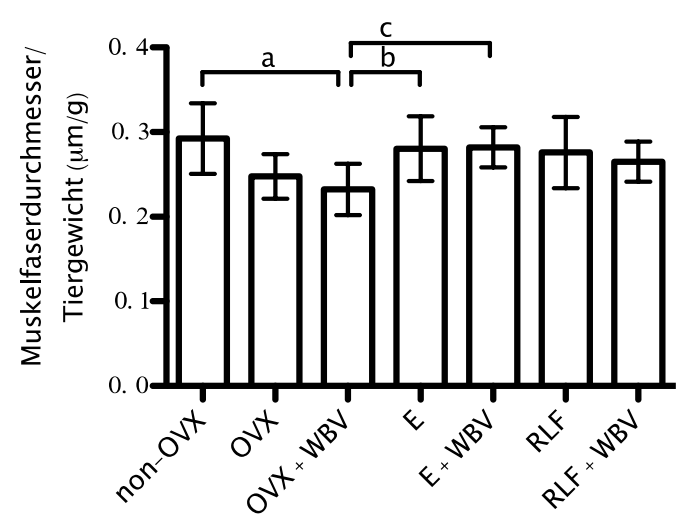

Abb. 24: Muskelfaserdurchmesser des FGFasertyps im Verhältnis zum Tiergewicht, M. longissimus

a: non-OVX signifikant zu OVX+WBV

b: OVX+WBV signifikant $z u E$

c: $O V X+W B V$ signifikant $z u E+W B V$

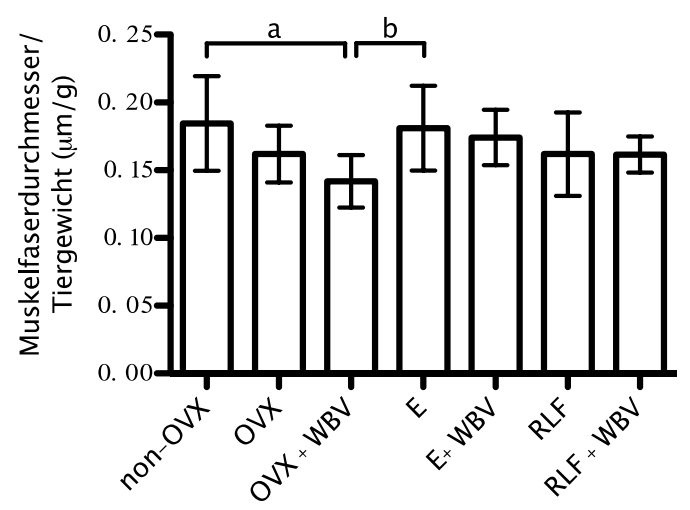

Abb. 25: Muskelfaserdurchmesser des FOG-+SOFasertyps im Verhältnis zum Tiergewicht, M. longissimus

a: non-OVX signifikant zu OVX+WBV

b: OVX+WBV signifikant zu $E$

Setzt man den Durchmesser der Zellen ins Verhältnis zum Tiergewicht, lässt sich bei beiden Fasertypen (siehe Abb. 24 und 25) eine signifikante Erniedrigung der OVX+WBV-Gruppe im Verhältnis zur non-OVX- und zur E-Gruppe nachweisen. Der FG-Fasertyp (siehe Abb. 24) zeigt außerdem eine signifikante Erniedrigung der OVX+WBV-Gruppe im Vergleich zur E+WBV-Gruppe.

Bei beiden Fasertyp-Gruppen weist die OVX+WBV-Gruppe das geringste Verhältnis auf. Die non-OVX-Gruppe weist im Vergleich bei beiden FasertypGruppen die höchsten Werte auf. In der FG-Fasertyp-Gruppe sind mit Ausnahme der OVX+WBV-Gruppe alle Verhältnisse höher als die der OVX-Gruppe. In der FOG-+SO-Fasertyp-Gruppe (siehe Abb. 25) sind mit Ausnahme der OVX+WBV- und RLF+WBV-Gruppe alle Verhältnisse höher als die der OVX-Gruppe.

Bei beiden Fasertyp-Gruppen liegt das Verhältnis der RLF+WBV-Gruppe oberhalb der OVX+WBV-Gruppe und unterhalb der E+WBV-Gruppe. In der FG-Fasertyp-Gruppe ist das Verhältnis der E-Gruppe minimal erniedrigt im Vergleich zur E+WBV-Gruppe. In der FOG-+SO-Fasertyp-Gruppe sind die Werte der E-Gruppe minimal erhöht im Vergleich zur E+WBV-Gruppe. Bei beiden Fasertypen sind die Werte der RLF-Gruppe leicht erhöht im Vergleich zur RLF+WBV-Gruppe.

Die E-Gruppen weisen bei beiden Fasertypen leicht erhöhte Werte im Vergleich zur RLF-Gruppe auf. 


\subsubsection{Fläche}

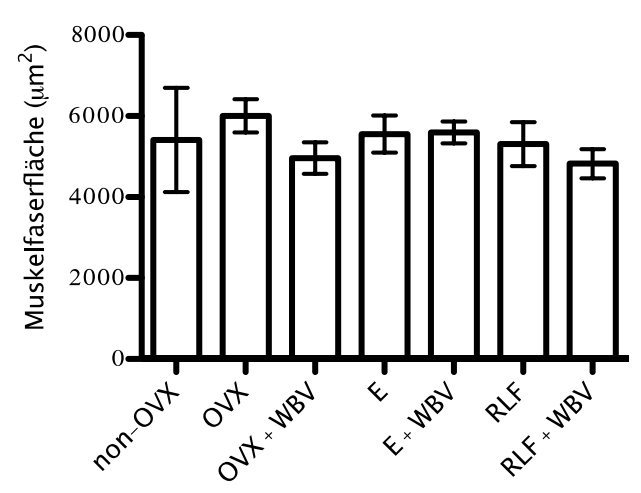

Abb. 26: Muskelfaserfläche des FG-Fasertyps, M. longissimus

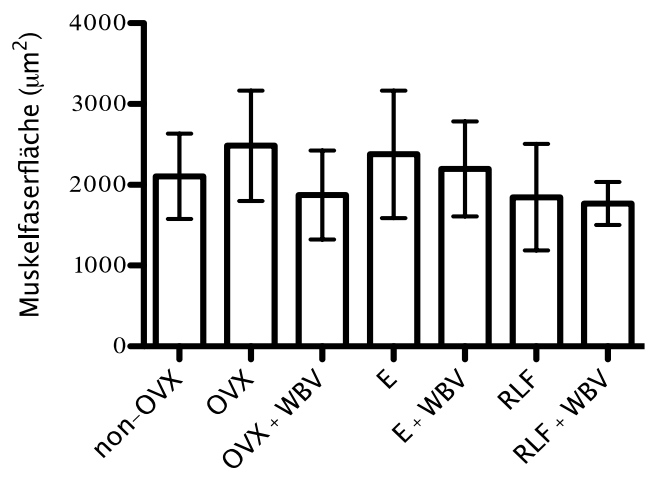

Abb. 27: Muskelfaserfläche des FOG-+SOFasertyps, M. longissimus

Bei beiden Fasertyp-Gruppen lassen sich beim Vergleich der Muskelfaserfläche (siehe Abb. 26 und 27) keine signifikanten Unterschiede bezüglich der Faserfläche nachweisen.

Im Vergleich weisen beide Fasertypen in der OVX-Gruppe die höchsten und in der RLF+WBV-Gruppe die niedrigsten Werte auf.

Die Flächen der OVX-, E- und E+WBV-Gruppe sind bei beiden Fasertypen erhöht und die Flächen der OVX+WBV-, R- und RLF+WBV-Gruppe erniedrigt im Vergleich zur non-OVX-Gruppe. Die Werte der OVX-Gruppe im Vergleich zu den Therapie-Gruppen (OVX+WBV, E, E+WBV, RLF und RLF+WBV) sind bei beiden Fasertypen erhöht.

Die RLF+WBV-Gruppe ist bei beiden Fasertyp-Gruppen im Vergleich zur OVX+WBV-Gruppe erhöht und im Vergleich zur E+WBV-Gruppe erniedrigt. In der FG-Fasertyp-Gruppe (siehe Abb. 26) ist die Fläche der E-Gruppe im Vergleich zur E+WBV-Gruppe leicht erniedrigt, in der FOG-+SO-FasertypGruppe (siehe Abb. 27) ist dieses dagegen erhöht. Bei beiden Fasertypen ist der Wert der RLF-Gruppe erhöht im Vergleich zur RLF+WBV-Gruppe. Die E-Gruppe weist im Vergleich zur RLF-Gruppe bei beiden Fasertypen höhere Werte auf. 


\subsubsection{Fläche/Gewicht}

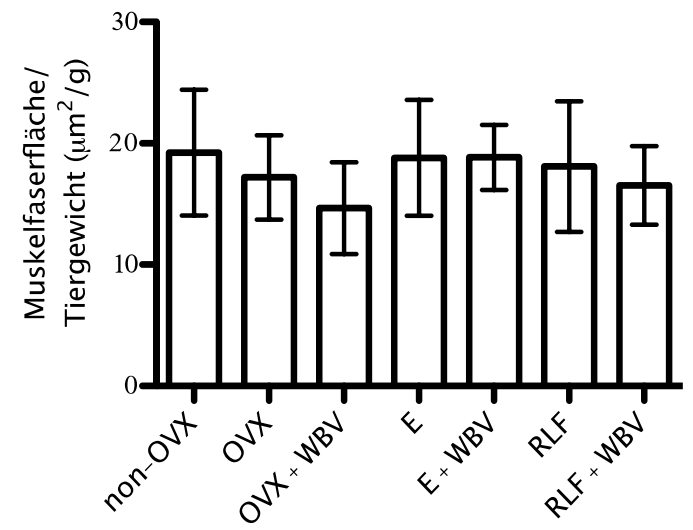

Abb. 28: Muskelfaserfläche des FG-Fasertyps im Verhältnis zum Tiergewicht, M. longissimus

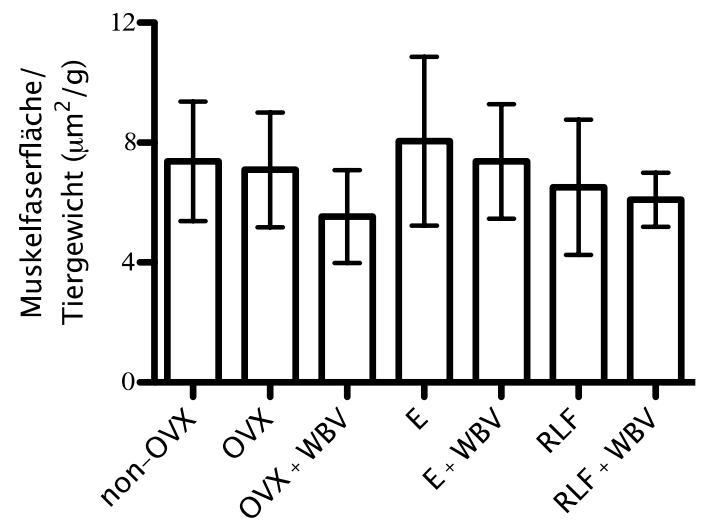

Abb. 29: Muskelfaserfläche des FOG-+SO-

Fasertyps im Verhältnis zum Tiergewicht, M. longissimus

Setzt man bei beiden Gruppen die Muskelfaserfläche ins Verhältnis zum Tiergewicht, lassen sich keine signifikanten Unterschiede nachweisen (siehe Abb. 28 und 29).

In der Gruppe des FG-Fasertyps (siehe Abb. 28) liegen alle Verhältnisse der ovarektomierten Tiere (OVX, OVX+WBV, E+WBV, RLF, RLF+WBV) niedriger im Vergleich zur non-OVX-Gruppe. In der Gruppe des FOG-+SO-Fasertyps (siehe Abb. 29) liegen alle Verhältnisse mit Ausnahme der E-Gruppe niedriger im Vergleich zur non-OVX-Gruppe.

Beim Vergleich der Gruppen zur OVX-Gruppe sind die Werte in der FG-Fasertyp-Gruppe mit Ausnahme der OVX+WBV- und RLF+WBV-Gruppe erhöht. In der FOG-+SO-Fasertyp-Gruppe sind die Werte der OVX+WBV-, RLF+WBV- und RLF-Gruppe niedriger als die der OVX-Gruppe.

Die RLF+WBV-Gruppe liegt mit ihren Werten im Vergleich zur OVX+WBV-Gruppe höher und im Vergleich zur E+WBV-Gruppe niedriger bei beiden Fasertypen. Beim FG-Fasertyp liegt die E+WBV-Gruppe minimal erhöht gegenüber der E-Gruppe. Bei der FOG-+SO-Fasertyp-Gruppe sind die Werte der E-Gruppe erhöht im Vergleich zur E+WBV-Gruppe. Die RLF-Gruppe weist bei beiden Fasertypen höhere Werte als die RLF+WBV-Gruppe auf. Die E-Gruppe ist bei beiden Fasertypen erhöht im Vergleich zur RLF-Gruppe. 


\subsubsection{M. gastrocnemius}

\subsubsection{Durchmesser}

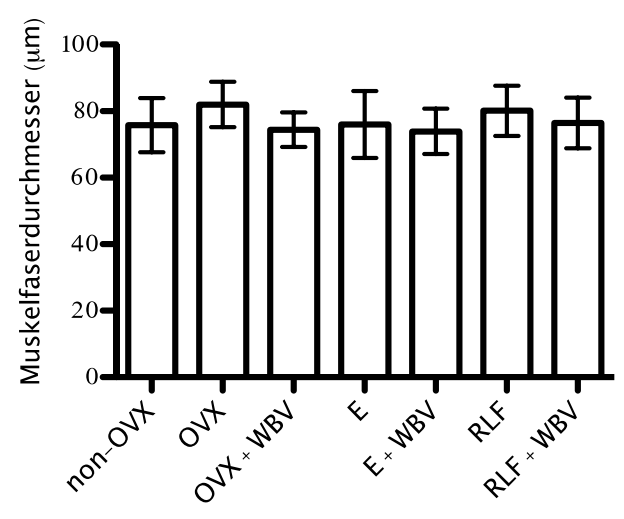

Abb. 30: Muskelfaserdurchmesser des FGFasertyps, M. gastrocnemius

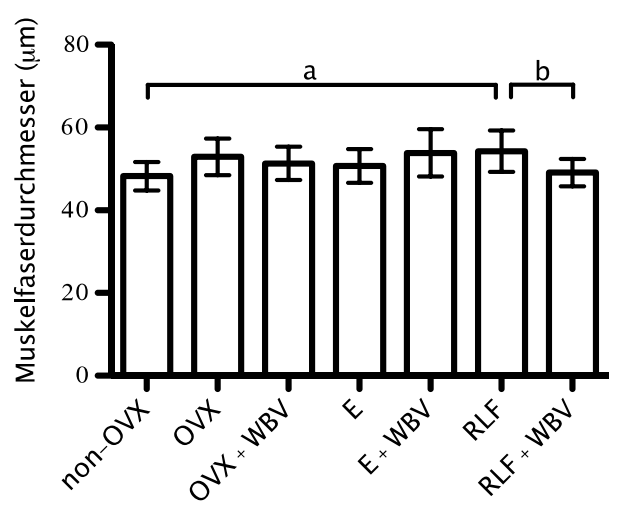

Abb. 31: Muskelfaserdurchmesser des FOG-+SOFasertyps, M. gastrocnemius a: non-OVX signifikant zu RLF b: RLF signifikant zu RLF+WBV

In der Gruppe des FG-Fasertyps (siehe Abb. 30) lassen sich beim Vergleich des Muskelfaserdurchmessers keine signifikanten Unterschiede nachweisen. In der Gruppe des FOG-+SO-Fasertyps (siehe Abb. 31) lässt sich eine signifikante Erhöhung der RLF-Gruppe im Vergleich zur non-OVX-Gruppe sowie im Vergleich zur RLF+WBV-Gruppe nachweisen.

In der Gruppe des FG-Fasertyps weisen mit Ausnahme der OVX+WBV- und E+WBV-Gruppe alle Gruppen (E, RLF, RLF+WBV, OVX) höhere Werte als die non-OVX-Gruppe auf. In der Gruppe des FG-+SO-Fasertyps weisen alle Therapie-Gruppen (OVX+WBV, E, E+WBV, RLF, RLF+WBV) und die OVX-Gruppe höhere Werte im Vergleich zur non-OVX-Gruppe auf. Mit Ausnahme der E+WBV- und RLF-Gruppe weisen die Therapie-Gruppen im Vergleich zur OVX-Gruppe niedrigere Werte beim FOG-+SO-Fasertyp auf. Die OVX-Gruppe weist beim FG-Fasertyp den höchsten Durchmesser im Verhältnis zu allen Therapie-Gruppen (OVX+WBV, E, E+WBV, RLF, RLF+WBV) auf.

Bei beiden Fasertypen weisen die Vibrationstherapie-Gruppen im Vergleich nur minimale Unterschiede auf. Beim FOG-+SO-Fasertyp ist der Durchmesser der E+WBV-Gruppe erhöht im Vergleich zur E-Gruppe, beim FG-Fasertyp hingegen erniedrigt. Bei beiden Fasertypen liegen die Durchmesser der RLF-Gruppe über den Werten der RLF+WBV-Gruppe. Die E-Gruppe weist im Vergleich zur RLF-Gruppe bei beiden Fasertypen niedrigere Werte auf. 


\subsubsection{Durchmesser/Gewicht}

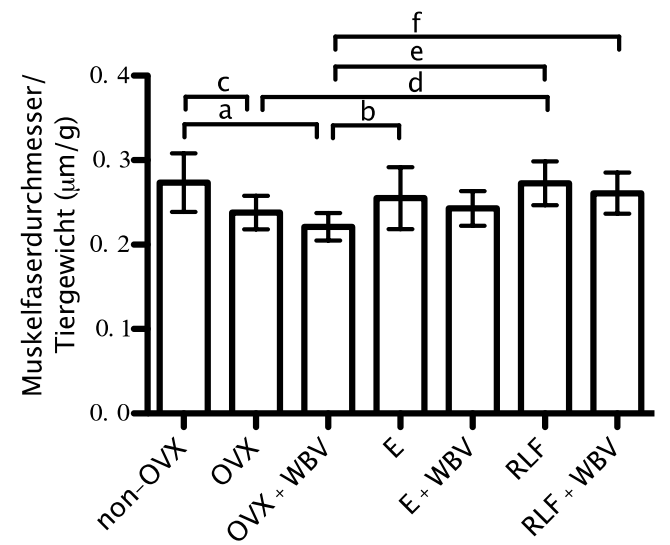

Abb. 32: Muskelfaserdurchmesser des FG-

Fasertyps im Verhältnis zum Tiergewicht, M. gastrocnemius

a: non-OVX signifikant zu OVX+WBV

b: OVX+WBV signifikant zu $E$

c: non-OVX signifikant zu OVX

d: OVX signifikant zu RLF

e: $O V X+W B V$ signifikant zu RLF

f: OVX+WBV signifikant $z u R L F+W B V$

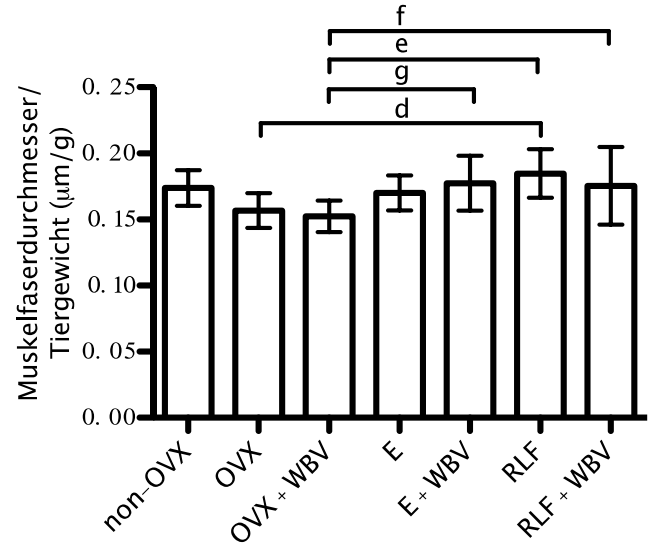

Abb. 33: Muskelfaserdurchmesser des FOG-+SOFasertyps im Verhältnis zum

Tiergewicht, M. gastrocnemius d: OVX signifikant zu RLF e: OVX+WBV signifikant zu RLF f: $O V X+W B V$ signifikant $z U R L F+W B V$ g: $O V X+W B V$ signifikant $z u E+W B V$

Setzt man den Durchmesser der Zellen ins Verhältnis zum Tiergewicht, so ergibt sich in beiden Fasertyp-Gruppen (siehe Abb. 32 und 33) eine signifikante Erniedrigung der OVX+WBV-Gruppe im Verhältnis zur RLF- und RLF+WBVGruppe. Außerdem zeigt sich bei beiden Fasertypen die OVX-Gruppe signifikant erniedrigt gegenüber der RLF-Gruppe. Beim FG-Fasertyp (siehe Abb. 32) sind zusätzlich noch die OVX+WBV-Gruppe signifikant erniedrigt im Vergleich zur E- und non-OVX-Gruppe sowie die OVX-Gruppe signifikant erniedrigt zur nonOVX-Gruppe. Beim FOG-+SO-Fasertyp (siehe Abb. 33) zeigt sich zusätzlich die OVX+WBV-Gruppe signifikant erniedrigt zur E+WBV-Gruppe.

Die non-OVX-Gruppe weist beim Vergleich zu den anderen Gruppen den höchsten Wert in der FG-Fasertyp-Gruppe auf. Beim FOG-+SO-Fasertyp liegen die Werte der RLF-, RLF+WBV- und E+WBV-Gruppe höher und die der OVX-, OVX+WBV- und E-Gruppe niedriger im Vergleich zur non-OVX-Gruppe.

Bei beiden Fasertypen liegt das Verhältnis mit Ausnahme der OVX+WBVGruppe über dem der OVX-Gruppe.

Beim Vergleich der WBV-Gruppen weist in der FG-Fasertyp-Gruppe die E+WBV-Gruppe einen höheren Wert als die OVX+WBV-Gruppe und einen niedrigeren Wert als die RLF+WBV-Gruppe auf. In der 
FOG-+SO-Fasertyp-Gruppe weist die E+WBV-Gruppe einen höheren Wert als die RLF+WBV und diese einen höheren Wert als die OVX+WBV-Gruppe auf. Die E+WBV-Gruppe ist im Vergleich zur E-Gruppe beim FG-Fasertyp erhöht und beim FOG-+SO-Fasertyp erniedrigt. Bei beiden Fasertyp-Gruppen ist das Verhältnis der RLF-Gruppe erhöht im Vergleich zur RLF+WBV-Gruppe. Die E-Gruppe weist im Vergleich zur RLF-Gruppe bei beiden Fasertypen erniedrigte Werte auf. 


\subsubsection{Fläche}

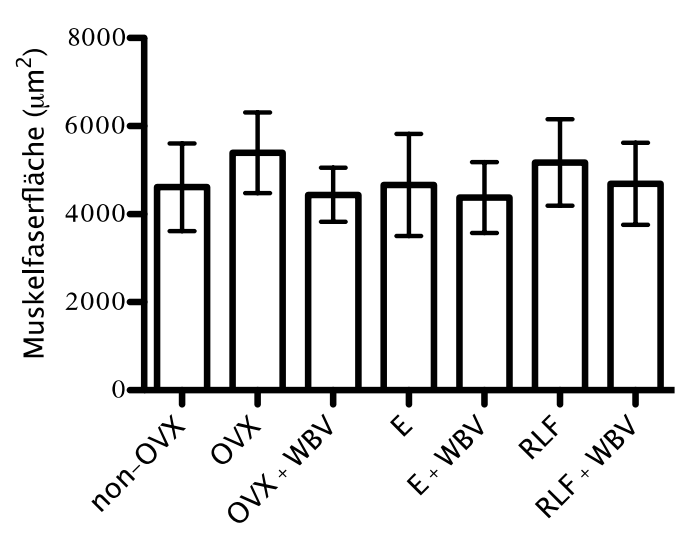

Abb. 34: Muskelfaserfläche des FG-Fasertyps, M. gastrocnemius

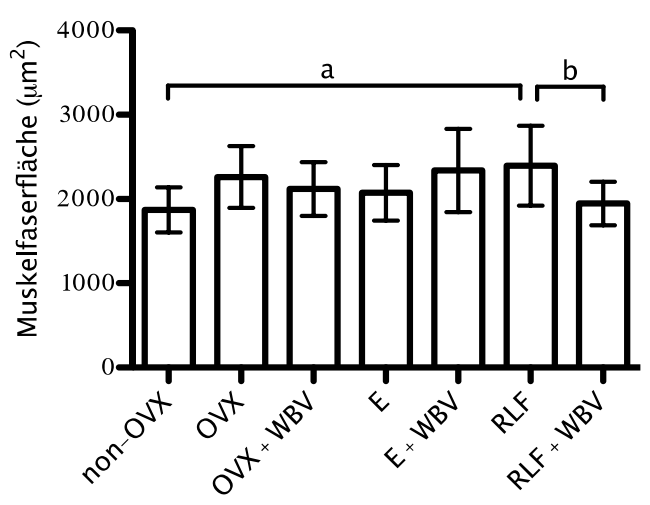

Abb. 35: Muskelfaserfläche des FOG-+SO-

Fasertyps, M. gastrocnemius a: non-OVX signifikant zu RLF b: $R L F$ signifikant $z u R L F+W B V$

In der Gruppe des FG-Fasertyps (siehe Abb. 34) lassen sich keine signifikanten Unterschiede im Vergleich der Muskelfaserfläche nachweisen. In der Gruppe des FOG-+SO-Fasertyps (siehe Abb. 35) zeigt sich eine signifikante Erhöhung der RLF-Gruppe im Vergleich zur non-OVX-Gruppe und ebenfalls im Vergleich zur RLF+WBV-Gruppe.

Mit Ausnahme der OVX+WBV- und E+WBV-Gruppe weisen alle Gruppen des FG-Fasertyps eine höhere Fläche als die non-OVX-Gruppe auf. Beim FOG-+SO-Fasertyp sind alle Flächenwerte größer als die der non-OVX-Gruppe. Vergleicht man in der FG-Fasertyp-Gruppe die Therapie-Gruppen gegenüber der OVX-Gruppe, so ist die Fläche der Muskelfasern erniedrigt. In der FOG-+SO-Fasertyp-Gruppe sind mit Ausnahme der E+WBV- und RLF-Gruppe die Flächen gegenüber der OVX-Gruppe ebenfalls erniedrigt.

In der FG-Fasertyp-Gruppe sind die Werte der OVX+WBV-Gruppe erniedrigt im Vergleich zur RLF+WBV-Gruppe und erhöht im Vergleich zur E+WBV-Gruppe. Beim FOG-+SO-Fasertyp sind die Werte der OVX+WBV-Gruppe erhöht im Vergleich zur RLF+WBV-Gruppe und erniedrigt im Vergleich zur E+WBV-Gruppe. In der FG-Fasertyp-Gruppe ist die E-Gruppe im Vergleich zur E+WBV-Gruppe erniedrigt, beim FOG-+SO-Fasertyp hingegen erhöht. Bei beiden Fasertypen liegen die Werte der RLF-Gruppe über denen der RLF+WBV-Gruppe. Die Werte der E-Gruppe liegen niedriger im Vergleich zur RLF-Gruppe bei beiden Fasertypen. 


\subsubsection{Fläche/Gewicht}

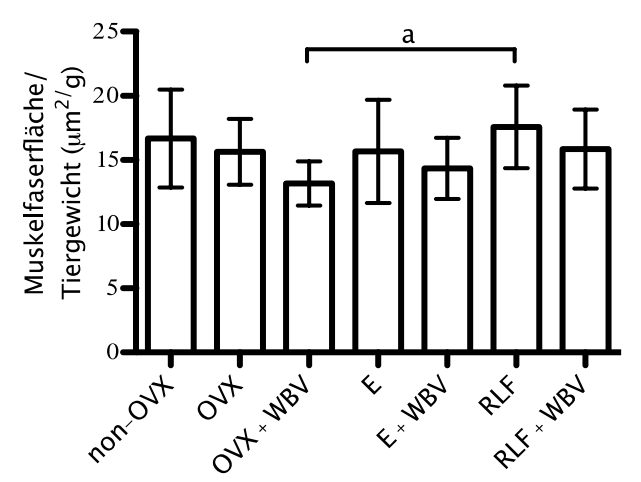

Abb. 36: Muskelfaserfläche des FG-Fasertyps im Verhältnis zum Tiergewicht, M. gastrocnemius a: OVX+WBV signifikant zu RLF

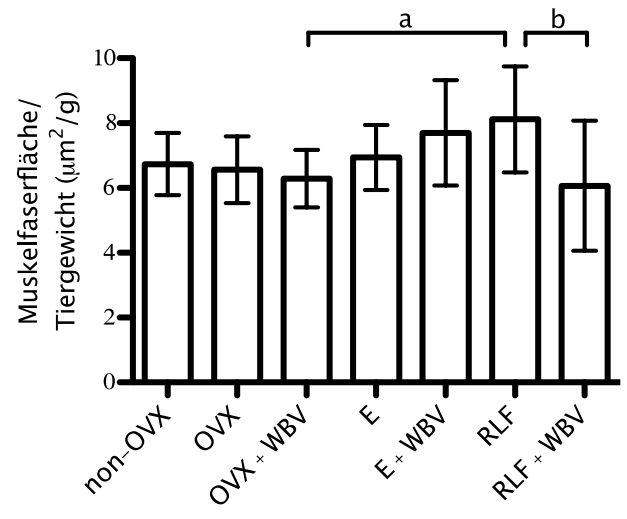

Abb. 37: Muskelfaserfläche des FOG-+SOFasertyps im Verhältnis zum Tiergewicht, M. gastrocnemius a: OVX+WBV signifikant zu RLF b: RLF signifikant zU RLF+WBV

Setzt man die Muskelfaserfläche ins Verhältnis zum Tiergewicht, lässt sich in der Gruppe des FG-Fasertyps (siehe Abb. 36) eine signifikante Erhöhung der RLF-Gruppe im Vergleich zur OVX+WBV-Gruppe nachweisen. In der Gruppe des FOG-+SO-Fasertyps (siehe Abb. 37) erweist sich die RLF-Gruppe signifikant erhöht im Vergleich zur RLF+WBV-Gruppe sowie zur OVX+WBV-Gruppe.

Beim FG-Fasertyp liegen die Verhältnisse der Gruppen mit Ausnahme der RLF-Gruppe unterhalb der non-OVX-Gruppe. Beim FOG-+SO-Fasertyp liegen die Verhältnisse der E-, E+WBV-, und RLF-Gruppe unterhalb der non-OVXGruppe, die Verhältnisse der OVX- OVX+WBV- und RLF+WBV-Gruppe darüber. Mit Ausnahme der OVX+WBV- und E+WBV-Gruppe liegen beim FG-Fasertyp im Vergleich aller ovarektomierten Gruppen die Werte höher als in der OVX-Gruppe. Beim FOG-+SO-Fasertyp liegen mit Ausnahme der OVX+WBVund RLF+WBV-Gruppe die Werte erhöht im Vergleich zur OVX-Gruppe vor.

Beim FG-Fasertyp weist die E+WBV-Gruppe einen höheren Wert als die OVX+WBV-Gruppe und einen niedrigeren Wert als die RLF+WBV-Gruppe auf. Beim FOG-+SO-Fasertyp weist die OVX+WBV-Gruppe einen niedrigeren Wert als die E+WBV-Gruppe und einen höheren Wert als die RLF+WBV-Gruppe auf. Die Werte der E-Gruppe sind beim FG-Fasertyp im Vergleich zur E+WBV-Gruppe erhöht, bei der FOG-+SO-Fasertyp-Gruppe sind sie erniedrigt. Bei beiden Fasertyp-Gruppen sind die Werte der RLF-Gruppe höher als die der RLF+WBV-Gruppe. Die E-Gruppe weist im Vergleich zur RLF-Gruppe bei beiden Fasertypen niedrigere Werte auf. 


\section{Diskussion}

Aufgrund der Veränderungen in der demographischen Entwicklung unserer Gesellschaft steht unser Gesundheitssystem in Zukunft nicht nur bei der Behandlung der Osteoporose, sondern auch zunehmend bei der Behandlung der Sarkopenie, vor neuen Herausforderungen.

Die Interaktion zwischen Muskeln und ihren Erkrankungen, wie der Sarkopenie, und Knochen und ihren Erkrankungen, wie der Osteoporose, wird derzeit weiter erforscht. Ob und wie die derzeitigen Medikamente der Osteoporosebehandlung auf die Muskelzellen wirken, ist bisher nicht ausreichend untersucht. Und obwohl die positive Wirkung der nicht-medikamentösen Vibrationstherapie nachgewiesen ist (Agnusdei und lori 2000, Anderson et al. 2004, Jankovich 1972, Roussouw et al. 2002, Rubin et al. 2001, Xie et al. 2008), ist unklar, ob sie durch Kombination mit Medikamenten einen gesteigerten Effekt erbringt. Ziel dieser Doktorarbeit war es daher, zu untersuchen, wie Östrogen, Raloxifen und die Ganzkörpervibration auf die Muskeln wirken und ob eine Kombination aus Vibrationstherapie + Östrogen und eine Vibrationstherapie + Raloxifen Vorteile gegenüber den Einzeltherapien bringen, um somit für die Zukunft einen möglichen verbesserten Therapieansatz bieten zu können.

\subsection{Die Ratte als Tiermodell}

Zur Untersuchung der Wirkungen von Östrogen, Raloxifen und Ganzkörpervibrationen als Mono- und Kombinationstherapie auf die Muskulatur bei Osteoporose wurde in diesem Versuch die ovarektomierte Ratte als Versuchstier genutzt.

Die Verwendung von Tieren als Osteoporosemodell ist vielfach erprobt. So wurden vorwiegend ovarektomierte Schafe, Hunde, Schweine und Ratten in Tierversuchen verwendet. Vor allem die Versuche im Großtiermodell sind meist sehr aufwendig und kostenintensiv. Außerdem zeigte sich, dass der Knochenmetabolismus nach Östrogenmangel im Vergleich von weiblichen Ratten und postmenopausalen Frau sehr ähnlich ist, so dass sich das Rattenmodell im Bereich der Erforschung der Osteoporose durchgesetzt hat (Barlet et al. 1994).

Durch Ovarektomie wird bei Ratten ein erhöhter Knochenumsatz am spongiösem Knochen der proximalen Tibia, dem distalen Femur und der Lendenwirbelsäule 
hervorgerufen, der zu einem Knochenverlust führt. Östrogen blockiert diese Aktivierung des Knochenumsatzes und somit den Knochenverlust (Thompson et al. 1995). Aber nicht nur das Ansprechen des Knochens auf Östrogen zeigte analoge Wirkungen bei Ratten im Tierversuch und der postmenopausalen Frau, auch Medikamente und mechanische Einwirkungen führen bei beiden zu ähnlichen Resultaten (Frost und Jee 1992, Kalu 1991).

Aufgrund der guten Übertragbarkeit bei Osteoporose wurde zur Untersuchung der Sarkopenie in der Vergangenheit ebenfalls das Rattenmodell vermehrt verwendet (Bollheimer et al. 2012, Chiu et al. 2011). Nach der Ovarektomie kommt es zu einem Östrogendefizit und zu einer verminderten Produktion an stark-bindenden Myosin. Dies führt dann wahrscheinlich im Anschluss zu einer Abnahme der Muskelkraft (Moran et al. 2006, Moran et al. 2007).

\subsection{Tiergewicht, Futteraufnahme, Muskelgewicht, Serumkreatininkinase}

In diesem Versuch zeigte der Gewichtsverlauf und die Futteraufnahme einen höheren Verlauf bei den ovarektomierten Tieren gegenüber den nichtovarektomierten Versuchstieren bis zum Zeitpunkt der Osteotomie. Diese Ergebnisse entsprechen denen aus früheren Versuchen (Komrakova et al. 2011, Komrakova et al. 2013). Die erhöhte Futteraufnahme scheint also auch zu einer Zunahme an Gewicht zu führen.

Da das Uterusgewicht bei den ovarektomierten Tieren signifikant niedriger war gegenüber den intakten Tieren (Stuermer et al. 2014), kann der Erfolg der Ovarektomie bestätigt werden. Die Ovarektomie führt zu einem Östrogendefizit und zu einem veränderten Metabolismus im Körper (Komrakova et al. 2009). Aufgrund der Tatsache, dass das Muskelgewicht bei den ovarektomierten Tieren nicht einheitlich zugenommen hat, ist eine Zunahme an Fettgewebe sehr wahrscheinlich.

Die Gewichtskurven zeigten ab dem Zeitpunkt des Therapiebeginns einen signifikanten Abfall bei den Tieren, die mit Östrogen oder Raloxifen (Mono- und Kombinationstherapie) behandelt wurden gegenüber den ovarektomierten Tieren ohne Therapie und mit alleiniger Vibrationstherapie. Da sich diese Unterschiede nicht durch eine gesteigerte Futteraufnahme erklären lassen, scheinen die Medikamente Östrogen und Raloxifen also zusätzlich auf den Metabolismus der 
Tiere zu wirken. Diese Wirkung ist so stark im Vergleich zur Vibrationstherapie, dass die Kombinationstherapien mit den Medikamenten keinen Unterschied gegenüber der Monotherapie mit Medikamenten zeigten, aber einen signifikanten Unterschied im Vergleich zur Monotherapie mit Ganzkörpervibration.

Die Untersuchung der Kreatininkinase (CK) ergab keinerlei signifikante Unterschiede innerhalb der Gruppen. Muskelverletzungen und Muskelerkrankungen, wie z. B. die Muskeldystrophie können jedoch zu einer CK-Erhöhung führen (Baird et al. 2012). Eine Untersuchung zeigte, dass längere Vibrationen über acht Wochen zu einem Anstieg der Kreatininkinase führen kann (Naghii et al. 2011). Diese Ergebnisse ließen sich in diesem Versuch jedoch nicht bestätigen. Die CK-Werte waren nicht verändert bei den Tieren, die vibriert wurden und stützen somit die Ergebnisse einer Studie, bei der verschiedene Vibrationregimes untersucht wurden (Komrakova et al 2013). Eine Untersuchung am Menschen zeigte, dass nur bei vereinzelten Patienten die Vibrationstherapie zu einem Anstieg der Kreatinin-kinase führte. Dies lässt die Vermutung zu, dass genetische Faktoren hierbei eine Rolle spielen (Gojanovic et al. 2011). Ebenfalls scheinen alle Therapien mit Medikamenten (Mono- und Kombinationstherapie) keinen negativen Einfluss auf die Muskelzellen zu haben, da sich die CK-Werte nicht von denen der ovarektomierten Tiere unterscheiden.

\subsection{Muskelgewichte}

Beim M. gastrocnemius zeigte sich eine Zunahme des Muskelgewichtes bei den ovarektomierten Tieren ohne Therapie und bei der Mono-Vibrationstherapie gegenüber den Medikamententherapiegruppen und den nicht-ovarektomierten Tieren.

Nachdem das Muskelgewicht ins Verhältnis zum Tiergewicht gesetzt wurde, ist beim M. gastrocnemius kein signifikanter Unterschied mehr innerhalb der Gruppen nachweisbar. Somit bestätigt sich, dass bei den schwereren Ratten auch die Muskeln schwerer waren und ein Zusammenhang zwischen Tiergewicht und Muskelgewicht besteht.

Beim M. soleus hingegen ist die Gruppe der Tiere mit der ÖstrogenKombinationstherapie nachdem das Muskelgewicht ins Verhältnis zum 
Tiergewicht gesetzt wurde, signifikant erhöht gegenüber der RaloxifenKombinationstherapie, gegenüber der Monotherapie mit Vibration und gegenüber den ovarektomierten Tieren ohne Therapie. Da auch der Durchmesser der Zellen und die Fläche in diesen Gruppen beim M. soleus dieselben Unterschiede vorweisen, liegt die Vermutung nahe, dass sich die Kombinationstherapie aus Östrogen + Vibration besonders positiv auf den Muskel auswirkt. Da die alleinige Vibrationstherapie keinen Effekt zeigt, scheint das Vorhandensein von Östrogen den Muskel sensitiver für die Vibrationstherapie zu machen, wohingegen die Gabe von Raloxifen die Ergebnisse der Vibration nicht verstärkt.

Über die Gründe, weshalb die oben beschriebenen Ergebnisse nur auf den M. soleus zutreffen und sich nicht beim M. gastrocnemius bestätigen, lässt sich spekulieren. Es ist möglich, dass die Größenunterschiede und die verschiedenen Funktionen beider Muskeln dazu führen. So ist der größere M. gastrocnemius aufgrund der Eigenschaften seiner Muskelzellen vor allem für schnelle und kurze Bewegungen geeignet. Es ist möglich, dass hier aufgrund der Größe des Muskels die Wirkungen der Therapien, besonders des Östrogens, abgeschwächt sind. Der kleinere M. soleus besitzt überwiegend oxidative Zellen und ist somit vor allem für längere Bewegungen geeignet. Es ist möglich, dass diese oxidativen Zellen besonders sensibel auf die Östrogentherapie in Kombination mit Vibration reagieren.

Die Ergebnisse von Oxlund, die keine signifikanten Unterschiede beim Muskelgewicht des M. gastrocnemius, M. soleus, M. tibialis anterior und M. extensor digitorum longus zwischen ovarektomierten und nicht-ovarektomierten Ratten zeigten (Oxlund et al. 2003), können durch diese Arbeit nicht bestätigt werden. Der M. gastrocnemius wies im Vergleich zum M. soleus, bevor er ins Verhältnis zum Tiergewicht gesetzt wurde, ein signifikant höheres Gewicht nach der Ovarektomie auf. Da Oxlund bei seinem Versuch bei entfetteten und gefriergetrockneten Muskeln das Gewicht ermittelte (Oxlund et al. 2003), ist es möglich, dass in dieser Arbeit der M. gastrocnemius einen höheren Wasser- oder Fettanteil nach der Ovarektomie aufwies und dies der Grund für das höhere Gewicht und die unterschiedlichen Ergebnisse ist. 


\subsection{Amylase-PAS-Färbung}

Bei der Untersuchung des Verhältnisses der Kapillaranzahl pro Muskelfaser zeigte sich innerhalb dieser Arbeit bei allen drei Muskeln (M. soleus, M. gastrocnemius, M. longissimus) eine tendenzielle Zunahme bei den ovarektomierten Tieren ohne Therapie gegenüber den nicht-ovarektomierten Tieren, die sich allerdings als nicht signifikant erwies. Auch eine frühere Studie zeigte keine signifikanten Unterschiede bei den verschiedenen Muskeln (Stuermer et al. 2010).

Eine Studie an Hasen zeigte, dass nach Ovarektomie die Gabe von $1 \mathrm{mg} / \mathrm{kg}$ bzw. $2 \mathrm{mg} / \mathrm{kg}$ Östrogen zu einem Anstieg der Angiogenese im Muskel führte (Kyriakides et al. 2001). Die Ergebnisse in dieser Arbeit lassen aber eher vermuten, dass die Ovarektomie (also die Abnahme von Östrogen) zu einem Anstieg der Angiogenese und die spätere Gabe von Östrogen wieder zu einem Abfall der Angiogenese führt, da die Tiere mit alleiniger Östrogentherapie und mit Östrogen-Kombinationstherapie tendenziell niedrige Verhältnisse aufweisen als die ovarektomierten Tiere ohne Therapie. Auch bei den Raloxifentherapien war bei allen Muskeln das Kapillar-Zell-Verhältnis unter Therapie niedriger als bei den ovarektomierten Tieren ohne Therapie.

Die Kombinationstherapie mit Östrogen und Vibration hat ein höheres KapillarZell-Verhältnis gezeigt im Vergleich zur alleinigen Östrogentherapie. Bei der Kombinationstherapie mit Raloxifen und Vibration fielen beim M. gastrocnemius und M. longissimus höhere Verhältnisse gegenüber der Monotherapie auf. Beim M. soleus war das Gegenteil der Fall. Auch die alleinige Therapie mit Ganzkörpervibration brachte ein geringeres Verhältnis als bei den ovarektomierten Tieren ohne Therapie.

Die Hypothese, dass durch die mechanische Stimulation bei Vibration die Durchblutung gefördert wird und somit ein höheres Kapillar-Zell-Verhältnis vorhanden sein müsste (Komrakova et al. 2013), lässt sich mit diesen Ergebnissen nicht bestätigen. Aufgrund der Tatsache, dass beim Vergleich von verschiedenen Vibrationsregimes die horizontale Vibration mit höheren Frequenzen zu einer Zunahme der Kapillardichte beim M. soleus führte und beim M. gastrocnemius keine Änderungen zeigte und auch die vertikale Vibration zu keiner Zunahme führte (Komrakova et al. 2013), lässt den Schluss zu, dass die Angiogenese unter Vibration abhängig von Frequenz und Bewegungsrichtung ist 
und dass verschiedene Muskeln auch unterschiedlich auf die Stimulation mit Vibration reagieren können.

Bei diesem Experiment führte die alleinige Vibrationstherapie und die Kombinationstherapie aus Östrogen + Vibration und Raloxifen + Vibration zu einer Abnahme des Kapillar-Muskelzellen-Verhältnisses und stützt die Untersuchungen der Arbeitsgruppe von Murfee. Hier wurden Mäuse über sechs Wochen mit einer Frequenz von $45 \mathrm{~Hz}$ vibriert. Es zeigte sich eine signifikante Abnahme des Kapillar-Zell-Verhältnisses am Rand des M. soleus. In der Mitte des Muskels war ebenfalls eine Reduktion des Verhältnisses nachweisbar, sie erwies sich als nicht signifikant (Murfee et al. 2005).

Die Ergebnisse werden weiterhin gestützt durch eine Untersuchung, bei denen bei Ratten durch Bewegungshemmung des Hinterbeins eine Muskelatrophie erzeugt wurde. Auch hier zeigte sich nach Vibration mit $55 \mathrm{~Hz}$ für 20 Minuten täglich über 2 Wochen eine Abnahme des Kapillar-Zell-Verhältnisses in der Vibrationsgruppe gegenüber den gehemmten Ratten ohne Therapie (Kaneguchi et al. 2014).

Das höchste Kapillar-Zell-Verhältnis war beim M. soleus feststellbar. Eine höhere Angiogenese ist hier notwendig, da im Muskel überwiegend oxidative Zellen vorhanden sind (Ariano et al. 1973, Armstrong und Phelps 1984) und somit mehr Sauerstoff für die Muskelarbeit benötigt wird. Der M. soleus gehört zu den langsam kontrahierenden Muskeln, die vor allem der ausdauernden Kontraktion dienen, wofür mehr Sauerstoff benötigt wird. Beim M. gastrocnemius und M. longissimus, die oxidative und glykolytische Zellen (FOG und FG) besitzen (Ariano et al. 1973, Armstrong und Phelps 1984), war das Kapillar-Zell-Verhältnis annähernd gleich. Diese beiden Muskeln gehören zu den schnell kontrahierenden Muskeln und benötigen weniger Sauerstoff. Sie ermüden jedoch auch schneller und sind daher besonders für schnelle und kurze Bewegungen geeignet.

\subsection{ATPase/Diaphorase-Färbung}

Bei der Untersuchung des Durchmessers und der Fläche der drei Muskeln wurden die absoluten Werte ins Verhältnis zum Tiergewicht gesetzt, um hier eine mögliche Fehlerquelle zu beseitigen und nur die Effekte der Therapien im Vergleich zu untersuchen. 
$\underline{\text { OVX }}$

Bevor die Daten ins Verhältnis zum Tiergewicht gesetzt wurden, waren die Durchmesser und die Faserflächen bei allen drei Muskeln und allen Muskelfasern bei den ovarektomierten Tieren nicht signifikant erhöht im Vergleich zu den nichtovarektomierten Tieren. Diese Ergebnisse stimmen mit denen aus früheren Versuchen überein (Stuermer et al. 2010, Komrakova 2013).

Nachdem die Daten mit dem Gewicht der Tiere ins Verhältnis gesetzt worden waren, führte die Ovarektomie bei allen Muskelfasern zu einer Abnahme der Durchmesser und der Faserfläche, die mit Ausnahme des Durchmessers der oxidativen Fasern beim M. soleus und des Durchmessers der glykolytischen Fasern beim M. gastrocnemius jedoch nicht signifikant war. Auch die Untersuchung von Moran et al. zeigte keine signifikanten Änderungen in der Querschnittsfläche der Muskelfasern (Moran et al 2006).

\section{OVX+WBV}

Die alleinige Vibrationstherapie hat in diesem Versuch, mit Ausnahme beim M. soleus, zu einer Abnahme der Faserfläche und des Durchmessers der Zellen gegenüber den ovarektomierten Tieren ohne Therapie geführt, die jedoch nicht signifikant war.

Bei Xie et al. zeigte sich eine signifikante Erhöhung der Fläche der Muskelfasern und des Muskelgewichts beim M. soleus unter Vibrationstherapie bei $45 \mathrm{~Hz}$ für 15 Minuten täglich (Xie et al. 2008). Auch bei unserem Versuch war die Faserfläche und der Durchmesser beim M. soleus vergrößert gegenüber den ovarektomierten Tieren ohne Therapie, allerdings waren diese Ergebnisse nicht signifikant.

Es ist möglich, dass das für diese Arbeit gewählte Vibrationsschema (37 Tage, zweimal täglich für 15 Minuten, $70 \mathrm{~Hz}$, Amplitude 0,4 mm) zu den Unterschieden in den Ergebnissen geführt hat und dass die Ergebnisse mit einem anderen Vibrationsschema anders ausgefallen wären. Generell wurde ein positiver Effekt auf die Muskeln unter Vibrationstherapie in Studien am Tier und Mensch nachgewiesen (Roelants et al. 2004, Russo et al. 2003, Xie et al. 2008). Es ist daher sehr wahrscheinlich, dass die Vibration in diesem Versuch nicht ausreichend oder zu intensiv war. 
Nachdem die Versuchsanordnung für diesen Versuch bereits mit $70 \mathrm{~Hz}$ geplant und durchgeführt war, ließen sich in einem anderen Versuch der Arbeitsgruppe die besten Ergebnisse für Muskelzellen sowie für Knochenzellen bei einer vertikalen Vibration mit $35 \mathrm{~Hz}$ bzw. $50 \mathrm{~Hz}$ nachweisen (Komrakova et al. 2013). So liegt die Vermutung nahe, dass höhere Frequenzen eher zu einer Abschwächung der gewünschten Ergebnisse führt und die Vibration in diesem Versuch zu stark war.

\section{E und E+WBV}

Bevor die Faserfläche und der Faserdurchmesser ins Verhältnis zum Tiergewicht gesetzt wurden, wiesen sie bei den ovarektomierten Tieren und bei den Tieren mit Monotherapie Östrogen annähernd gleiche Werte auf. Diese Werte stimmen mit denen aus einem anderen Versuch überein, bei dem die Wirkung verschiedener Medikamente, wie z. B. Östrogen, auf den M. gastrocnemius bei ovarektomierten Ratten untersucht wurde (Komrakova et al. 2009).

Nachdem der Durchmesser und die Fläche der Muskeln in Bezug zum Tiergewicht gesetzt wurden, zeigten sie bei allen Muskeln unter der Monotherapie mit Östrogen höhere Werte gegenüber den ovarektomierten Tieren ohne Therapie, die allerdings nur beim Durchmesser des M. soleus signifikant waren. In einer Arbeit von McCormick zeigte sich beim M. soleus eine signifikant geringere Fläche bei den Tieren unter Östrogentherapie gegenüber den ovarektomierten Tieren (McCormick et al. 2004), wobei dies absolute Werte waren. Eine mögliche Ursache für die unterschiedlichen Werte wäre die andere Applikationsart, die hier verwendet wurde (Singh et al. 1995). Außerdem wurden die Tiere in dem Versuch dieser Arbeit im Gegensatz zu den Tieren bei McCormicks Versuch osteotomiert. Es ist also denkbar, dass dieser Eingriff ebenfalls Einfluss auf die Muskelzellen hat und dies zu den Unterschieden in den Ergebnissen geführt hat.

Auch die Faserfläche und der Durchmesser zeigten mit Ausnahme des M. soleus keine signifikanten Unterschiede beim Vergleich der ovarektomierten Tiere mit den Tieren unter Kombinationstherapie aus Östrogen + Vibration. Des Weiteren erwies sich der Vergleich zwischen der Mono- und der Kombinationstherapie mit Östrogen als nicht signifikant und ergab keine einheitliche Tendenz, welche Therapie einen größeren Durchmesser oder eine größere Fläche bewirkt. Somit 
liegt die Vermutung nahe, dass keine der beiden Therapiemethoden bei diesem Versuch einen Vorteil gegenüber der anderen besitzt.

Eine Untersuchung der Knochenheilung an der Tibia zeigte zumeist bessere Werte bei den Tieren mit der Monotherapie mit Östrogen gegenüber der Kombinationstherapie mit Östrogen, wobei die Unterschiede minimal und nichtsignifikant waren (Stuermer et al. 2014). Intakte Knochen wurden bisher nicht auf die Osteoporose-Auswirkungen untersucht.

\section{$\underline{\text { RLF und RLF+WBV }}$}

Die Monotherapie mit Raloxifen zeigte, nachdem der Durchmesser und die Faserfläche ins Verhältnis zum Tiergewicht gesetzt worden waren, eine signifikante Erhöhung der Faserfläche beim M. soleus und der Faserfläche der intermediären + oxidativen Zellen beim M. gastrocnemius in der Monotherapie mit Raloxifen gegenüber der Kombinationstherapie mit Raloxifen + Vibration. Generell lässt sich bei den Ergebnissen mit Raloxifen eine Tendenz zu größeren Werten der Faserfläche und des Durchmessers unter Monotherapie feststellen. $\mathrm{Da}$ dies bisher die einzigen Werte sind, die unter einem bestimmten Vibrationsregime ermittelt wurden, sollten weitere Untersuchungen folgen, bei denen diese Werte möglicherweise bestätigt werden.

Bei der Untersuchung der Knochenheilung der Tibia war ebenfalls die Monotherapie mit Raloxifen bei den meisten Parametern besser als die Kombinationstherapie mit Raloxifen+Vibration (Stuermer et al 2014). Aber auch diese Unterschiede waren zumeist gering und nicht-signifikant. Die Auswirkung auf die Osteoporose-Entwicklung wurde bisher nicht untersucht.

Generell ist es möglich, dass die Ergebnisse mit einem anderen Vibrationsschema noch aussagekräftigere Werte in die eine oder andere Richtung geliefert hätten.

\section{E und RLF}

Beim Vergleich der Monotherapie mit Östrogen mit der Monotherapie mit Raloxifen zeigten sich bei keinem Muskel signifikante Unterschiede im Durchmesser und der Muskelfaserfläche.

Die ermittelten Werte zeigen eine Tendenz, dass die Östrogentherapie im Vergleich zur Raloxifentherapie höhere Durchmesser und eine größere Zunahme der Faserfläche bringt. Auch bei der Untersuchung der Tibia waren die 
untersuchten Parameter nicht-signifikant besser unter Monotherapie mit Östrogen gegenüber der mit Raloxifen. Lediglich die Frakturheilung zeigte unter Raloxifentherapie (Mono- und Kombinationstherapie) tendenziell bessere Werte als beide Östrogentherapien, diese waren jedoch nicht signifikant (Stuermer et al. 2014).

\subsection{Schlussfolgerungen für den klinischen Alltag}

Da bei der Definition der Sarkopenie nicht nur die Muskelmasse, sondern auch die Muskelkraft eine wichtige Rolle spielt, ist es notwendig, die untersuchten Muskelparameter diesbezüglich ins Verhältnis zu setzen. Wie oben bereits erwähnt, führte die Untersuchung von Moran et al. zu keiner signifikanten Änderung in der Querschnittsfläche der Muskelfasern nach Ovarektomie. Aber es zeigte sich eine Abschwächung der Beinmuskulatur (Moran et al 2006).

Es ist bisher nicht möglich eine Aussage darüber zu treffen, ob eine Zunahme der Fläche, des Durchmessers oder des Gewichts der Muskeln mit einer Zunahme der Muskelkraft korreliert, da derzeit zuverlässige und eindeutige Untersuchungen diesbezüglich fehlen.

Die Untersuchung des M. psoas major bei Fußballspielern im Vergleich zu gleichaltrigen Nichtsportlern zeigte eine signifikant erhöhte Querschnittsfläche und erhöhte Kraft bei der Hüftflexion (Hoshikawa et al. 2012). Bei Marathonläufern zeigte sich im M. gastrocnemius ein größerer Durchmesser bei den langsamen und schnellen Muskelfasern im Vergleich zu Gelegenheitsläufern (Harber und Trappe 2008). Eine Untersuchung zwischen Sportlern verschiedener Sportarten und Studenten zeigte hingegen keine signifikante Änderung in der Fläche der Muskelfasern, sondern eine prozentuale Zunahme der SO-Fasern (langsam oxidativ) beim M. vastus bei Läufern und beim M. deltoideus bei Kayakfahrern (Tesch und Karlsson 1985). Das Ausdauertraining scheint hier also zu einer Zunahme der Anzahl der SO-Muskelfasern geführt zu haben, die Größe der Fasern aber nicht beeinflusst zu haben. Die Kraft der Sportler wurde in diesem Experiment zwar nicht untersucht, es ist aber davon auszugehen, dass sie höher als die Kraft untrainierter Studenten ist. 
Es ist also möglich, dass die Muskelzellen unter Beanspruchung von schnellen Fasern in langsame Fasern umgewandelt werden, um auf lange Sicht mehr Leistung erbringen zu können. Da diese Umbauprozesse Zeit benötigen, ist es denkbar, dass die Zellen erst einmal an Fläche und Durchmesser zunehmen, um kurzfristig ebenfalls mehr Kraft erzeugen zu können. Bei Ausdauertrainierten ist dieser Unterschied dann nicht mehr sichtbar, sondern nur noch die prozentuale Zunahme an langsamen ausdauernden Muskelfasern.

Die Untersuchung von Tesch und Karlsson zeigte ebenfalls, dass ein hoher BMI mit größeren, schnellen Fasern korreliert. Die Größe der langsamen Fasern und das prozentuale Verhältnis bleiben hingegen gleich (Tesch und Karlsson 1985). Dies würde erklären, weshalb übergewichtige Menschen mehr Kraft haben als normalgewichtige Menschen. Diese Kraft kann aber nur kurzzeitig eingesetzt werden, da sie von kurzen und kräftigen Fasern erzeugt wird. Ein Versuch unter fettreicher Diät zeigte, dass der Prozentsatz an langsamen Fasern bei männlichen Mäusen abnahm. Weibliche Mäuse hingegen besaßen primär schon einen wesentlich höheren Anteil an langsamen Fasern, die unter der fettreichen Diät auch nicht weiter abnahmen. Es zeigte sich aber auch, dass langsame Fasern in Hybridfasern übergingen, die eine Zwischenstufe von langsamen und schnellen Fasern darstellen (DeNies et al. 2014). Die langsamen, ausdauernden Fasern scheinen also in schnelle, kurz kontrahierende Fasern überzugehen und bestätigen somit die Untersuchungen von Tesch und Karlsson am Menschen (Tesch und Karlsson 1985).

Eine Immobilisation zeigte bei Ratten eine Abnahme der Muskelmasse und der Muskelquerschnittsfläche des M. soleus, eine Untersuchung der Muskelkraft erfolgte hier ebenfalls nicht (Hauschka et al. 1987). Allerdings zeigte eine Untersuchung auf einer Intensivstation eine Abnahme der Muskelstärke diverser Muskeln von 10-13 \% (Samosawala et al. 2016). Es ist also davon auszugehen, dass die Größe der Muskelfaserzellen im Zusammenhang mit der Muskelkraft steht. Wie stark dieser Zusammenhang aber tatsächlich ist, sollte Gegenstand zukünftiger Untersuchungen sein. Derzeit fehlen Untersuchungen diesbezüglich, und aufgrund fehlender gut geeigneter Messmethoden der Muskelkraft in Tierexperimenten ist demnächst nicht mit Veröffentlichungen zu dieser Thematik zu rechnen. 
Mit den Ergebnissen dieser Arbeit lassen sich letztendlich nur Aussagen über die Veränderungen unter Vibrationstherapie innerhalb des Versuchszeitraums von 37 Tagen treffen. Wie sich die Therapien langfristig auswirken, kann mit den hier erzielten Ergebnissen nicht prognostiziert werden. Langzeitwirkungen müssen Gegenstand weiterer Untersuchungen sein. Ebenfalls muss in Langzeitstudien untersucht werden, ob die langfristige Anwendung, vor allem der Vibrationstherapie, evtl. sogar negative Folge auf das muskuloskelettale System haben kann.

Die unterschiedlichen Ergebnisse zwischen Tierversuchen und Untersuchungen am Menschen nach Ganzkörpervibration sind eventuell dadurch zu erklären, dass sich die Tiere auf der Vibrationsplattform frei bewegen können und die menschlichen Probanden dazu angehalten sind, auf der Plattform still zu stehen (Edwards und Reilly 2015). Des Weiteren stehen die Tiere mit vier Pfoten auf der Plattform, Menschen hingegen nur mit zwei Beinen. Es ist also möglich, dass durch die größere Auflagefläche bei Tieren die Vibration andere Ergebnisse hervorruft und somit die Ergebnisse nicht 1:1 auf den Menschen übertragbar sind.

Obwohl das Modell der ovarektomierten Ratte in der Erforschung der Osteoporose ein gut erforschtes Modell ist und es viele Parallelen zur postmenopausalen Frau gibt, ist nicht eindeutig geklärt, ob alle Untersuchungen komplett auf den Menschen übertragbar sind. Auch eine Übertragung der Ergebnisse auf Männer ist nicht ausreichend erforscht. Das Geschlechtshormon Testosteron wirkt auf Muskeln und Knochen (Christe und Meier 2015) sowohl direkt über Androgenrezeptoren als auch nach Umwandlung durch Aromatase in Östradiol. Die negative Wirkung auf den Knochen bei der Entstehung der Osteoporose wird vor allem durch den Östrogenmangel erklärt (Bartl 2006). Da die Ersatztherapie von Östrogenen zu einer Verweiblichung führt, werden diese beim Mann nicht eingesetzt. Zur Prävention der Osteoporose bei Männern kann ein Testosteron-Defizit mit einer Ersatzapplikation ausgeglichen werden (Bartl 2006). Studien am Menschen zeigten dabei einen Vorteil für Muskeln und Knochen (Hackett 2016). Bei Ratten wurde ebenfalls ein positiver Effekt auf Knochen nachgewiesen und auch Raloxifen konnte gute Ergebnisse bei der Knochenstabilität vorweisen (Stuermer et al. 2009. Diese waren nicht so gravierend wie die von Östrogen, der Einsatz könnte jedoch eine Alternative zur 
Östrogentherapie darstellen. Aber auch SERMs, wie Raloxifen, werden bei Männern nicht eingesetzt, da die Studienlage unzureichend ist. Zur Therapie bei Männern sind daher derzeit nur Alendronat, Risedronat, Strontiumranelat, Zoledronat und Teriparatid zugelassen (Leitlinie Osteoporose 2014). Selektive Androgenrezeptor-Modulatoren (SARMs) stellen einen neuen Therapie-Ansatz dar, sind aber noch in der experimentellen Erprobung und derzeit nicht zugelassen.

Die Auswirkungen der hier verwendeten Therapiemethoden bei Frauen und Männern sollten daher in Zukunft noch gründlicher untersucht werden.

\subsection{Fazit}

Die alleinige Östrogentherapie ist derzeit aufgrund der negativen Auswirkungen (vgl. Kapitel 1.5.1.1) nur in besonderen Fällen als Mono-Therapie indiziert. Die hier erzielten, teilweise guten Ergebnisse unter Östrogentherapie als Mono- und Kombinationstherapie, bringen keine so viel besseren Ergebnisse, dass der Einsatz von Östrogen unter Inkaufnahme der Risiken gerechtfertigt wäre. Somit wird auch in der Zukunft die Östrogentherapie weiterhin eine eher untergeordnete Rolle in der Therapie der Osteoporose spielen.

Positiv anzumerken ist, dass auch die Raloxifentherapie durchaus gute Ergebnisse vorweisen konnte. Dieser positive Effekt wird nach den Ergebnissen dieser Arbeit durch die Ganzkörpervibration aber abgeschwächt, sodass ein Vorteil der Monotherapie gegenüber der Kombinationstherapie besteht. Es sollten aber weitere Untersuchungen mit anderen Vibrationsschemata erfolgen, bevor eine generelle Ablehnung der Ganzkörpervibration in Kombination mit Raloxifen erfolgt.

Da die Vibrationstherapie ebenfalls einen Ansatz als Präventionsmaßnahme bietet, sollte vor allem auch nach einem Regime gesucht werden, welches in der täglichen Anwendung gut geeignet ist. So stellt vor allem die mehrmalige, tägliche Anwendung einen Punkt dar, der im klinischen Alltag nicht gut praktikabel ist und zu einer geringen Compliance im Langzeitverlauf führen wird.

Auch mögliche negative Auswirkungen bei Langzeittherapien mit Vibration sollten nicht außer Acht gelassen werden und in Zukunft Gegenstand von Untersuchungen sein. 


\section{ZUSAMMENFASSUNG}

Durch den Wandel in der Altersstruktur treten Erkrankungen des höheren Alters immer mehr in den Mittelpunkt unseres Gesundheitssystems. Die Behandlung der Osteoporose nimmt daher einen immer größeren Stellenwert ein. Nach dem Bekanntwerden der Nebenwirkungen der Hormonersatztherapie nehmen Medikamente, wie die SERM, einen beträchtlichen Bestandteil der Osteoporosetherapie ein. $\mathrm{Da}$ die Vibrationstherapie in Untersuchungen bei minimalen Nebenwirkungen einen guten Effekt erzielen konnte, stellt sich die Frage, ob sich der positive Effekt der verwendeten Medikamente durch Vibration noch steigern lässt. Ein Vorteil der Kombinationstherapie bei der Knochenheilung wurde bereits nachgewiesen (Stuermer et al. 2013). Da der Knochen aber nicht allein für die Stabilität unseres Körpers verantwortlich ist, sondern vielmehr das Zusammenspiel aus Knochen und Muskeln eine wichtige Rolle spielt, lag der Fokus dieser Arbeit beim Vergleich wichtiger Muskelparameter unter Monotherapie mit Östrogen, Raloxifen und Vibration gegenüber der Kombinationstherapie mit Östrogen + Vibration und Raloxifen + Vibration.

Hierzu wurden 72 Ratten ovarektomiert, um eine Osteoporose und Sarkopenie zu erzeugen. Zwölf Tiere dienten zur Kontrolle. Nach 53 Tagen wurden alle Ratten einer Osteotomie unterzogen und mit einer Platten-Osteosynthese versorgt. Ab diesem Zeitpunkt wurde das Futter der Medikamentengruppen ersetzt. 24 Tiere erhielten $10 \mathrm{mg} / \mathrm{kg}$ Futter 17ß-Östradiolbenzoate und 24 Tiere $167 \mathrm{mg} / \mathrm{kg}$ Futter Raloxifen als Futterzusatz. Ab Tag 5 nach der Osteosynthese begann die Vibrationstherapie. Hierzu wurden 36 Tiere bei $70 \mathrm{~Hz}$ vertikal zweimal täglich

für 15 Minuten über 37 Tage vibriert. Von diesen Ratten erhielten jeweils 12 Tiere Futter ohne Zusatz, und jeweils 12 Tiere erhielten zusätzlich zur Vibration in ihrem Futter 17ß-Östradiolbenzoate (10 mg/kg Futter) oder Raloxifen (167 mg/kg Futter).

Bei der Untersuchung des Kapillar-Zell-Verhältnisses führte die Ovarektomie der Tiere im Vergleich zur Kontrollgruppe (non-OVX) zu einer Zunahme des Verhältnisses. Bei allen Therapiegruppen (OVX+WBV, E, E+WBV, RLF und $\mathrm{RLF}+\mathrm{WBV}$ ) zeigte sich mit zwei Ausnahmen keine signifikante Veränderung beim Kapillar-Zell-Verhältnis. Lediglich beim $M$. soleus zeigten die alleinige Vibrationstherapie und die Monotherapie mit Östrogen eine signifikante 
Abnahme des Verhältnisses. Diese Ergebnisse stützen und ergänzen bisherige Ergebnisse (Murfee et al. 2005).

Die Monotherapie mit Vibration hat in diesem Versuch keinen positiven Effekt auf die Faserfläche und den Durchmesser der Muskelzellen im Vergleich zu den ovarektomierten Tieren gezeigt. Dieses Ergebnis deckt sich nicht eindeutig mit bisherigen Ergebnissen (Xie et al. 2008). Eine mögliche Ursache könnte das für diese Arbeit gewählte Vibrationsschema sein.

Die höchsten Werte bei der Untersuchung der Faserfläche und des Querschnitts der Muskelzellen zeigten sich in den Östrogen-Gruppen, wobei die Unterschiede zwischen der Monotherapie im Vergleich zur Kombinationstherapie meist nur minimal ausfielen. Auch das Gewicht der Muskeln zeigte die höchsten Werte unter Östrogentherapie (Mono- und Kombinationstherapie). Somit scheint die Östrogentherapie gegenüber der Raloxifen-Therapie einen nicht-signifikanten Vorteil zu haben, wobei hier egal ist, ob die alleinige oder die Kombinationstherapie mit Vibration angewandt wurde.

Da die alleinige Östrogentherapie aufgrund der negativen Auswirkungen (vgl. Kapitel 1.5.1.1) nur in besonderen Fällen als alleinige Therapie indiziert ist, können die hier nachgewiesenen, teilweise guten Ergebnisse unter Östrogentherapie auch in Kombination mit Vibrationstherapie keine so hohen Unterschiede gegenüber der Raloxifentherapie (Mono- und Kombinationstherapie) vorweisen, dass ein vermehrter Einsatz gerechtfertigt wäre. Somit wird die Östrogentherapie auch weiterhin in der Zukunft eher eine untergeordnete Rolle in der Behandlung der Osteoporose spielen.

Der positive Therapieeffekt von Raloxifen wird nach den Ergebnissen der hier durchgeführten Untersuchungen durch die Ganzkörpervibration abgeschwächt. Da diese Ergebnisse jedoch nur beim M. gastrocnemius beim Durchmesser und der Faserfläche bei den oxidativen + intermediären Zellen signifikant waren und für diesen Versuch nur ein Vibrationsschema verwendet wurde, sollten weitere Untersuchungen mit anderen Schemata erfolgen, bevor eine generelle Ablehnung der Ganzkörpervibration in Kombination mit Raloxifen erfolgt. 
Diese Arbeit zeigte aber auch, dass die Behandlung der Osteoporose einen positiven Effekt auf die Muskelzellen, als wichtigen Bestandteil des muskoloskelettalen Systems und dessen Stabilität im Körper, besitzt.

Aufgrund der demographischen Entwicklung sollte der Fokus in der Zukunft aber nicht nur in der Behandlung der Osteoporose, sondern auch in der Früherkennung und Prävention liegen. Hierbei ist die Ganzkörpervibration ein wichtiger Ansatzpunkt. Da die Effekte der Vibration bei verschiedenen Schemata jedoch sehr unterschiedlich ausfallen, sollten diese in Zukunft noch eingehender untersucht werden. Wenn ein geeignetes Schema gefunden wird, wäre die Vibration möglicherweise auch als Präventionsmaßnahme sinnvoll einsetzbar, und die Vibrationstherapie könnte schlussendlich auch eine Unterstützung der Behandlung mit Medikamenten darstellen. 


\section{ANHANG}

\subsection{Abbildungsverzeichnis}

Abb. 1: Algorithmus zur Diagnosestellung der Sarkopenie 6

Abb. 2: Östrogen-Synthese aus Cholesterin 17

Abb. 3: Versuchsablauf 25

Abb. 4: Vibrationseinheit $\quad 27$

Abb. 5: Auszählung der Zellen und Kapillaren in der Amylase-PAS-Färbung 32

Abb. 6: ATPase-/Diaphorase-Färbung, M. longissimus mit drei Zelltypen 33

Abb. 7: ATPase-/Diaphorase-Färbung, M. soleus mit einem Zelltyp 34

Abb. 8: Gewichtsverlauf während des Versuchsablauf 36

Abb. 9: Verlauf der Futteraufnahme während des Versuchsablauf 37

Abb. 10: Muskelgewicht, M. soleus 38

Abb. 11: Muskelgewicht im Verhältnis zum Tiergewicht, M. soleus 39

Abb. 12: Muskelgewicht, M. gastrocnemius $\quad 40$

Abb. 13: Muskelgewicht im Verhältnis zum Tiergewicht, M. gastrocnemius 41

Abb. 14: Kreatininkinase im Serum 42

Abb. 15: Anzahl Kapillaren im Verhältnis zu Muskelfasern, M. soleus $\quad 43$

Abb. 16: Anzahl Kapillaren im Verhältnis zu Muskelfasern, M. longissimus 44

Abb. 17: Anzahl Kapillaren im Verhältnis zu Muskelfasern, M. gastrocnemius 45

Abb. 18: Muskelfaserdurchmesser, M. soleus 47

Abb. 19: Muskelfaserdurchmesser im Verhältnis zum Tiergewicht, M. soleus 48

Abb. 20: Muskelfaserfläche, M. soleus 49

Abb. 21: Muskelfaserfläche im Verhältnis zum Tiergewicht, M. soleus $\quad 50$

Abb. 22: Muskelfaserdurchmesser des FG-Fasertyps, M. longissimus 51

Abb. 23: Muskelfaserdurchmesser des FOG-+SO-Fasertyps, M. longissimus

Abb. 24: Muskelfaserdurchmesser des FG-Fasertyps im Verhältnis zum Tiergewicht, $M$. longissimus

Abb. 25: Muskelfaserdurchmesser des FOG-+SO-Fasertyps im Verhältnis zum Tiergewicht, M. longissimus

Abb. 26: Muskelfaserfläche des FG-Fasertyps, M. longissimus 53

Abb. 27: Muskelfaserfläche des FOG-+SO-Fasertyps, M. longissimus 53

Abb. 28: Muskelfaserfläche des FG-Fasertyps im Verhältnis zum

Tiergewicht, $\mathrm{M}$. longissimus

Abb. 29: Muskelfaserfläche des FOG-+SO-Fasertyps im Verhältnis zum Tiergewicht, M. longissimus 
Abb. 30: Muskelfaserdurchmesser des FG-Fasertyps, M. gastrocnemius

Abb. 31: Muskelfaserdurchmesser des FOG-+SO-Fasertyps, M. gastrocnemius

Abb. 32: Muskelfaserdurchmesser des FG-Fasertyps im Verhältnis zum Tiergewicht, M. gastrocnemius

Abb. 33: Muskelfaserdurchmesser des FOG-+SO-Fasertyps im Verhältnis zum Tiergewicht, M. gastrocnemius

Abb. 34: Muskelfaserfläche des FG-Fasertyps, M. gastrocnemius

Abb. 35: Muskelfaserfläche des FOG-+SO-Fasertyps, M. gastrocnemius

Abb. 36: Muskelfaserfläche des FG-Fasertyps im Verhältnis zum

Tiergewicht, M. gastrocnemius

Abb. 37: Muskelfaserfläche des FOG-+SO-Fasertyps im Verhältnis zum Tiergewicht, M. gastrocnemius 


\subsection{Tabellenverzeichnis}

Tab. 1: Auswahl an Ursachen und Beispielen für Sarkopenie 4

Tab. 2: Einteilung nach WHO-Kriterien 8

Tab. 3: Knochenzelltypen 14

Tab. 4 Kraft und Auswirkung auf den Knochen 15

Tab. 5: Rezeptorvorkommen im Gewebe 18

Tab. 6: Gruppeneinteilung mit Eingriff und Therapie 24

Tab. 7: Nahrungszusätze der Medikamenten-Gruppen 26

Tab. 8: Spritzplan der Farbmarkierungen 28

Tab. 9: Färbeprotokoll für Amylase-PAS-Färbung 29

Tab. 10: Chemikalien-Herstellung für Amylase-PAS-Färbung 29

Tab. 11: Färbeprotokoll für ATPase-/Diaphorase-Färbung 30

Tab. 12: Chemikalien-Herstellung für ATPase-/Diaphorase-Färbung 30

Tab. 13: Verwendete Chemikalien mit Herstellerfirmen 79

Tab. 14: Herstellung der Phosphatpuffer-Lösung 80

Tab. 15: Herstellung der Glycinstammlösung $\quad 80$

Tab. 16: Signifikanzen der Ergebnisse $\quad 81$

Tab. 17: Kreatininkinase im Serum in U/l 81

Tab. 18: Muskelgewichte der einzelnen Muskeln in g 81

Tab. 19: Muskelgewichte im Verhältnis zum Tiergewicht der einzelnen Muskeln $\quad 82$

Tab. 20: Anzahl der Kapillaren im Verhältnis zu den Zellen der einzelnen Muskeln $\quad 82$

Tab. 21: Auswertung der ATPase-/Diaphorase-Färbung, M. soleus 83

Tab. 22: Auswertung der ATPase-/Diaphorase-Färbung, M. gastrocnemius 84

Tab. 23: Auswertung der ATPase-/Diaphorase-Färbung, M. longissimus 85 


\subsection{Verwendete Chemikalien}

Tab. 13: Verwendete Chemikalien mit Herstellerfirmen

\begin{tabular}{|l|l|}
\hline Chemikalie & Firma \\
\hline Ammoniumsulfid & Merck, Darmstadt \\
\hline Amylase & Sigma Aldrich, Seelze \\
\hline ATP & Roth GmbH + Co. KG, Karlsruhe \\
\hline CaCl2-2-hydrat & Fluka-AG, Buchs (Schweiz) \\
\hline Chloroform & Merck, Darmstadt \\
\hline Eisessig & AppliChem GmbH, Darmstadt \\
\hline Essigsäure & AppliChem GmbH, Darmstadt \\
\hline Ethanol & Roth GmbH + Co. KG, Karlsruhe \\
\hline Glycin & AppliChem GmbH, Darmstadt \\
\hline Kaliumchlorid & Merck, Darmstadt \\
\hline Kaliumdisulfid-Lösung & Merck, Darmstadt \\
\hline Kobaltchlorid & AppliChem GmbH, Darmstadt \\
\hline NADH-Dinatriumsalz & AppliChem GmbH, Darmstadt \\
\hline Natriumphosphat & Merck, Darmstadt \\
\hline Nitro-Blaues Tetrazoliumchlorid & Roth GmbH + Co. KG, Karlsruhe \\
\hline Paraformaldehyd & Roth GmbH + Co. KG, Karlsruhe \\
\hline Perjodsäure & Merck, Darmstadt \\
\hline Saccharose & AppliChem GmbH, Darmstadt \\
\hline Salzsäure & Merck, Darmstadt \\
\hline Schiffs Reagenz & Roth GmbH + Co. KG, Karlsruhe \\
\hline Tris & Roth GmbH + Co. KG, Karlsruhe \\
\hline & \\
\hline
\end{tabular}




\subsection{Herstellung der Phosphatpuffer-Lösung und Glycinstammlösung}

Tab. 14: Herstellung der Phosphatpuffer-Lösung

\begin{tabular}{|c|c|c|c|}
\hline \multicolumn{4}{|c|}{$\begin{array}{l}\text { Phosphatpuffer (0.1 M), pH 7,4; } \\
100 \mathrm{ml} \text { Puffer = 15,9 ml Lösung } 1+84,1 \mathrm{ml} \text { Lösung } 2\end{array}$} \\
\hline Lösung 1 & & Lösung 2 & \\
\hline $\begin{array}{l}0.1 \mathrm{M} \text { primärer } \\
\text { Natriumphosphat }\end{array}$ & $18,8 \mathrm{~g}$ & $\begin{array}{l}0.1 \mathrm{M} \text { sekundärer } \\
\text { Natriumphosphat }\end{array}$ & $17,8 \mathrm{~g}$ \\
\hline Aqua dest. & $1000 \mathrm{ml}$ & Aqua dest. & $1000 \mathrm{ml}$ \\
\hline
\end{tabular}

Tab. 15: Herstellung der Glycinstammlösung

\begin{tabular}{|ll|}
\hline Glycinstammlösung \\
\hline Glycin $(\mathrm{M}=75.07 \mathrm{~g} / \mathrm{mol})$ & $7,51 \mathrm{~g}$ \\
\hline Aqua dest & $250 \mathrm{ml}$ \\
\hline
\end{tabular}




\subsection{Ergebnistabellen}

Tab. 16: Signifikanzen der Ergebnisse

\begin{tabular}{|l|l|l|l|l|l|}
\hline $\mathbf{a}$ & non-OVX zu OVX & $\mathbf{h}$ & OVX zu E & $\mathbf{0}$ & $O V X+W B V z u R L F+W B V$ \\
\hline $\mathbf{b}$ & non-OVX zu OVX+WBV & $\mathbf{i}$ & $O V X z u E+W B V$ & $\mathbf{p}$ & $E z u E+W B V$ \\
\hline $\mathbf{c}$ & non-OVX zu E & $\mathbf{j}$ & $O V X z u R L F$ & $\mathbf{q}$ & $E z u R L F$ \\
\hline $\mathbf{d}$ & non-OVX zu E+WBV & $\mathbf{k}$ & $O V X z u R L F+W B V$ & $\mathbf{r}$ & $E z u R L F+W B V$ \\
\hline $\mathbf{e}$ & non-OVX zu RLF & $\mathbf{I}$ & $O V X+W B V z u$ & $\mathbf{s}$ & $E+W B V z u R L F$ \\
\hline $\mathbf{f}$ & non-OVX zu $R L F+W B V$ & $\mathbf{m}$ & $O V X+W B V z u E+W B V$ & $\mathbf{t}$ & $E+W B V z u R L+W B V$ \\
\hline $\mathbf{g}$ & $O V X z u O V X+W B$ & $\mathbf{n}$ & $O V X+W B V z u R L F$ & $\mathbf{u}$ & $R L F z u R L F+W B V$ \\
\hline
\end{tabular}

\subsubsection{Ergebnisse der Kreatininkinase}

Tab. 17: Kreatininkinase im Serum in U/l (Mittelwert \pm SD)

\begin{tabular}{|l|l|l|l|l|l|l|}
\hline Non-OVX & OVX & OVX+WBV & E & E+WBV & RLF & RLF+WBV \\
\hline 8940 & 11004 & 12025 & 10058 & 11172 & 10458 & 10123 \\
\pm 3528 & \pm 3220 & \pm 5070 & \pm 3136 & \pm 5434 & \pm 4468 & \pm 2821 \\
\hline
\end{tabular}

\subsubsection{Ergebnisse der Muskelgewichte}

Tab. 18: Muskelgewichte der einzelnen Muskeln in g (Mittelwert $\pm S D$ )

\begin{tabular}{|l|l|l|l|l|l|l|l|}
\hline Muskel & $\begin{array}{l}\text { Non- } \\
\text { OVX }\end{array}$ & OVX & $\begin{array}{l}\text { OVX+ } \\
\text { WBV }\end{array}$ & E & E+WBV & RLF & RLF+ \\
\hline M. soleus & $\begin{array}{l}0,1217^{\mathrm{d}} \\
\pm 0,0200\end{array}$ & $\begin{array}{l}0,1417 \\
\pm 0,0175\end{array}$ & $\begin{array}{l}0,1345 \\
\pm 0,0170\end{array}$ & $\begin{array}{l}0,1338 \\
\pm 0,0176\end{array}$ & $\begin{array}{l}0,1525^{\mathrm{t}} \\
\pm 0,0226\end{array}$ & $\begin{array}{l}0,1283 \\
\pm 0,0233\end{array}$ & $\begin{array}{l}0,1245 \\
\pm 0,0170\end{array}$ \\
\hline $\begin{array}{l}\text { M. gastro- } \\
\text { cnemius }\end{array}$ & $\begin{array}{l}1,807^{\mathrm{a}, \mathrm{b}} \\
\pm 0,311^{2}\end{array}$ & $\begin{array}{l}2,138^{\mathrm{h}} \\
\pm 0,168\end{array}$ & $\begin{array}{l}2,130^{\prime} \\
\pm 0,171\end{array}$ & $\begin{array}{l}1,784 \\
\pm 0,342\end{array}$ & $\begin{array}{l}1,979 \\
\pm 0,245\end{array}$ & $\begin{array}{l}1,898 \\
\pm 0,203\end{array}$ & $\begin{array}{l}1,863 \\
\pm 0,220\end{array}$ \\
\hline
\end{tabular}




\subsubsection{Ergebnisse der Muskelgewichte im Verhältnis zum Tiergewicht}

Tab. 19: Muskelgewichte im Verhältnis zum Tiergewicht der einzelnen Muskeln (Mittelwert \pm SD)

\begin{tabular}{|c|c|c|c|c|c|c|c|c|}
\hline & & Non-OVX & ovx & OVX+WBV & $\mathbf{E}$ & $E+W B V$ & RLF & RLF+WBV \\
\hline 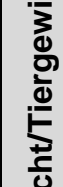 & $\begin{array}{l}\stackrel{0}{\partial} \\
\text { む) } \\
\text { ¿ } \\
\Sigma \\
\Sigma\end{array}$ & $\begin{array}{l}4,39 \times 10^{-4} \\
\pm 6,46 \times 10^{-5}\end{array}$ & $\begin{array}{l}4,13 \times 10^{-4} \\
\pm 5,34 \times 10^{-5}\end{array}$ & $\begin{array}{l}4,00 \times 10^{-4} \mathrm{~m} \\
\pm 4,33 \times 10^{-5}\end{array}$ & $\begin{array}{l}4,51 \times 10^{-4} \\
\pm 4,80 \times 10^{-5}\end{array}$ & $\begin{array}{l}5,06 \times 10^{-4 t} \\
\pm 6,23 \times 10^{-5}\end{array}$ & $\begin{array}{l}4,36 \times 10^{-4} \\
\pm 7,58 \times 10^{-5}\end{array}$ & $\begin{array}{l}4,29 \times 10^{-4} \\
\pm 5,52 \times 10^{-5}\end{array}$ \\
\hline $\begin{array}{l}3 \\
\frac{3}{0} \\
\text { o } \\
\text { d } \\
\text { D } \\
\Sigma\end{array}$ & 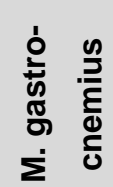 & $\begin{array}{l}6,52 \times 10^{-3} \\
\pm 10,48 \times 10^{-4}\end{array}$ & $\begin{array}{l}6,22 \times 10^{-3} \\
\pm 4,54 \times 10^{-4}\end{array}$ & $\begin{array}{l}6,35 \times 10^{-3} \\
\pm 3,82 \times 10^{-4}\end{array}$ & $\begin{array}{l}5,98 \times 10^{-3} \\
\pm 8,86 \times 10^{-4}\end{array}$ & $\begin{array}{l}6,57 \times 10^{-3} \\
\pm 6,02 \times 10^{-4}\end{array}$ & $\begin{array}{l}6,43 \times 10^{-3} \\
\pm 5,93 \times 10^{-4}\end{array}$ & $\begin{array}{l}6,35 \times 10^{-3} \\
\pm 5,96 \times 10^{-4}\end{array}$ \\
\hline
\end{tabular}

\subsubsection{Ergebnisse der Kapillarfärbung}

Tab. 20: Anzahl der Kapillaren im Verhältnis zu den Zellen der einzelnen Muskeln (Mittelwert \pm SD)

\begin{tabular}{|c|c|c|c|c|c|c|c|}
\hline $\begin{array}{l}\text { Kapillaren/ } \\
\text { Zellen }\end{array}$ & Non-OVX & ovX & OVX+WBV & $E$ & $E+W B V$ & RLF & RLF+WBV \\
\hline M. soleus & $\begin{array}{l}2,097 \\
\pm 0,265\end{array}$ & $\begin{array}{l}2,230 \mathrm{g,h} \\
\pm 0,233\end{array}$ & $\begin{array}{l}1,882 \\
\pm 0,273\end{array}$ & $\begin{array}{l}1,911 \\
\pm 0,225\end{array}$ & $\begin{array}{l}2,055 \\
\pm 0,239\end{array}$ & $\begin{array}{l}1,932 \\
\pm 0,179\end{array}$ & $\begin{array}{l}2,215 \\
\pm 0,274\end{array}$ \\
\hline $\begin{array}{l}\text { M. gastro- } \\
\text { cnemius }\end{array}$ & $\begin{array}{l}1,772^{\mathrm{f}, \mathrm{h}, \mathrm{j}, \mathrm{k}} \\
\pm 0,325\end{array}$ & $\begin{array}{l}1,979 \\
\pm 0,251\end{array}$ & $\begin{array}{l}1,655 \\
\pm 0,408\end{array}$ & $\begin{array}{l}1,494 \\
\pm 0,238\end{array}$ & $\begin{array}{l}1,642 \\
\pm 0,309\end{array}$ & $\begin{array}{l}1,520 \\
\pm 0,257\end{array}$ & $\begin{array}{l}1,392 \\
\pm 0,221\end{array}$ \\
\hline $\begin{array}{l}\text { M. long- } \\
\text { issimus }\end{array}$ & $\begin{array}{l}1,548 \\
\pm 0,207\end{array}$ & $\begin{array}{l}1,733 \\
\pm 0,256\end{array}$ & $\begin{array}{l}1,682 \\
\pm 0,294\end{array}$ & $\begin{array}{l}1,486 \\
\pm 0,166\end{array}$ & $\begin{array}{l}1,768 \\
\pm 0,329\end{array}$ & $\begin{array}{l}1,678 \\
\pm 0,200\end{array}$ & $\begin{array}{l}1,593 \\
\pm 0,285\end{array}$ \\
\hline
\end{tabular}




\subsubsection{Ergebnisse der ATPase-/Diaphorase-Färbung}

Tab. 21: Auswertung der ATPase-/Diaphorase-Färbung, M. soleus (Mittelwert $\pm S D$ )

\begin{tabular}{|c|c|c|c|c|c|c|c|}
\hline & Non-OVX & ovx & OVX+WBV & E & $E+W B V$ & RLF & $R L F+W B V$ \\
\hline $\begin{array}{l}\text { Fläche } \\
\text { in } \mu m^{2}\end{array}$ & $\begin{array}{l}3863 \\
\pm 753,0\end{array}$ & $\begin{array}{l}4116 \\
\pm 788,1\end{array}$ & $\begin{array}{l}4467 \\
\pm 1084\end{array}$ & $\begin{array}{l}4123 \\
\pm 299,8\end{array}$ & $\begin{array}{l}4656^{t} \\
\pm 790,1\end{array}$ & $\begin{array}{l}4118 \\
\pm 1027\end{array}$ & $\begin{array}{l}3533 \\
\pm 436,5\end{array}$ \\
\hline $\begin{array}{l}\text { Fläche/ } \\
\text { Gewicht } \\
\text { in } \mu \mathrm{m}^{2} / \mathrm{g}\end{array}$ & $\begin{array}{l}14,01 \\
\pm 2,797\end{array}$ & $\begin{array}{l}11,92^{i} \\
\pm 2,268\end{array}$ & $\begin{array}{l}13,22 \\
\pm 2,855\end{array}$ & $\begin{array}{l}13,79 \\
\pm 1,172\end{array}$ & $\begin{array}{l}15,57^{t} \\
\pm 3,150\end{array}$ & $\begin{array}{l}13,83 \\
\pm 3,131\end{array}$ & $\begin{array}{l}12,18 \\
\pm 1,597\end{array}$ \\
\hline $\begin{array}{l}\text { Durchmesser } \\
\text { in } \mu \mathrm{m}\end{array}$ & $\begin{array}{l}67,52 \\
\pm 8,836\end{array}$ & $\begin{array}{l}71,72 \\
\pm 6,427\end{array}$ & $\begin{array}{l}71,04 \\
\pm 14,050\end{array}$ & $\begin{array}{l}71,99 \\
\pm 2,598\end{array}$ & $\begin{array}{l}76,32 \\
\pm 6,203\end{array}$ & $\begin{array}{l}68,90 \\
\pm 12,030\end{array}$ & $\begin{array}{l}66,51 \\
\pm 4,165\end{array}$ \\
\hline $\begin{array}{l}\text { Durchmesser/ } \\
\text { Gewicht } \\
\text { in } \mu \mathrm{m} / \mathrm{g}\end{array}$ & $\begin{array}{l}0,2517^{a} \\
\pm 0,0267\end{array}$ & $\begin{array}{l}0,2078^{h, i, j} \\
\pm 0,0192\end{array}$ & $\begin{array}{l}0,2214 \\
\pm 0,0208\end{array}$ & $\begin{array}{l}0,2408 \\
\pm 0,0156\end{array}$ & $\begin{array}{l}0,2548 \\
\pm 0,0298\end{array}$ & $\begin{array}{l}0,2405 \\
\pm 0,0285\end{array}$ & $\begin{array}{l}0,2294 \\
\pm 0,0181\end{array}$ \\
\hline
\end{tabular}


Tab. 22: Auswertung der ATPase-/Diaphorase-Färbung, M. gastrocnemius (Mittelwert \pm SD)

\begin{tabular}{|c|c|c|c|c|c|c|c|c|}
\hline & & Non-OVX & OVX & OVX+WBV & $\mathbf{E}$ & E+WBV & RLF & RLF+WBV \\
\hline \multirow{4}{*}{ 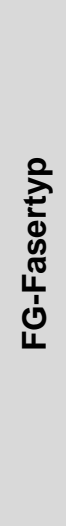 } & $\begin{array}{l}\text { Fläche } \\
\text { in } \mu \mathrm{m}^{2}\end{array}$ & $\begin{array}{l}4614 \\
\pm 995,8\end{array}$ & $\begin{array}{l}5395 \\
\pm 914,1\end{array}$ & $\begin{array}{l}4440 \\
\pm 612,9\end{array}$ & $\begin{array}{l}4667 \\
\pm 1161\end{array}$ & $\begin{array}{l}4377 \\
\pm 802,3\end{array}$ & $\begin{array}{l}5171 \\
\pm 981,9\end{array}$ & $\begin{array}{l}4692 \\
\pm 929,7\end{array}$ \\
\hline & $\begin{array}{l}\text { Fläche/Gewicht } \\
\text { in } \mu \mathrm{m}^{2} / \mathrm{g}\end{array}$ & $\begin{array}{l}16,67 \\
\pm 3,812\end{array}$ & $\begin{array}{l}15,64^{j} \\
\pm 2,560\end{array}$ & $\begin{array}{l}13,17 \\
\pm 1,718\end{array}$ & $\begin{array}{l}15,67 \\
\pm 4,018\end{array}$ & $\begin{array}{l}14,35 \\
\pm 2,385\end{array}$ & $\begin{array}{l}17,58 \\
\pm 3,213\end{array}$ & $\begin{array}{l}15,85 \\
\pm 3,077\end{array}$ \\
\hline & $\begin{array}{l}\text { Durchmesser } \\
\text { in } \mu \mathrm{m}\end{array}$ & $\begin{array}{l}75,76 \\
\pm 8,146\end{array}$ & $\begin{array}{l}81,98 \\
\pm 6,815\end{array}$ & $\begin{array}{l}74,43 \\
\pm 5,183\end{array}$ & $\begin{array}{l}75,99 \\
\pm 10,090\end{array}$ & $\begin{array}{l}73,94 \\
\pm 6,800\end{array}$ & $\begin{array}{l}80,09 \\
\pm 7,602\end{array}$ & $\begin{array}{l}76,43 \\
\pm 7,639\end{array}$ \\
\hline & $\begin{array}{l}\text { Durchmesser/Gewicht } \\
\text { in } \mu \mathrm{m} / \mathrm{g}\end{array}$ & $\begin{array}{l}0,2736^{a, b} \\
\pm 0,0349\end{array}$ & $\begin{array}{l}0,2379 \\
\pm 0,0198\end{array}$ & $\begin{array}{l}0,2211^{1, j, k} \\
\pm 0,0163\end{array}$ & $\begin{array}{l}0,2552 \\
\pm 0,0366\end{array}$ & $\begin{array}{l}0,2429 \\
\pm 0,0205\end{array}$ & $\begin{array}{l}0,2726 \\
\pm 0,0260\end{array}$ & $\begin{array}{l}0,2605 \\
\pm 0,0243\end{array}$ \\
\hline \multirow{4}{*}{ 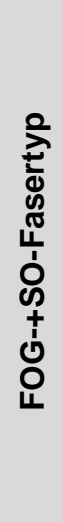 } & $\begin{array}{l}\text { Fläche } \\
\text { in } \mu \mathrm{m}^{2}\end{array}$ & $\begin{array}{l}1870^{e} \\
\pm 267,2\end{array}$ & $\begin{array}{l}2263 \\
\pm 364,9\end{array}$ & $\begin{array}{l}2119 \\
\pm 320,4\end{array}$ & $\begin{array}{l}2074 \\
\pm 329,3\end{array}$ & $\begin{array}{l}2340 \\
\pm 494,1\end{array}$ & $\begin{array}{l}2396^{u} \\
\pm 476,1\end{array}$ & $\begin{array}{l}1945 \\
\pm 258,1\end{array}$ \\
\hline & $\begin{array}{c}\text { Fläche/Gewicht } \\
\text { in } \mu \mathrm{m}^{2} / g\end{array}$ & $\begin{array}{l}6,735 \\
\pm 0,956\end{array}$ & $\begin{array}{l}6,559 \\
\pm 1,028\end{array}$ & $\begin{array}{l}6,288^{n} \\
\pm 0,894\end{array}$ & $\begin{array}{l}6,939 \\
\pm 1,000\end{array}$ & $\begin{array}{l}7,700 \\
\pm 1,630\end{array}$ & $\begin{array}{l}8,116^{u} \\
\pm 1,635\end{array}$ & $\begin{array}{l}6,065 \\
\pm 2,008\end{array}$ \\
\hline & $\begin{array}{l}\text { Durchmesser } \\
\text { in } \mu \mathrm{m}\end{array}$ & $\begin{array}{l}48,23 \text { e } \\
\pm 3,456\end{array}$ & $\begin{array}{l}52,93 \\
\pm 4,433\end{array}$ & $\begin{array}{l}51,33 \\
\pm 4,039\end{array}$ & $\begin{array}{l}50,73 \\
\pm 4,097\end{array}$ & $\begin{array}{l}53,89 \\
\pm 5,706\end{array}$ & $\begin{array}{l}54,27 \text { u } \\
\pm 5,029\end{array}$ & $\begin{array}{l}49,10 \\
\pm 3,289\end{array}$ \\
\hline & $\begin{array}{l}\text { Durchmesser/Gewicht } \\
\text { in } \mu \mathrm{m} / \mathrm{g}\end{array}$ & $\begin{array}{l}0,1739 \\
\pm 0,0136\end{array}$ & $\begin{array}{l}0,1567^{j} \\
\pm 0,0132\end{array}$ & $\begin{array}{l}0,1525^{m, n, o} \\
\pm 0,0120\end{array}$ & $\begin{array}{l}0,1701 \\
\pm 0,0132\end{array}$ & $\begin{array}{l}0,1774 \\
\pm 0,0210\end{array}$ & $\begin{array}{l}0,1848 \\
\pm 0,0184\end{array}$ & $\begin{array}{l}0,1754 \\
\pm 0,0295\end{array}$ \\
\hline
\end{tabular}


Tab. 23: Auswertung der ATPase-/Diaphorase-Färbung, M. longissimus (Mittelwert $\pm S D$ )

\begin{tabular}{|c|c|c|c|c|c|c|c|c|}
\hline & & Non-OVX & OVX & OVX+WBV & $\mathbf{E}$ & E+WBV & RLF & RLF+WBV \\
\hline \multirow{4}{*}{ 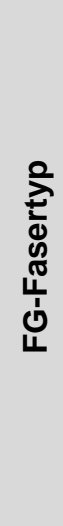 } & $\begin{array}{l}\text { Fläche } \\
\text { in } \mu \mathrm{m}^{2}\end{array}$ & $\begin{array}{l}5413 \\
\pm 1290\end{array}$ & $\begin{array}{l}6006 \\
\pm 1228\end{array}$ & $\begin{array}{l}4962 \\
\pm 1356\end{array}$ & $\begin{array}{l}5555 \\
\pm 1287\end{array}$ & $\begin{array}{l}5597 \\
\pm 718\end{array}$ & $\begin{array}{l}5309 \\
\pm 1622\end{array}$ & $\begin{array}{l}4824 \\
\pm 1084\end{array}$ \\
\hline & $\begin{array}{l}\text { Fläche/ Gewicht } \\
\text { in } \mu \mathrm{m}^{2} / \mathrm{g}\end{array}$ & $\begin{array}{l}19,24 \\
\pm 5,167\end{array}$ & $\begin{array}{l}17,19 \\
\pm 3,472\end{array}$ & $\begin{array}{l}14,66 \\
\pm 3,780\end{array}$ & $\begin{array}{l}18,81 \\
\pm 4,773\end{array}$ & $\begin{array}{l}18,85 \\
\pm 2,691\end{array}$ & $\begin{array}{l}18,09 \\
\pm 5,387\end{array}$ & $\begin{array}{l}16,55 \\
\pm 3,249\end{array}$ \\
\hline & $\begin{array}{l}\text { Durchmesser } \\
\text { in } \mu \mathrm{m}\end{array}$ & $\begin{array}{l}81,91 \\
\pm 9,411\end{array}$ & $\begin{array}{l}86,46 \\
\pm 9,238\end{array}$ & $\begin{array}{l}78,34 \\
\pm 11,300\end{array}$ & $\begin{array}{l}82,98 \\
\pm 9,089\end{array}$ & $\begin{array}{l}83,71 \\
\pm 5,210\end{array}$ & $\begin{array}{l}80,86 \\
\pm 12,630\end{array}$ & $\begin{array}{l}77,03 \\
\pm 8,344\end{array}$ \\
\hline & $\begin{array}{l}\text { Durchmesser/Gewicht } \\
\text { in } \mu \mathrm{m} / \mathrm{g}\end{array}$ & $\begin{array}{l}0,2924 \mathrm{~b} \\
\pm 0,0417\end{array}$ & $\begin{array}{l}0,2476 \\
\pm 0,0264\end{array}$ & $\begin{array}{l}0,2322 \mathrm{l}, \mathrm{m} \\
\pm 0,0302\end{array}$ & $\begin{array}{l}0,2804 \\
\pm 0,0384\end{array}$ & $\begin{array}{l}0,2819 \\
\pm 0,0237\end{array}$ & $\begin{array}{l}0,2759 \\
\pm 0,0421\end{array}$ & $\begin{array}{l}0,2652 \\
\pm 0,0237\end{array}$ \\
\hline \multirow{4}{*}{ 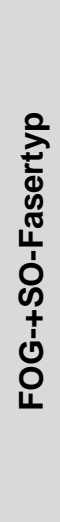 } & $\begin{array}{l}\text { Fläche } \\
\text { in } \mu \mathrm{m}^{2}\end{array}$ & $\begin{array}{l}2105 \\
\pm 527,6\end{array}$ & $\begin{array}{l}2484 \\
\pm 685,5\end{array}$ & $\begin{array}{l}1875 \\
\pm 551,5\end{array}$ & $\begin{array}{l}2378 \\
\pm 791,8\end{array}$ & $\begin{array}{l}2197 \\
\pm 590,3\end{array}$ & $\begin{array}{l}1846 \\
\pm 659,7\end{array}$ & $\begin{array}{l}1768 \\
\pm 267,8\end{array}$ \\
\hline & $\begin{array}{l}\text { Fläche/ Gewicht } \\
\text { in } \mu \mathrm{m}^{2} / \mathrm{g}\end{array}$ & $\begin{array}{l}7,385 \\
\pm 1,996\end{array}$ & $\begin{array}{l}7,098 \\
\pm 1,913\end{array}$ & $\begin{array}{l}5,532 \\
\pm 1,551\end{array}$ & $\begin{array}{l}8,047 \\
\pm 2,810\end{array}$ & $\begin{array}{l}7,375 \\
\pm 1,913\end{array}$ & $\begin{array}{l}6,509 \\
\pm 2,257\end{array}$ & $\begin{array}{l}6,093 \\
\pm 0,901\end{array}$ \\
\hline & Durchmesser in $\mu \mathrm{m}$ & $\begin{array}{l}51,81 \\
\pm 8,452\end{array}$ & $\begin{array}{l}55,25 \\
\pm 8,007\end{array}$ & $\begin{array}{l}47,88 \\
\pm 7,394\end{array}$ & $\begin{array}{l}53,59 \\
\pm 8,235\end{array}$ & $\begin{array}{l}51,77 \\
\pm 6,314\end{array}$ & $\begin{array}{l}47,36 \\
\pm 8,507\end{array}$ & $\begin{array}{l}46,80 \\
\pm 3,476\end{array}$ \\
\hline & $\begin{array}{l}\text { Durch-messer/Gewicht } \\
\text { in } \mu \mathrm{m} / \mathrm{g}\end{array}$ & $\begin{array}{l}0,1845^{b} \\
\pm 0,0349\end{array}$ & $\begin{array}{l}0,1618 \\
\pm 0,0209\end{array}$ & $\begin{array}{l}0,1418 \\
\pm 0,0193\end{array}$ & $\begin{array}{l}0,1810 \\
\pm 0,0312\end{array}$ & $\begin{array}{l}0,1740 \\
\pm 0,0204\end{array}$ & $\begin{array}{l}0,1619 \\
\pm 0,0309\end{array}$ & $\begin{array}{l}0,1615 \\
\pm 0,0134\end{array}$ \\
\hline
\end{tabular}




\section{LITERATURVERZEICHNIS}

Agnusdei D, lori N (2000): Raloxifene: results from the MORE study. J Musculoskelet Neuronal Interact 1, 127-132

Andersen P (1975): Capillary density in skeletal muscle of man. Acta Physiol

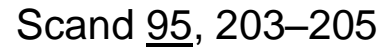

Anderson GL, Limacher M, Assaf AR, Bassford T, Beresford SAA, Black $H$, Bonds D, Brunner R, Brzyski R, Caan B, et al. (2004): Effects of conjugated equine estrogen in postmenopausal women with hysterectomy: the Women's Health Initiative randomized controlled trial. JAMA 291, 1701-1712

Ariano MA, Armstrong RB, Edgerton VR (1973): Hindlimb muscle fiber populations of five mammals. J Histochem Cytochem 21, 51-55

Armstrong RB, Phelps RO (1984): Muscle fiber type composition of the rat hindlimb. Am J Anat 171, 259-272

Aust G, Aumüller G, Kirsch J, Conrad A, Engele J: Duale Reihe Anatomie. Thieme, Stuttgart 2014

Bahat G, Tufan A, Tufan F, Kilic C, Akpinar TS, Kose M, Erten N, Karan MA, Cruz-Jentoft AJ (2016): Cut-off points to identify sarcopenia according to European Working Group on Sarcopenia in Older People (EWGSOP) definition. Clin Nutr 35, 1557-1563

Bainbridge KE, Sowers M, Crutchfield M, Lin X, Jannausch M, Harlow SD (2002): Natural History of Bone Loss over 6 Years among Premenopausal and Early Postmenopausal Women. Am J Epidemiol 156, 410-417

Baird MF, Graham SM, Baker JS, Bickerstaff GF (2012): Creatine-kinase- and exercise-related muscle damage implications for muscle performance and recovery. J Nutr Metab 2012, 960363

Baltgalvis KA, Greising SM, Warren GL, Lowe DA (2010): Estrogen regulates estrogen receptors and antioxidant gene expression in mouse skeletal muscle. PLoS ONE $\underline{5}$, e10164

Barlet JP, Coxam V, Davicco MJ, Gaumet N (1994): [Animal models of postmenopausal osteoporosis]. Reprod Nutr Dev $\underline{34}, 221-236$

Barrett-Connor E, Grady D, Sashegyi A, Anderson PW, Cox DA, Hoszowski K, Rautaharju P, Harper KD, MORE Investigators (Multiple Outcomes of Raloxifene Evaluation) (2002): Raloxifene and cardiovascular events in osteoporotic postmenopausal women: four-year results from the MORE (Multiple Outcomes of Raloxifene Evaluation) randomized trial. JAMA 287, 847-857

Barrett-Connor E, Mosca L, Collins P, Geiger MJ, Grady D, Kornitzer M, McNabb MA, Wenger NK, Raloxifene Use for The Heart (RUTH) Trial Investigators (2006): Effects of raloxifene on cardiovascular events and breast cancer in postmenopausal women. N Engl J Med 355, 125-137

Bartl R: Osteoporose: Prävention, Diagnostik, Therapie. 4. Auflage; Thieme, Stuttgart; New York, 2011 
Bautmans I, Van Hees E, Lemper J-C, Mets T (2005): The feasibility of whole body vibration in institutionalised elderly persons and its influence on muscle performance, balance and mobility: a randomised controlled trial [ISRCTN62535013]. BMC Geriatr $\underline{5}, 17$

Beaudart C, Gillain S, Petermans J, Reginster JY, Bruyère O (2014): [Sarcopenia: what's new in 2014]. Rev Med Liege 69, 251-257

Behrends J, Bischofberger J, Deutzmann R, Ehmke H, Frings S: Duale Reihe Physiologie. 2. Auflage; Thieme, Stuttgart 2012

Benninghoff A, Drenckhahn D: Anatomie: Makroskopische Anatomie, Histologie, Embryologie, Zellbiologie. Band 1: Zelle, Gewebe, Entwicklung, Skelett- und Verdauungssystem, Harn- und Genitalsystem. 17. Auflage; Urban \& Fischer Verlag/Elsevier GmbH, München u. a. 2008

Beral V, Bull D, Reeves G, Million Women Study Collaborators (2005): Endometrial cancer and hormone-replacement therapy in the Million Women Study. Lancet $\underline{365}, 1543-1551$

Bollheimer LC, Buettner R, Pongratz G, Brunner-Ploss R, Hechtl C, Banas M, Singler K, Hamer OW, Stroszczynski C, Sieber CC, Fellner C (2012): Sarcopenia in the aging high-fat fed rat: a pilot study for modeling sarcopenic obesity in rodents. Biogerontology $\underline{13}, 609-620$

Bowen TS, Schuler G, Adams V (2015): Skeletal muscle wasting in cachexia and sarcopenia: molecular pathophysiology and impact of exercise training. J Cachexia Sarcopenia Muscle $\underline{6}$, 197-207

Brooks SV, Faulkner JA (1988): Contractile properties of skeletal muscles from young, adult and aged mice. J Physiol (Lond) 404, 71-82

Bundesministerium für Arbeit und Soziales (2005): Merkblatt zur Berufskrankheit Nr. 2110

https://www.baua.de/DE/Angebote/Rechtstexte-und-Technische-

Regeln/Berufskrankheiten/pdf/Merkblatt-

2110.pdf;jsessionid=3D25436381D7123ECDCF34D44A0FD009.s2t1

?_blob=publicationFile $\& v=3$

(abgerufen am 27.05.2017)

Bunratsami S, Udomuksorn W, Kumarnsit E, Vongvatcharanon S, Vongvatcharanon U (2015): Estrogen replacement improves skeletal muscle performance by increasing parvalbumin levels in ovariectomized rats. Acta Histochem 117, 163-175

Burger EH, Klein-Nulend J (1999): Mechanotransduction in bone--role of the lacuno-canalicular network. FASEB J 13 Suppl, S101-112

Chen X, Mao G, Leng SX (2014): Frailty syndrome: an overview. Clin Interv Aging $\underline{9}, 433-441$

Chiu C-S, Weber H, Adamski S, Rauch A, Gentile MA, Alves SE, Kath G, Flores O, Wilkinson HA (2011): Non-invasive muscle contraction assay to study rodent models of sarcopenia. BMC Musculoskelet Disord $\underline{12}$, 246

Cho SH, Kim JH, Song W (2016): In Vivo Rodent Models of Skeletal Muscle Adaptation to Decreased Use. Endocrinol Metab (Seoul) 31, 31-37 
Christe N, Meier CA (2015): Hypotestosteronaemia in the aging male: should we treat it? Swiss Med Wkly $\underline{145}$, w14216

Collins CA, Olsen I, Zammit PS, Heslop L, Petrie A, Partridge TA, Morgan JE (2005): Stem cell function, self-renewal, and behavioral heterogeneity of cells from the adult muscle satellite cell niche. Cell 122, 289-301

Cook J (1989): Nathan Shock, Pioneer on Aging. The New York Times, 15.11.1989

Cooper C (1997): The crippling consequences of fractures and their impact on quality of life. Am J Med 103, 12S-17S; discussion 17S-19S

Couse JF, Lindzey J, Grandien K, Gustafsson J-Å, Korach KS (1997): Tissue Distribution and Quantitative Analysis of Estrogen Receptor- $\alpha(E R \alpha)$ and Estrogen Receptor- $\beta$ (ER $\beta)$ Messenger Ribonucleic Acid in the Wild-Type and ERa-Knockout Mouse. Endocrinology 138, 4613-4621

Cruz-Jentoft AJ, Baeyens JP, Bauer JM, Boirie Y, Cederholm T, Landi F, Martin FC, Michel J-P, Rolland Y, Schneider SM, et al. (2010): Sarcopenia: European consensus on definition and diagnosis Report of the European Working Group on Sarcopenia in Older People. Age Ageing $\underline{39}, 412-423$

Cruz-Jentoft AJ, Landi F, Schneider SM, Zúñiga C, Arai H, Boirie Y, Chen L-K, Fielding RA, Martin FC, Michel J-P, et al. (2014): Prevalence of and interventions for sarcopenia in ageing adults: a systematic review. Report of the International Sarcopenia Initiative (EWGSOP and IWGS). Age Ageing 43, 748-759

Cui J, Shen Y, Li R (2013): Estrogen synthesis and signaling pathways during aging: from periphery to brain. Trends Mol Med 19, 197-209

Cummings SR, Nevitt MC, Browner WS, Stone K, Fox KM, Ensrud KE, Cauley J, Black D, Vogt TM (1995): Risk factors for hip fracture in white women. Study of Osteoporotic Fractures Research Group. N Engl J Med 332, 767-773

DVO-Leitlinie 2014 zur Prophylaxe, Diagnostik und Therapie der Osteoporose bei Männern ab dem 60. Lebensjahr und bei postmenopausalen Frauen

Dahlman-Wright K, Cavailles V, Fuqua SA, Jordan VC, Katzenellenbogen JA, Korach KS, Maggi A, Muramatsu M, Parker MG, Gustafsson J-A (2006): International Union of Pharmacology. LXIV. Estrogen receptors. Pharmacol Rev $\underline{58}$, 773-781

DeNies MS, Johnson J, Maliphol AB, Bruno M, Kim A, Rizvi A, Rustici K, Medler $S$ (2014): Diet-induced obesity alters skeletal muscle fiber types of male but not female mice. Physiol Rep $\underline{2}$

Dieli-Conwright CM, Spektor TM, Rice JC, Todd Schroeder E (2009): Oestradiol and SERM treatments influence oestrogen receptor coregulator gene expression in human skeletal muscle cells. Acta Physiol (Oxf) 197, 187-196

Duncan RL, Turner CH (1995): Mechanotransduction and the functional response of bone to mechanical strain. Calcif Tissue Int $\underline{57}, 344-358$ 
Edwards JH, Reilly GC (2015): Vibration stimuli and the differentiation of musculoskeletal progenitor cells: Review of results in vitro and in vivo. World J Stem Cells ㄱ, 568-582

Frost HM (1987): Bone „mass“ and the „mechanostat“: a proposal. Anat Rec $\underline{219}$, $1-9$

Frost HM, Jee WS (1992): On the rat model of human osteopenias and osteoporoses. Bone Miner 18, 227-236

Fuller K, Chambers TJ (1989): Effect of arachidonic acid metabolites on bone resorption by isolated rat osteoclasts. J Bone Miner Res 4, 209-215

Gesundheit und Krankheit im Alter (2009). Robert Koch-Institut: http://www.rki.de/DE/Content/Gesundheitsmonitoring/Gesundheitsbe richterstattung/GBEDownloadsB/alter_gesundheit.pdf?_blob=public ationFile (abgerufen am 25.05.2017)

Gibson MC, Schultz E (1983): Age-related differences in absolute numbers of skeletal muscle satellite cells. Muscle Nerve $\underline{6}, 574-580$

Gojanovic B, Feihl F, Liaudet L, Gremion G, Waeber B (2011): Whole-body vibration training elevates creatine kinase levels in sedentary subjects. Swiss Med Wkly 141, w13222

Guralnik JM, Simonsick EM, Ferrucci L, Glynn RJ, Berkman LF, Blazer DG, Scherr PA, Wallace RB (1994): A short physical performance battery assessing lower extremity function: association with self-reported disability and prediction of mortality and nursing home admission. $J$ Gerontol 49, M85-94

Hackett G (2016): An update on the role of testosterone replacement therapy in the management of hypogonadism. Ther Adv Urol $\underline{8}, 147-160$

Hadji P, Klein S, Gothe H, Häussler B, Kless T, Schmidt T, Steinle T, Verheyen F, Linder R (2013): The epidemiology of osteoporosis--Bone Evaluation Study (BEST): an analysis of routine health insurance data. Dtsch Arztebl Int 110, 52-57

Harber M, Trappe S (2008): Single muscle fiber contractile properties of young competitive distance runners. J Appl Physiol 105, 629-636

Hauschka EO, Roy RR, Edgerton VR (1987): Size and metabolic properties of single muscle fibers in rat soleus after hindlimb suspension. J Appl Physiol $\underline{62}, 2338-2347$

Hersh AL, Stefanick ML, Stafford RS (2004): National use of postmenopausal hormone therapy: annual trends and response to recent evidence. JAMA 291, 47-53

Hojo Y, Higo S, Kawato S, Hatanaka Y, Ooishi Y, Murakami G, Ishii H, Komatsuzaki Y, Ogiue-lkeda M, Mukai H, Kimoto T (2011): Hippocampal Synthesis of Sex Steroids and Corticosteroids: Essential for Modulation of Synaptic Plasticity. Front Endocrinol 2, 43

Horak V (1983): A successive histochemical staining for succinate dehydrogenase and "reversed"-ATPase in a single section for the skeletal muscle fibre typing. Histochemistry $\underline{78}, 545-553$ 
Hoshikawa Y, lida T, li N, Muramatsu M, Nakajima Y, Chumank K, Kanehisa H (2012): Cross-sectional area of psoas major muscle and hip flexion strength in youth soccer players. Eur J Appl Physiol 112, 3487-3494

Jacobsen DE, Samson MM, Emmelot-Vonk MH, Verhaar HJJ (2010): Raloxifene and body composition and muscle strength in postmenopausal women: a randomized, double-blind, placebo-controlled trial. Eur $\mathrm{J}$ Endocrinol 162, 371-376

Jankovich JP (1972): The effects of mechanical vibration on bone development in the rat. J Biomech $\underline{5}, 241-250$

Johnell O, Kanis JA, Odén A, Sernbo I, Redlund-Johnell I, Petterson C, De Laet C, Jönsson B (2004): Fracture risk following an osteoporotic fracture. Osteoporos Int 15, 175-179

Kalu DN (1991): The ovariectomized rat model of postmenopausal bone loss. Bone Miner $\underline{15}$, 175-191

Kaneguchi A, Ozawa J, Kawamata S, Kurose T, Yamaoka K (2014): Intermittent whole-body vibration attenuates a reduction in the number of the capillaries in unloaded rat skeletal muscle. BMC Musculoskelet Disord $\underline{15}$

Kerschan-Schindl K (2012): Das Mechanostat-Modell. J Miner Stoffwechs $\underline{19}$, 159-162

Kim TN, Choi KM (2013): Sarcopenia: Definition, Epidemiology, and Pathophysiology. J Bone Metab 20, 1-10

Klein-Nulend J, van der Plas A, Semeins CM, Ajubi NE, Frangos JA, Nijweide PJ, Burger EH (1995): Sensitivity of osteocytes to biomechanical stress in vitro. FASEB J $\underline{9}, 441-445$

Komrakova M, Werner C, Wicke M, Nguyen BT, Sehmisch S, Tezval M, Stuermer KM, Stuermer EK (2009): Effect of daidzein, 4-methylbenzylidene camphor or estrogen on gastrocnemius muscle of osteoporotic rats undergoing tibia healing period. J Endocrinol 201, 253-262

Komrakova M, Krischek C, Wicke M, Sehmisch S, Tezval M, Rohrberg M, Brandsch T, Stuermer KM, Stuermer EK (2011): Influence of intermittent administration of parathyroid hormone on muscle tissue and bone healing in orchiectomized rats or controls. J Endocrinol 209, 9-19

Komrakova M, Sehmisch S, Tezval M, Ammon J, Lieberwirth P, Sauerhoff C, Trautmann L, Wicke M, Dullin C, Stuermer KM, Stuermer EK (2013): Identification of a vibration regime favorable for bone healing and muscle in estrogen-deficient rats. Calcif Tissue Int $\underline{92}, 509-520$

Konnopka A, Jerusel N, König H-H (2009): The health and economic consequences of osteopenia- and osteoporosis-attributable hip fractures in Germany: estimation for 2002 and projection until 2050. Osteoporos Int 20, 1117-1129 
Kyriakides ZS, Petinakis $P$, Kaklamanis L, Sbarouni E, Karayannakos P, Iliopoulos D, Dontas I, Kremastinos DT (2001): Intramuscular administration of estrogen may promote angiogenesis and perfusion in a rabbit model of chronic limb ischemia. Cardiovasc Res $\underline{49}, 626-$ 633

Lang T, Streeper T, Cawthon P, Baldwin K, Taaffe DR, Harris TB (2010): Sarcopenia: etiology, clinical consequences, intervention, and assessment. Osteoporos Int 21, 543-559

Lauretani F, Russo CR, Bandinelli S, Bartali B, Cavazzini C, lorio AD, Corsi AM, Rantanen T, Guralnik JM, Ferrucci L (2003): Age-associated changes in skeletal muscles and their effect on mobility: an operational diagnosis of sarcopenia. J Appl Physiol 95, 1851-1860

Lemoine S, Granier P, Tiffoche C, Rannou-Bekono F, Thieulant M-L, Delamarche $P$ (2003): Estrogen receptor alpha mRNA in human skeletal muscles. Med Sci Sports Exerc 35, 439-443

Leitlinie Osteoporose: siehe DVO-Leitlinie 2014

Lin JT, Lane JM (2004): Osteoporosis: a review. Clin Orthop Relat Res $\underline{425}, 126-$ 134

Lowe DA, Surek JT, Thomas DD, Thompson LV (2001): Electron paramagnetic resonance reveals age-related myosin structural changes in rat skeletal muscle fibers. Am J Physiol, Cell Physiol 280, C540-547

Lüllmann-Rauch R: Taschenlehrbuch Histologie. 3., vollständig überarbeitete Auflage; Thieme, Stuttgart; New York, 2009

Mahmood S, Taher M, Mandal UK (2014): Experimental design and optimization of raloxifene hydrochloride loaded nanotransfersomes for transdermal application. Int J Nanomedicine $\underline{9}$, 4331-4346

Maurel DB, Boisseau N, Benhamou CL, Jaffre C (2012): Alcohol and bone: review of dose effects and mechanisms. Osteoporos Int 23, 1-16

McCormick KM, Burns KL, Piccone CM, Gosselin LE, Brazeau GA (2004): Effects of ovariectomy and estrogen on skeletal muscle function in growing rats. J Muscle Res Cell Motil 25, 21-27

Million Women Study Collaborators (2003): Breast cancer and hormonereplacement therapy in the Million Women Study. Lancet $\underline{362}$, 419427

Misra M, Klibanski A (2011): Bone health in anorexia nervosa. Curr Opin Endocrinol Diabetes Obes $\underline{18}, 376-382$

Moran AL, Warren GL, Lowe DA (2006): Removal of ovarian hormones from mature mice detrimentally affects muscle contractile function and myosin structural distribution. J Appl Physiol 100, 548-559

Moran AL, Nelson SA, Landisch RM, Warren GL, Lowe DA (2007): Estradiol replacement reverses ovariectomy-induced muscle contractile and myosin dysfunction in mature female mice. J Appl Physiol 102, 13871393 
Morley JE, Anker SD, von Haehling S (2014): Prevalence, incidence, and clinical impact of sarcopenia: facts, numbers, and epidemiology-update 2014. J Cachexia Sarcopenia Muscle $\underline{5}, 253-259$

Murfee WL, Hammett LA, Evans C, Xie L, Squire M, Rubin C, Judex S, Skalak TC (2005): High-frequency, low-magnitude vibrations suppress the number of blood vessels per muscle fiber in mouse soleus muscle. $J$ Appl Physiol 98, 2376-2380

Naghii MR, Ghanizadeh G, Darvishi P, Ebrahimpour Y, Mofid M, Torkaman G, Asgari AR, Hedayati M (2011): Whole body vibration is a safe exercise training method and induces no impaired alterations on rat plasma parameters. Acta Physiol Hung 98, 442-448

NIH Consensus Development Panel on Osteoporosis Prevention, Diagnosis, and Therapy, March 7-29, 2000: highlights of the conference (2001) South Med J $\underline{94}, 569-573$

Omi N, Morikawa N, Ezawa I (1994): The effect of voluntary exercise on bone mineral density and skeletal muscles in the rat model at ovariectomized and sham stages. Bone Miner 24, 211-222

Otsuka E, Hirano K, Matsushita S, Inoue A, Hirose S, Yamaguchi A, Hagiwara H (1998): Effects of nitric oxide from exogenous nitric oxide donors on osteoblastic metabolism. Eur J Pharmacol $\underline{349}$, 345-350

Oxlund BS, Ørtoft G, Andreassen TT, Oxlund H (2003): Low-intensity, highfrequency vibration appears to prevent the decrease in strength of the femur and tibia associated with ovariectomy of adult rats. Bone $\underline{32}$, 69-77

Patel HP, White MC, Westbury L, Syddall HE, Stephens PJ, Clough GF, Cooper C, Sayer AA (2015): Skeletal muscle morphology in sarcopenia defined using the EWGSOP criteria: findings from the Hertfordshire Sarcopenia Study (HSS). BMC Geriatr 15, 171

Pedersen BK (2013): Muscle as a secretory organ. Compr Physiol $\underline{3}$, 1337-1362

Phillips SK, Rook KM, Siddle NC, Bruce SA, Woledge RC (1993): Muscle weakness in women occurs at an earlier age than in men, but strength is preserved by hormone replacement therapy. Clin Sci 84, 95-98

Quinn LS, Anderson BG, Strait-Bodey L, Stroud AM, Argilés JM (2009): Oversecretion of interleukin-15 from skeletal muscle reduces adiposity. Am J Physiol Endocrinol Metab 296, E191-E202

Raisz LG, Fall PM, Gabbitas BY, McCarthy TL, Kream BE, Canalis E (1993): Effects of prostaglandin E2 on bone formation in cultured fetal rat calvariae: role of insulin-like growth factor-I. Endocrinology $\underline{133}, 1504-$ 1510

Rapp K, Cameron ID, Kurrle S, Klenk J, Kleiner A, Heinrich S, König H-H, Becker C (2010): Excess mortality after pelvic fractures in institutionalized older people. Osteoporos Int 21, 1835-1839

Rauch F (2009): Vibration therapy. Dev Med Child Neurol ㅁ1, 166-168 
Ravdin PM, Cronin KA, Howlader N, Berg CD, Chlebowski RT, Feuer EJ, Edwards BK, Berry DA (2007): The decrease in breast-cancer incidence in 2003 in the United States. N Engl J Med 356, 1670-1674

Rittweger J (2010): Vibration as an exercise modality: how it may work, and what its potential might be. Eur J Appl Physiol 108, 877-904

Roelants M, Delecluse C, Goris M, Verschueren S (2004): Effects of 24 weeks of whole body vibration training on body composition and muscle strength in untrained females. Int J Sports Med 25, 1-5

Rolland Y, Onder G, Morley JE, Gillette-Guyonet S, Abellan van Kan G, Vellas B (2011): Current and future pharmacologic treatment of sarcopenia. Clin Geriatr Med 27, 423-447

Rosenberg IH (2011): Sarcopenia: origins and clinical relevance. Clin Geriatr Med 27, 337-339

Rossouw JE, Anderson GL, Prentice RL, LaCroix AZ, Kooperberg C, Stefanick $\mathrm{ML}$, Jackson RD, Beresford SAA, Howard BV, Johnson KC, et al. (2002): Risks and benefits of estrogen plus progestin in healthy postmenopausal women: principal results From the Women's Health Initiative randomized controlled trial. JAMA 288, 321-333

Ross PD, Davis JW, Epstein RS, Wasnich RD (1991): Pre-existing fractures and bone mass predict vertebral fracture incidence in women. Ann Intern Med 114, 919-923

Rubin C, Turner AS, Bain S, Mallinckrodt C, McLeod K (2001): Anabolism. Low mechanical signals strengthen long bones. Nature 412, 603-604

Rubin J, Rubin C, Jacobs CR (2006): Molecular pathways mediating mechanical signaling in bone. Gene 367, 1-16

Russo CR, Lauretani F, Bandinelli S, Bartali B, Cavazzini C, Guralnik JM, Ferrucci $L$ (2003): High-frequency vibration training increases muscle power in postmenopausal women. Arch Phys Med Rehabil 84, 18541857

Samosawala NR, Vaishali K, Kalyana BC (2016): Measurement of muscle strength with handheld dynamometer in Intensive Care Unit. Indian J Crit Care Med 20, 21-26

Santen RJ, Brodie H, Simpson ER, Siiteri PK, Brodie A (2009): History of Aromatase: Saga of an Important Biological Mediator and Therapeutic Target. Endocr Rev 30, 343-375

SchiessI H, Frost HM, Jee WS (1998): Estrogen and bone-muscle strength and mass relationships. Bone $22,1-6$

Schönau E, Werhahn E, Schiedermaier U, Mokow E, Schiessl H, Scheidhauer K, Michalk D (1996): Influence of muscle strength on bone strength during childhood and adolescence. Horm Res 45 Suppl 1, 63-66

Seneca LA: Philosophische Schriften. Vierter Band: Briefe an Lucilius. Zweiter Teil.108. Brief. Übers., mit Einl. und Anm. vers. von Otto Apelt. Matrix, Wiesbaden 2004 
Sehmisch S, Galal R, Kolios L, Tezval M, Dullin C, Zimmer S, Stuermer KM, Stuermer EK (2009): Effects of low-magnitude, high-frequency mechanical stimulation in the rat osteopenia model. Osteoporos Int 20, 1999-2008

Shampo MA, Kyle RA, Steensma DP (2012): Adolf Butenandt-Nobel Prize for Chemistry. Mayo Clin Proc $\underline{87}$, e27

Shock NW (1956): Some Physiological Aspects of Aging in Man. Bull N Y Acad Med 32, 268-283

Simoni RD, Hill RL, Vaughan M (2002): The Discovery of Estrone, Estriol, and Estradiol and the Biochemical Study of Reproduction. The Work of Edward Adelbert Doisy. J Biol Chem 277, e17-e17

Singh M, Meyer EM, Simpkins JW (1995): The effect of ovariectomy and estradiol replacement on brain-derived neurotrophic factor messenger ribonucleic acid expression in cortical and hippocampal brain regions of female Sprague-Dawley rats. Endocrinology 136, 2320-2324

Snow MH (1977): The effects of aging on satellite cells in skeletal muscles of mice and rats. Cell Tissue Res $\underline{185}$, 399-408

Statistisches Bundesamt. Bevölkerung Deutschlands bis 2050 - 11. koordinierte Bevölke-rungsvorausberechnung. 2006:

https://www.destatis.de/DE/PresseService/Presse/Pressekonferenze n/2006/Bevoelkerungsentwicklung/bevoelkerungsprojektion2050.pdf; jsessionid=8E2729B9648217B919899C3AE9051ABE.cae1?_blob= publicationFile

(abgerufen am 25.05.2017)

Steensberg A, van Hall G, Osada T, Sacchetti M, Saltin B, Klarlund Pedersen B (2000): Production of interleukin-6 in contracting human skeletal muscles can account for the exercise-induced increase in plasma interleukin-6. J Physiol (Lond) $529 \mathrm{Pt} 1,237-242$

Ström O, Borgström F, Kanis JA, Compston J, Cooper C, McCloskey EV, Jönsson B (2011): Osteoporosis: burden, health care provision and opportunities in the EU: a report prepared in collaboration with the International Osteoporosis Foundation (IOF) and the European Federation of Pharmaceutical Industry Associations (EFPIA). Arch Osteoporos $\underline{6}, 59-155$

Stuermer EK, Sehmisch S, Tezval M, Tezval H, Rack T, Boekhoff J, Wuttke W, Herrmann TRW, Seidlova-Wuttke D, Stuermer KM (2009): Effect of testosterone, raloxifene and estrogen replacement on the microstructure and biomechanics of metaphyseal osteoporotic bones in orchiectomized male rats. World J Urol 27, 547-555

Stuermer EK, Komrakova M, Werner C, Wicke M, Kolios L, Sehmisch S, Tezval M, Utesch C, Mangal O, Zimmer S, et al. (2010): Musculoskeletal response to whole-body vibration during fracture healing in intact and ovariectomized rats. Calcif Tissue Int $\underline{87}, 168-180$

Stuermer EK, Komrakova M, Sehmisch S, Tezval M, Dullin C, Schaefer N, Hallecker J, Stuermer KM (2014): Whole body vibration during fracture healing intensifies the effects of estradiol and raloxifene in estrogendeficient rats. Bone $\underline{64}, 187-194$ 
Svedbom A, Hernlund E, Ivergård M, Compston J, Cooper C, Stenmark J, McCloskey EV, Jönsson B, Kanis JA (2013): Osteoporosis in the European Union: a compendium of country-specific reports. Arch Osteoporos $\underline{8}$

Tesch PA, Karlsson J (1985): Muscle fiber types and size in trained and untrained muscles of elite athletes. J Appl Physiol $\underline{59}, 1716-1720$

Thompson DD, Simmons HA, Pirie CM, Ke HZ (1995): FDA Guidelines and animal models for osteoporosis. Bone 17, 125S-133S

Turner CH, Pavalko FM (1998): Mechanotransduction and functional response of the skeleton to physical stress: the mechanisms and mechanics of bone adaptation. J Orthop Sci $\underline{3}$, 346-355

van't Hof RJ, Ralston SH (1997): Cytokine-induced nitric oxide inhibits bone resorption by inducing apoptosis of osteoclast progenitors and suppressing osteoclast activity. J Bone Miner Res 12, 1797-1804

von Haehling S, Morley JE, Anker SD (2010): An overview of sarcopenia: facts and numbers on prevalence and clinical impact. $J$ Cachexia Sarcopenia Muscle 1, 129-133

Weinbaum S, Cowin SC, Zeng Y (1994): A model for the excitation of osteocytes by mechanical loading-induced bone fluid shear stresses. J Biomech 27, 339-360

Welsch U, Kummer W, Deller T: Sobotta Lehrbuch Histologie. 4. Auflage; Urban \& Fischer Verlag/Elsevier $\mathrm{GmbH}$, München 2014

Wiik A, Glenmark B, Ekman M, Esbjörnsson-Liljedahl M, Johansson O, Bodin K, Enmark E, Jansson E (2003): Oestrogen receptor beta is expressed in adult human skeletal muscle both at the mRNA and protein level. Acta Physiol Scand 179, 381-387

Wiik A, Ekman M, Johansson O, Jansson E, Esbjörnsson M (2009): Expression of both oestrogen receptor alpha and beta in human skeletal muscle tissue. Histochem Cell Biol 131, 181-189

Wolff J (2010): Das Gesetz der Transformation der Knochen. Reprint der Ausgabe, August Hirschwald, Berlin 1892. Pro Business, Berlin 2010

Xie L, Rubin C, Judex S (2008): Enhancement of the adolescent murine musculoskeletal system using low-level mechanical vibrations. J Appl Physiol 104, 1056-1062

Xi G, Rosen CJ, Clemmons DR (2016): IGF-I and IGFBP-2 Stimulate AMPK Activation and Autophagy, Which Are Required for Osteoblast Differentiation. Endocrinology 157, 268-281

Yoon V, Maalouf NM, Sakhaee K (2012): The effects of smoking on bone metabolism. Osteoporos Int 23, 2081-2092 


\section{Danksagung}

In erster Linie gilt mein Dank Prof. Dr. med. Stephan Sehmisch für die Überlassung des Themas dieser Promotionsarbeit.

Für ihre Ratschläge und Ideen bei der Probenaufarbeitung danke ich besonders Ruth Wigger. Weiterhin danke ich Julius Graf für die Überlassung einiger Proben. Frau Dr. rer. nat. Marina Komrakova, Ramona Castro-Machguth und Annette Witt danke ich für ihre fachliche Unterstützung und aufmunternden Gespräche während der gesamten Durchführung.

Mein größter Dank gilt Frau Anke Knopek für ihre stetige Unterstützung und fortwährende Motivation bei der Erstellung dieser Dissertation. Weiterhin danke ich Judith Probstmeyer für die Korrekturen und meinem Bruder Michael Schiefer für die Ratschläge bezüglich der Gestaltung dieser Arbeit.

Diese Promotion wurde von der Deutschen Forschungsgemeinschaft (DFG, STU 478/3-2) gefördert. 


\section{Lebenslauf}

Ich wurde am 11.07.1985 als erstes Kind von Petra Schiefer, geb. Neumann und Jörg Schiefer in der Landeshauptstadt Magdeburg geboren.

Von 1992 bis 1996 besuchte ich in Magdeburg die Grundschule „Bruno-Beye-Ring“. Anschließend wechselte ich auf das Albert-Einstein-Gymnasium und erlangte dort 2005 die Allgemeine Hochschulreife.

Von 2005 bis 2008 absolvierte ich eine Ausbildung zur Gesundheits- und Krankenpflegerin an der Kranken- und Kinderkrankenpflegeschule der Universitätsklinik Göttingen. Im Anschluss war ich dort als OP-Schwester im Bereich Allgemein-, Viszeral- und Kinderchirurgie und im Bereich Unfallchirurgie, Orthopädie und Plastische Chirurgie bis 2011 in Vollzeit tätig. Während meines Studium der Humanmedizin an der Georg-August-Universität Göttingen war ich von Oktober 2011 bis Dezember 2016 dort noch in Teilzeit beschäftigt.

Im Oktober 2013 und Oktober 2016 bestand ich die Prüfung zum 1. und 2. Abschnitt der Ärztlichen Prüfung. Mein Praktisches Jahr absolvierte ich in Göttingen, Aarau (Schweiz) und Kapstadt (Südafrika).

Während meines Studiums engagierte ich mich in der lokalen Arbeitsgruppe der Bundesvertretung der Medizinstudierenden in Deutschland e.v. (bvmd) für Austauschstudenten aus der ganzen Welt. 